Florida International University FIU Digital Commons

FIU Electronic Theses and Dissertations

University Graduate School

6-25-2009

\title{
Emotional Intelligence and Leadership in Organization: A Meta-analytic Test of Process Mechanisms
}

Daniel S. Whitman

Florida International University, daniel.whitman@fiu.edu

DOI: $10.25148 /$ etd.FI09120813

Follow this and additional works at: https://digitalcommons.fiu.edu/etd

Part of the Business Administration, Management, and Operations Commons, Human $\underline{\text { Resources Management Commons, Industrial and Organizational Psychology Commons, }}$

Management Sciences and Quantitative Methods Commons, Organizational Behavior and Theory

Commons, Personality and Social Contexts Commons, Social Influence and Political

Communication Commons, $\underline{\text { Social Psychology Commons, and the Work, Economy and }}$

Organizations Commons

\section{Recommended Citation}

Whitman, Daniel S., "Emotional Intelligence and Leadership in Organization: A Meta-analytic Test of Process Mechanisms" (2009). FIU Electronic Theses and Dissertations. 113.

https://digitalcommons.fiu.edu/etd/113

This work is brought to you for free and open access by the University Graduate School at FIU Digital Commons. It has been accepted for inclusion in FIU Electronic Theses and Dissertations by an authorized administrator of FIU Digital Commons. For more information, please contact dcc@fiu.edu. 


\section{FLORIDA INTERNATIONAL UNIVERSITY}

Miami, Florida

\section{EMOTIONAL INTELLIGENCE AND LEADERSHIP IN ORGANIZATIONS:}

\section{A META-ANALYTIC TEST OF PROCESS MECHANISMS}

A dissertation submitted in partial fulfillment of the

requirements for the degree of

DOCTOR OF PHILOSOPHY

in

PSYCHOLOGY

by

Daniel S. Whitman

2009 


\section{To: Dean Kenneth Furton}

College of Arts and Sciences

This dissertation, written by Daniel S. Whitman, and entitled Emotional Intelligence and Leadership in Organizations: A Meta-Analytic Test of Process Mechanisms, having been approved in respect to style and intellectual content, is referred to you for judgment.

We have read this dissertation and recommend that it be approved.

$\begin{array}{r}\text { Victoria Pace } \\ \hline \text { William Kurtines } \\ \hline \text { Nathan Hiller } \\ \hline\end{array}$

Chockalingam Viswesvaran, Major Professor

Date of Defense: June 25, 2009

The dissertation of Daniel S. Whitman is approved.

$\begin{array}{r}\begin{array}{r}\text { Dean Kenneth Furton } \\ \text { College of Arts and Sciences }\end{array} \\ \hline \begin{array}{r}\text { Dean George Walker } \\ \text { University Graduate School }\end{array}\end{array}$

Florida International University, 2009 


\section{DEDICATION}

I dedicate this dissertation to the two greatest women I have ever known - Mema and Suzette Caleo. 


\section{ACKNOWLEDGMENTS}

I would like to acknowledge the following people for their help with my dissertation: Suzette Caleo, for her undying emotional support and her valiant article gathering and editing skills; Mom and Dad, for always supporting and never questioning my educational odyssey along the way; Angela Reeves, for being the perfect research assistant; Jeff Thomas, for being a true friend and a true researcher; Nathan Hiller, for the many drinks at Clarke's and invaluable career advice; Christian Resick, for his "tough" love; David Van Rooy, for providing me with a successful graduate school model; and most importantly, my mentor Vish, for his patience, guidance, and editing skills over the past five years. 


\title{
ABSTRACT OF THE DISSERTATION \\ EMOTIONAL INTELLGENCE AND LEADERSHIP IN ORGANIZATIONS: A META-ANALYTIC TEST OF PROCESS MECHANISMS
}

by

\author{
Daniel S. Whitman \\ Florida International University, 2009 \\ Miami, Florida \\ Professor Chockalingam Viswesvaran, Major Professor
}

The present study - employing psychometric meta-analysis of 92 independent studies with sample sizes ranging from 26 to 322 leaders - examined the relationship between EI and leadership effectiveness. Overall, the results supported a linkage between leader EI and effectiveness that was moderate in nature $(\rho=.25)$. In addition, the positive manifold of the effect sizes presented in this study, ranging from .10 to .44 , indicate that emotional intelligence has meaningful relations with myriad leadership outcomes including effectiveness, transformational leadership, LMX, follower job satisfaction, and others. Furthermore, this paper examined potential process mechanisms that may account for the EI-leadership effectiveness relationship and showed that both transformational leadership and LMX partially mediate this relationship. However, while the predictive validities of EI were moderate in nature, path analysis and hierarchical regression suggests that EI contributes less than or equal to $1 \%$ of explained variance in leadership effectiveness once personality and intelligence are accounted for. 


\section{TABLE OF CONTENTS}

CHAPTER $\quad$ PAGE

PROLOGUE................................................................ 1

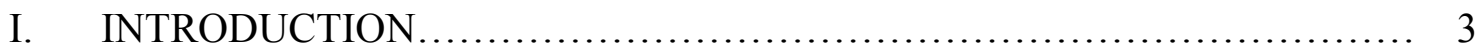

Emotional Intelligence.................................................. 6

Purpose of the Dissertation................................................ 8

II. LITERATURE REVIEW ............................................... 11

What is Known About Leadership?................................................. 12

Trait-Based Approach to Leadership....................................... 14

Personality and Leadership............................................... 17

General Mental Ability and Leadership.................................. 18

Changing Nature of Leadership...................................... 20

Emotion in the Workplace............................................. 22

Emotion and Leadership............................................ 26

Emotional Intelligence.................................................. 29

Linking EI with Leadership Effectiveness................................ 33

Theoretical Linkages................................................ 34

Empirical Linkages...................................................... 37

Transformational Leadership.......................................... 40

Leader-Member Exchange................................................ 44

Mediation of the EI-Leadership Effectiveness Relationship................... 46

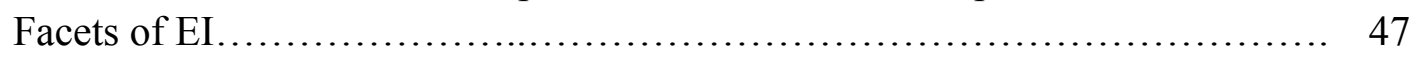

Appraisal and Expression of Emotion....................................... 47

Use of Emotion to Facilitate Cognitive Processes.............................. 49

Understanding of Emotion................................................. 50

Appraisal and Expression of Emotion..................................... 50

Management and Regulation of Emotion.................................. 51

Incremental Validity of EI............................................. 53

Moderating Influences on Meta-Analyzed Relationships.................... 56

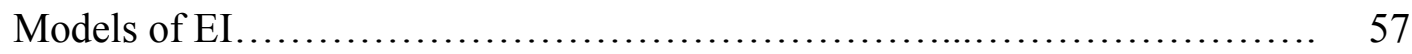

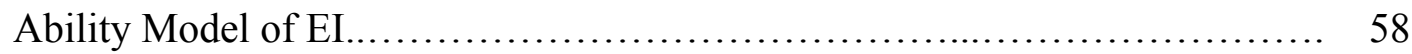

Mixed Model EI....................................................... $\quad 60$

Measures and Scoring Format of EI...................................... 63

Emotional Quotient Inventory........................................... 64

Emotional Competence Inventory......................................... 65

The Mayer-Salovey-Caruso Emotional Intelligence Test ...................... 66

Wong and Law Emotional Intelligence Scale............................... 67

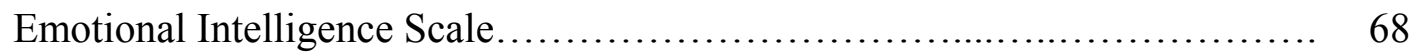




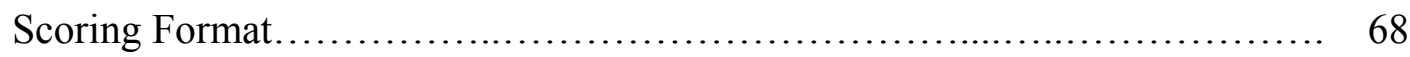

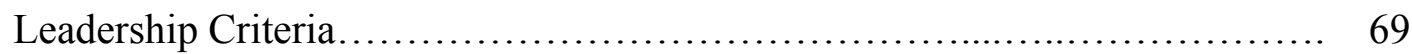

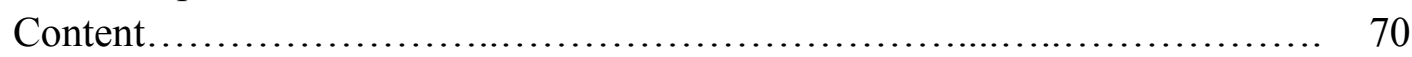

Levels of Analysis...................................................... 71

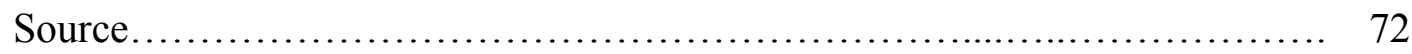

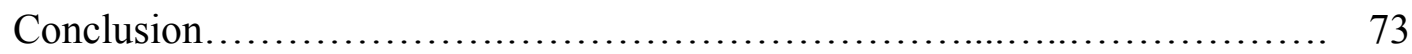

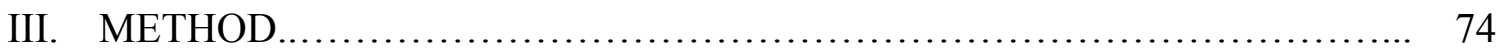

Search for Primary Data............................................... 74

Criteria for Inclusion and Variables Coded.................................. 74

Meta-Analytic Procedure..................................................... 77

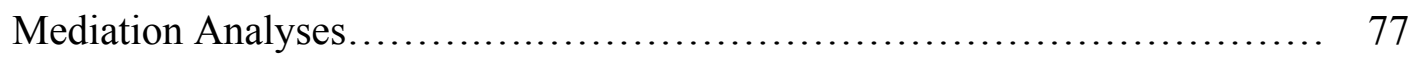

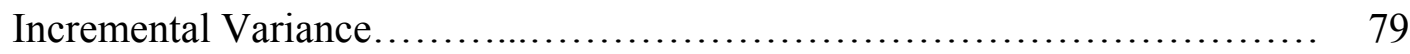

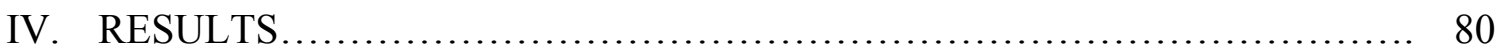

Leadership Style as a Mediator......................................... 81

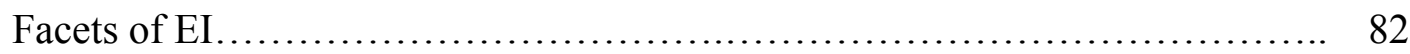

Leadership Style as a Mediator of the Facets of EI ......................... 83

Incremental Validity of EI............................................ 84

Moderator Analysis by Model of EI....................................... $\quad 85$

Moderators of EI by Measure and Scoring Format........................... 85

Moderators of EI by Content, Level-of-Analysis, and Source.................. 87

Moderators of EI by Level of Leadership and Industry-Type.................. 88

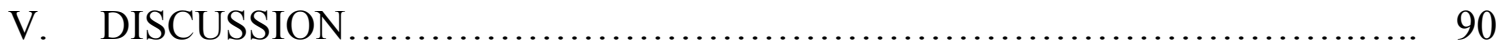

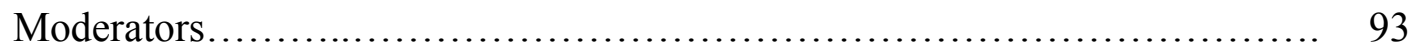

Theoretical Implications................................................... 96

Practical Implication........................................................ 98

Limitations and Future Research..................................... 100

Conclusion............................................................... 105

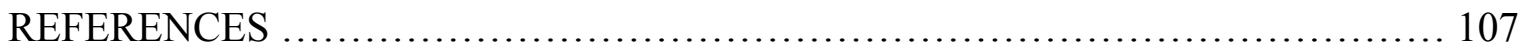

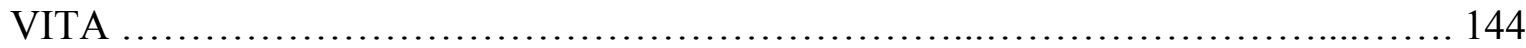




\section{LIST OF TABLES}

TABLE

PAGE

1. Meta-Analysis of Emotional Intelligence and Leadership

Effectiveness

2. Meta-Analysis of Emotional Intelligence and Transformational

Leadership.

122

3. Meta-Analysis of Emotional Intelligence and

Leader-Member Exchange

4. Summary of Path Analysis for Leadership Behavior

Mediating the Relationship between Emotional

Intelligence and Leadership Effectiveness.

5. Meta-Analysis of Appraisal of Emotion Dimension and

Leadership Outcomes...

6. Meta-Analysis of Use of Emotion Dimension and

Leadership Outcomes

126

7. Meta-Analysis of Understanding of Emotion Dimension and

Leadership Outcomes

8. Meta-Analysis of Regulation and Management of

Emotion Dimension and Leadership Outcomes.

9. Summary of Path Analysis Results for Transformational Leadership

Mediating the Relationship Between Facets of Emotional Intelligence

and Leadership Effectiveness

10. Summary of Path Analysis Results for LMX Mediating the Relationship

Between Facets of Emotional Intelligence and

Leadership Effectiveness.

11. Hierarchical Regression Analysis for Leadership

Effectiveness onto EI, Personality, and GMA

12. Meta-Analysis of Ability EI and Leadership Outcomes

13. Meta-Analysis of Mixed EI and Leadership Outcomes

14. Hierarchical Regression Analysis for Leadership Effectiveness onto

Ability EI, Personality, and GMA.

15. Hierarchical Regression Analysis for Leadership Effectiveness onto Mixed EI, Personality, and GMA.

16. Meta-Analysis of Measures of EI and Leadership Outcomes

17. Meta-Analysis of Emotional Intelligence and Leadership

Effectiveness by Scoring Format.

18. Meta-Analysis of Emotional Intelligence and Leadership

Effectiveness by Content, Level-of-Analysis, and Source....

19. Meta-Analysis of Emotional Intelligence and Leadership

Effectiveness by Level of Leader

20. Meta-Analysis of Emotional Intelligence and Leadership

Effectiveness by Industry Type. ...

21. Meta-Correlation Matrix of Dimensions of

Emotional Intelligence 
22. Summary of Path Analysis for Each Competing Model of EI Mediating the Relationship between the Alternative Model and Leadership Effectiveness........................................ 


\section{Prologue}

The historian Thomas Carlyle famously once noted that "the history of the world was the biography of great men" (Carlyle, 1907, p.18). While this statement may be accurate from the historian's perspective - that is, the force of extraordinary leaders has shaped world history - it suggests a limited understanding of geography, human civilization and behavior. Indeed, even the most notorious mercenaries (e.g., Genghis Kahn) and hegemonies (e.g., the Roman Empire) conquered and ruled only a very small percentage of their contemporary civilizations (Huntington, 1993). Up until the twilight of the 20th century, it was impossible for even the most powerful groups of men - much less a single great man - to have an influence over the entire world. For instance, even the catastrophic World Wars I and II were fought in and between a handful of nation-states. Thus, much like his fellow historians who studied leadership during the 20th century, Carlyle's thesis reveals the detached, leisurely blinders that only those in peaceful, prosperous nations can afford to wear.

There is little doubt that these blinders were forever removed on September 11, 2001. For the first time since the War of 1812, the United States was violently attacked on the native soil of one of its original thirteen colonies. Made perfectly clear after those first few moments in New York City and Washington, D.C. was the fact that, in effect, the world had become flat (Freidman, 2003). Extremely rapid advances in technology (e.g., internets, jet engines, satellites) had made physical and psychological boundaries obsolete. At the same time, the proliferation of weapons of mass destruction had made the threat of nuclear annihilation more salient than ever in the minds of Americans. Those technological innovations of the 20th century - the ones that initially sustained our 
freedom and prosperity - would not simply disappear. The angst, rage, and shame in the American psyche manifested itself in an awareness that only the upper-echelons of national leadership, by definition, wielded the power to take immediate, collective action. It was inevitable that leaders with this new, indisputably "worldwide" influence (e.g., George W. Bush, Osama bin Ladin) would emerge from this first-of-its-kind global crucible. We can now see the nascent, post-modern truth of Carlyle's words: the quality of the rest of our lives rests on the quality of our leadership.

That a handful of great or diabolical leaders will chart the rest of the course of world civilization suggests that leadership should be studied in a different context than that in which we study most other subjects in the Arts and Sciences. As Bennis (2007, p. 331) notes, we should study leadership "with the same self-interested intensity with which we study diabetes and other life-threatening diseases. Only when we understand leaders will we be able to control them." 


\section{CHAPTER I}

\section{Introduction}

Burns (1978) suggested that leadership is one of the most often observed yet least understood human phenomena. Likewise, Bennis $(1959$, p.301) noted that it is ironic that "probably more has been written and less is known about leadership than about any other topic in the behavioral sciences." Indeed, after almost a century of social scientific study, a review of the leadership literature reveals a number of foundational shifts and an almost contentious body of knowledge (Yukl, 2007). Even the most basic concept of leadership how it should be defined - is often a hotly debated topic (Bass, 1985).

Despite this complexity and diversity, however, the study of leadership continues to attract the attention of researchers. Bass $(1990$, p.3) has attributed this unbridled research enthusiasm to the fact that leadership is recognized as a universal activity evident in all of human civilization, noting that "from its infancy, the study of history has been the study of leaders — what they did and why they did it." Whether it is the world of business (e.g., Steve Jobs, Kenneth Lay), military (e.g., Robert E. Lee, Adolph Hitler), or politics (e.g., Mohandas Gandhi, Fidel Castro), the importance of leadership has always been recognized as essential to societal achievement and performance (Bryman, 1992; Gill, 2007).

After almost 100 years of study, no single definition of leadership conceptualized in its many managerial, political, transformational, and transactional forms - is widely accepted. However, while the specifics differ across contexts, there exist some common causes that make leadership a fruitful topic for investigation. Of these, scholars tend to agree that leadership is best understood "as the nature of the 
influencing process - and its resultant outcomes - that occurs between a leader and followers and how this influencing process is explained," (Antonakis, Cianciolo, \& Sternberg, 2004, p. 5).

A review of the history of leadership research suggests that a handful of theories have contributed towards better understanding of this central process of influence. Some of the more notable theories have attempted to study the leader's behavior (e.g., the University of Michigan studies), the situation (e.g., Fiedler, 1967), and leader-follower relations (e.g., LMX; Graen \& Uhl-Bien, 1995) to explain the influence process. More recently, what House and Aditya (1997) referred to as the "New Leadership" paradigm has been used to enhance understanding of how leader's influence their followers. Specifically, these "new" theories have examined the role that a leader's vision and charisma play in influencing followers to achieve goals at high levels.

Perhaps the most prominent theory of leadership, however, is the trait perspective. Also known as the "great man" perspective, this theory was originally shaped by historians like Thomas Carlyle, who noted that "the history of the world was the biography of great men," (Carlyle, 1907, p.18). The scientific study of traits associated with effective leadership - that is, the dispositional characteristics that separated successful leaders from unsuccessful leaders - has a prominent research history in applied psychology (e.g., Terman, 1904). Moreover, after a brief research moratorium in the midpart of the century, the trait perspective has reemerged to help provide a much clearer picture of extant understanding of the leadership process (e.g., House, Spangler, \& Woycke, 1991; Judge, Bono, Ilies, \& Gerhardt, 2002). 
Stodgill (1948) originally identified two traits - intelligence and extraversion associated with effective leadership. Stodgill's findings were later confirmed in a metaanalysis by Lord, De Vader, and Alliger (1986). More recently, a meta-analytic study by Judge and his colleagues (2002) found that a majority of the Big Five personality factors (i.e., openness, conscientiousness, extraversion, agreeableness, neuroticism) were related to leadership emergence and effectiveness. In particular, emotional stability, extraversion, and conscientiousness were found to have the strongest correlations with leadership. These meta-analytic findings, as well as other leadership studies examining intelligence and Big Five personality factors (e.g., Peterson et al., 2004; Zaccaro, Foti, \& Kenny, 1991), have continued to spur research interest in the trait school of leadership.

However, there is less cumulative knowledge concerning the relationship between leadership and traits other than intelligence and the Big Five. Such lack of knowledge is somewhat surprising considering researchers have suggested that the examination of alternative models of personality as well as alternative models of intelligence may provide fruitful avenues of research (e.g., Day \& Zaccaro, 2007; Higgs \& Dulewicz, 1999; Hogan et al., 1990; Hough \& Oswald, 2008). Moreover, the rapid technological and post-modern advances in society have led some to suggest the competencies that previously constituted leadership effectiveness have changed markedly in the 21 st century (Sternberg, 1996). In particular, Bass and Avolio (1990) noted that the work environment has become increasingly emotionally laden. Their findings coincide with the more general consensus that emotions are now a fundamental aspect of the contemporary workplace (Barsade, Brief, \& Spataro, 2003) given the shift from a Weberian bureaucratic organization to a more organic customer-centered organization (Cascio, 
2003). Leadership scholars have also called for a better understanding of the dispositional traits that effect the way leaders evoke, frame and, mobilize emotions in the workplace (Ashford \& Humphrey, 1995).

\section{Emotional Intelligence}

One area evolving from the growing interest in emotions in the workplace is the study of emotional intelligence (Salovey and Mayer, 1990). Salovey \& Mayer (1990, p. 189) define emotional intelligence as "the ability to monitor one's own and others' feelings and emotions, to discriminate among them, and to use this information to guide one's thinking and actions." In short, it is theorized that individuals have varying abilities to recognize, process, and extrapolate emotional information, thus leading to variations in how different individuals react to the same type of emotional stimuli (Mayer, Salovey, \& Caruso, 2002).

Emotional intelligence (EI) has emerged as a construct that is of interest to both academics and practitioners and has become one of the most topical areas in psychological research (e.g., Mayer \& Salovey, 1997; Murphy, 2006). Coinciding with the surge in research interest has been the increasingly prevalent use of EI in organizational selection, training, and development decisions (e.g., Bar-On, 1997; Law, Wong, \& Song, 2004; Mayer \& Salovey, 1997; Whitman, Van Rooy, Viswesvaran, \& Kraus, 2007, 2008). While some researchers have questioned the validity of the construct (e.g., Landy, 2005), others have suggested that EI is a useful predictor of leadership and job performance (e.g., Wong \& Law, 2002; Van Rooy \& Viswesvaran, 2004).

For instance, Bennis (1994, p.103) wrote, "Emotional intelligence is much more powerful than IQ in determining who emerges as a leader. IQ is a threshold. You need it, 
but it doesn't make you a star. Emotional intelligence can." Bass (2002) suggested that a fundamental component of leadership is the emotional or affective nature of the process, and Ashkanasy and Tse (2000) argued that leadership is simply a function of emotion management.

In recent years, there have also been a number of empirical examinations of the EI-leadership linkage. Wong and Law (2002) found that a leader's level of EI was significantly related to subordinates work outcomes. Kerr, Garvin, Heaton, and Boyle (2005) showed that EI predicts a number of different organizational outcomes (e.g., productivity) associated with leadership effectiveness. Relationships between EI and other theories of leadership have also been established, including transformational leadership (e.g., Barbuto \& Burbach, 2006), leader-member-exchange (e.g., Rahim \& Psenicka, 2005), strategic-level leadership (e.g., Harrison \& Clough, 2006), and teambased leadership (e.g., Wolff, Pescosolido, \& Druskat, 2002).

However, as these EI-leadership effectiveness studies have begun to accumulate, closer scrutiny reveals that the empirical results are often inconsistent. Some studies have exhibited strong relationships (Barbuto \& Barbuch, 2006) while others have exhibited trivial relationships (Kobe et al., 2001). The inconsistent relationships reported across studies may be partly due to sampling error (Hunter \& Schmidt, 2004), but also may be a result of what Locke (2005) and Landy (2005) describe as murky extant theoretical rationales. For example, some researchers have suggested that EI is an elusive construct and that it has no predictive power beyond that of general mental ability (GMA) and the Big five (e.g., Roberts et al., 1998). There is also continuing disagreement among scientists as to the proper conceptualization of EI (Petrides \& Furnham, (2001). Some 
contend that EI is an intelligence (the ability model of EI) while others suggest EI is a combination of cognitive, motivational, and affective constructs (the mixed model of EI). There is even some uncertainty as to the proper format to measure EI (self-report vs. performance tests). Nevertheless, the proliferation of studies investigating EI and leadership effectiveness, as well as the opposing theoretical rationales and models positing differential construct relations, suggest that conceptual integration and clarification of this literature is warranted.

\section{Purpose of the Dissertation}

Accordingly, the purpose of this dissertation is to qualitatively review and quantitatively cumulate the research literature assessing the relationship between emotional intelligence and leadership effectiveness in organizational settings. The cumulative empirical evidence will be used to test process mechanisms linking EI and leadership as well as the moderating influences of this link. Specifically, I seek to address the following questions regarding EI and leadership: (1) Does EI predict leadership effectiveness? Does EI predict transformational leadership? Does EI predict leadermember relations? Is the EI-leadership effectiveness link mediated by transformational leadership or LMX? (2) Do both models of EI (i.e., the ability model, the mixed model) predict leadership effectiveness? Does one model predict leadership better than the other? Do the facets of EI predict leadership? For instance, does the ability to regulate one's emotions predict leadership? (3) Does EI provide any incremental variance in predicting leadership above and beyond the Big Five personality factors and general mental ability? (4) Does EI predict specific leadership outcomes? For example, does EI predict follower satisfaction or follower organizational citizenship behaviors? and (5) Does context 
moderate the EI-leadership relationship? What are the situational constraints and factors that may moderate the validity of the EI-leadership relationship? For instance, does level of leadership (CEO vs. shop supervisor) matter? Does industry (academic vs. business) matter?

To address these questions, and to make use of the wealth of existing research that has explored related questions, I employ meta-analytic methodology (Hunter \& Schmidt, 2004). As mentioned above, many studies have explored EI and leadership in varying contexts (e.g., Barbuto \& Burbach, 2006; Harrison \& Clough, 2006; Rahim \& Psenicka, 2005; Wolff, Pescosolido, \& Druskat, 2002; Wong \& Law, 2002). Given the breadth of research available on the potential utility of EI for predicting leadership effectiveness, it appears to be an appropriate time to synthesize extant findings so that researchers and practitioners can benefit from available knowledge. My dissertation will be guided by theory-driven research in both the EI and leadership fields, and the findings should estimate EI-leadership effectiveness relations across a variety of studies that were conducted using different types of samples, methodologies, and analytical approaches. Meta-analysis offers insights not available from individual studies due to constraints with samples, methods, and study characteristics. Further, given the number of studies that have examined EI and leadership, including the diversity of the theories, measures, samples, and contexts, results from meta-analytic findings should offer more generalizability than is possible with individual studies.

By qualitatively and quantitatively summarizing competing theoretical rationales of EI and leadership theory, my dissertation will serve the dual purposes of (1) allowing for a more molar and holistic understanding of the emotional intelligence construct and 
(2) broadening understanding of the relationship between EI, leadership effectiveness and team, group, and organizational performance (Ashkanasy \& Daus, 2004). The findings in my dissertation should also be useful for human resource practitioners. Because measures of EI are widely used by practitioners (Murphy, 2006), conclusions based on results of this dissertation should have important implications for leadership selection and promotion decisions as well as leadership training and development programs.

In the following chapter, I provide an introduction to the theoretical bases and review of the literature relevant to this dissertation. First, I define leadership, summarize the theory surrounding the trait-based approach to leadership, and discuss the changing nature of leadership in the 21 st century. Second, I review the concept of emotional intelligence, including its competing models and measures, and make a theoretical argument linking it with leadership effectiveness. Third, I discuss the relationship between general mental ability (GMA), the Big Five personality factors, and EI, including what some researchers have referred to as EI's "elusive" nature. Finally, I briefly review the many situational factors that may moderate the validity of EI in predicting leadership. 


\section{CHAPTER II}

\section{Literature Review}

Perhaps no single topic in the social sciences fascinates the general public more than leadership. Indeed, Bass writes: "The study of history has been the study of leaders - what they did and why they did it" (1990, p. 3). Over the course of human history, it is difficult to overstate the importance of leadership. To a great extent, the quality of people's lives was directly reflected in the quality of their leadership. The lasting impact and influence of great leaders such as Abraham Lincoln, Mohandas Gandhi, Martin Luther King, Jr., and Nelson Mandela is testament to this truth.

While most will agree that "extraordinary" leaders help shape the course of civilization, one would be hard pressed to answer the question: What is leadership? This simple question is difficult even for scholars of the topic to answer, as there is no single definition that has universal acceptance. For instance, Bennis (1994, p.1) noted "Leadership is like beauty; it's hard to define but you know it when you see it."

However, there are some similarities among the many competing definitions. For instance, Chemers (1997, p.1) provides an academic definition that "Leadership is a process of social influence in which one person is able to enlist the aid and support of others in the accomplishment of a common task." Bass (1990, p. 7) defined leadership as activities engaged by individuals or group members that significantly contribute to “development and maintenance of role structure and goal direction necessary for effective group performance." Similarly, Stodgill (1974) defined it as the ability of leaders to influence followers. And, as Northouse (2008) suggests, a fundamental 
component of the definition of leadership concerns the process of a leader influencing followers.

Beyond defining leadership, studies consistently center on the question: What makes a leader in an organization effective or ineffective? Because industrial/organizational (I/O) psychology focuses on topics in the workplace, most of the definitions for leadership effectiveness concern organizational criteria. For instance, Yukl (2002) asserted leadership effectiveness is best quantified by organizational outcomes and results. Moreover, there is some consensus among organizational researchers that a leader is seen as being effective to the extent that he or she influences organizational stakeholders (Hogan et al., 1994). Therefore, for the purposes of this dissertation, I will conceptualize leadership effectiveness as "a leader's performance in influencing and guiding the activities of his or her unit toward achievement of its goals," (Judge et al., 2002, p. 767).

Defining and conceptualizing leadership effectiveness in this way allows for a broader construal of leadership criteria. For instance, ratings of leadership effectiveness from peers, subordinates, or supervisors, as well as outcome measures in terms of group, team, or organizational effectiveness can both represent a leader's ability to influence his or her subordinates. I now review a few of the major theories of leadership, specifically elaborating on the trait-based approach to leadership and which traits are known to predict leadership effectiveness.

\section{What is Known About Leadership?}

As Antonakis and colleagues (2004, p. 4) write, "Leadership researchers had struggled for most of the last century to put together an integrated, theoretically cohesive 
view of the nature of leadership." At times, the dissatisfaction among leadership scholars had reached the point were noteworthy academics called for a research moratorium on the subject (e.g., Miner, 1975). However, in the past two decades a more clearer and optimistic picture of leadership is beginning to emerge, and research efforts have been revitalized in many areas that were thought to lack consistency.

For instance, the seminal Ohio State studies (Stodgill \& Coons, 1957) and University of Michigan studies (e.g., Katz, Gurin, \& Floor, 1951) began a line of research that examined leadership behavior. That is, these schools were interested in identifying the specific behavioral styles that predicted leadership effectiveness. Although these initial studies identified some critical dimensions of leader behavior (e.g., consideration, initiating structure), later studies were marked with inconsistencies and contradictory findings. Not surprisingly, the behavioral approach was abandoned in a search for alternative explanatory theories.

However, a review of extant leadership literature shows that much of the research from the initial "behavioral" schools was incorporated into "new" studies of leadership style (Bryman, 1992). Theories of the "new" leadership school, such as charismatic and transformational leadership theory, explicitly focus on the types of behaviors (e.g., charismatic behaviors, transactional behaviors) that predict leadership effectiveness. Some have even contended that the new leadership paradigm is "old wine in a new bottle," (e.g., House \& Aditya, 1997).

Other areas have seen a similar resurgence. Fiedler's (1967) contingency theory and House's (1971) path-goal theory were two of the first to suggest that the quality of leader-member relations was an important factor in predicting leadership effectiveness. 
And although work on these theories has tapered off (Lowe \& Gardner, 2000), other theories, such as leader-member exchange (LMX; Graen \& Uhl-Bien, 1995) theory, have built substantially upon their previous findings.

Perhaps the area that has seen the most resurgence, however, is the trait-based approach to leadership (Lowe \& Gardner, 2000). Indeed, the focus on traits (or dispositional characteristics) that predict leadership effectiveness has a long and storied history in the organizational sciences. I will now review the relevant aspects of the traitbased approach to leadership and summarize what is known about this particular theory as it relates to leadership effectiveness.

\section{Trait-Based Approach to Leadership}

Drucker (1954, p. 158) noted, "Leadership cannot be created or promoted. It cannot be taught or learned." Although this statement preceded much of the development of the leadership theories that were previously discussed, recent evidence has emerged that supports Drucker's notion that leadership may have a dispositional basis. For instance, the University of Minnesota twin studies have shown positive correlations of the heritability of specific leadership traits (Arvey, Rotundo, McGue, and Johnson, 2003; Jan, Livesley, \& Vernon, 1996; Lohelin, 1992). Moreover, the question “Are leaders born or made?" is probably the most debatable research topic in leadership studies (Bass, 1990).

Galton's (1869) attempt to quantify the study of leadership using a "personal qualities" perspective was the initial highpoint in a trait-based approach to leadership that has waxed and waned in research interest over the past 150 years (Zaccaro, 2007). The initial trait-based perspective of leadership dominated scholarship until the late 1940s. 
However, influential reviewers like Gibb (1947) and Jenkins (1947, p.75) concluded "no single trait or group of traits has been isolated which sets off the leader from the members of his group," (Jenkins, 1947, p. 75). Stodgill (1948), in his review of studies of leadership traits, while not calling for a complete abandonment of trait study, noted that an alternative approaches and theories should be considered.

It is worth noting here that even though a moratorium on trait-based leadership studies was suggested, the major reviews $d i d$ find that some traits were associated with leadership effectiveness. In particular, intelligence and extraversion were identified as being consistently related to leadership (Stodgill, 1948). However, the fact that only two dispositional characteristics were significantly related across studies suggested to researchers (at that time) that the study of leadership traits should be terminated.

In hindsight, we now see that the early studies of trait characteristics were extremely valuable, but ultimately suffered from two major problems that stifled research conclusions. The first was the lack of substantiated personality and trait-based theory that could have been used to guide research towards the types of specific leadership traits that predicted effectiveness. Without such a framework (i.e., the Five Factor model of personality), it was very difficult to replicate trait studies. Further, the lack of a developed measurement theory led researchers to use varying operational definitions. Even the quality of measures of intelligence was not sufficient at that time (Judge et al., 2002).

A second major problem concerned the analytic techniques used to test hypotheses and draw conclusions. Correlational analyses and ANOVA were considered cutting-edge techniques in the 1950s, and statistical advancements such as factor analysis and path analysis were difficult to do without labor-intensive and time-consuming 
calculations. As a result, these scholars called for leadership research to move into new directions (e.g., situational contingencies) and, thus, the trait-based approach to leadership was abandoned for several decades.

It was not until the 1990s, when methodological and statistical advancements were able to provide a clearer theoretical framework of the structure of personality (e.g., Barrick \& Mount, 1991; Costa \& McCrae, 1992; Goldberg, 1990) and intelligence (Carroll, 1993), that trait-based theories of leadership re-emerged as a topic of interest in the organizational sciences. For instance, the development of the Five-Factor model of personality (i.e., the Big Five) through factor analytic studies provided an avenue to develop personality measures that were reliable and valid. At the same time, Carroll's (1993) exhaustive factor analytic work on intelligence - or general mental ability (GMA) - further advanced our understanding of the cognitive ability trait.

In short, trait-based perspectives of leadership submit that a combination of relatively stable leader personal attributes (e.g., personality, GMA) predict leader effectiveness across a variety of organizational situations (Yukl, 2006). A number of studies have advanced understanding of trait-based leadership theories using such an approach over the past decade (cf. Spangler, House, \& Palrecha, 2004). Interestingly, recent meta-analyses have shown that the traits that best predict leadership - extraversion and GMA - were the same ones previously identified in the leadership reviews of the 1950s. However, other aspects of the Big Five were also found to be related to leadership effectiveness. In the next two sections, I review what is known about PersonalityLeadership and GMA-Leadership relations 


\section{Personality and Leadership}

In the past two decades, a substantial amount of research has converged in the taxonomy of personality factors known as the Big Five (e.g., Barrick \& Mount, 1991). As they pertain to leadership, subsequent meta-analytic research has related these five personality factors to various leadership behaviors as well as measures of leadership emergence and effectiveness (Judge et al., 2002). Judge and his colleagues found that four of the Big Five were significantly correlated with leadership effectiveness. Specifically, extraversion was the strongest of the five $(p=.31)$, and then conscientousness $(p=.28)$, emotional stability $(p=.24)$ and openness to experience ( $p=$ .24); agreeableness was not related to leadership criteria. In summarizing, Judge and colleagues note that there is overwhelming evidence that leaders are born—not made. They also concluded that more narrow or broader personality factors may prove to be fruitful research endeavors in the leadership domain.

Unfortunately, there has been less research examining the relationship between non-Big Five traits and leadership effectiveness. A lack of alternative incremental findings is surprising considering a number of researchers have suggested that the examination of both narrow facets of the Big Five traits, as well as alternative personality models may provide fruitful avenues of research (e.g., Day \& Zaccaro, 2007; Hogan et al., 1990; Hough, 1992). A number of recent personality frameworks have been developed (e.g., dark-side personality, positive psychology personality, mixed model emotional intelligence), yet conclusions related to leadership effectiveness are limited. Furthermore, as I discuss below, there is some evidence that the changing nature of 
leadership in the 21 st century may require competencies extending beyond those of the Big Five.

\section{General Mental Ability and Leadership}

Defined as "the ability to reason, plan, solve problems and learn from experience" (Gottfredson, 1997, p. 13), GMA is commonly agreed to be the most valid predictor of future work performance and learning (e.g., Schmidt \& Hunter, 1998). Thus, it is not surprising that the leadership reviews in the 1950s found that GMA was a significant predictor of leadership across situations. More recently, Judge, Colbert, and Ilies (2004) found that the true score correlation for the GMA-leadership effectiveness relationship was .21. Although the relationship found by Judge and colleagues is significant, it is much lower than the relationship $(\rho=.53)$ that exists between GMA and general work performance (Schmidt \& Hunter, 1998).

Some have suggested that the smaller correlation may be the result of range restriction that occurs in leadership positions (e.g., Goleman, 1998). For instance, as the more intelligent workers are promoted, the difference between employee's GMA at higher levels becomes minimal. At the very top, the "star" performers (i.e., leaders) are thought to all have high levels of GMA. Thus, GMA is less of a factor in predicting leadership effectiveness than it is in predicting the performance of, say, shop workers or salespeople (Bennis, 1994).

As with conclusions concerning the personality-leadership relationship, it is also the case that alternative models of intelligence need to be explored. As House and Aditya (1997, p. 418) wrote, "Contemporary research on intelligence offers renewed potential for leadership trait research. The notion of multiple intelligences and Sternberg's theory 
of triarchic intelligence have implications for managerial roles. Leadership is embedded in a social context, and the idea of a social intelligence as a required leadership trait is a powerful one."

Thorndike (1920) was one of the first to suggest that "social" intelligence may be beneficial in the understanding of fellow men and women. Similarly, Gardner (1983) proposed a theory of multiple intelligences that included "interpersonal" facets. These facets were hypothesized to tap the ability "to notice and make distinctions among other individuals, in particular, among their moods, temperaments, motivations, and intentions," (Gardner, 1985, p. 239). In a similar vein, Boal and Hooijberg (2000) suggested that theories of emotional intelligence should be able to explain the underlying ability that governs leaders' behavioral complexities.

At the same time, there is reason to believe that the competencies that previously characterized leadership effectiveness in the 20th century may be changing. Rousseau (1995) identified the changing nature of the psychological contract as one of the major shifts in the workplace in the last 100 years. As organizations have begun to downsize (i.e., lay off large numbers of employees), in turn, employees have begun to have less trust in and less commitment towards the organization (Rousseau, 1995). "Modern" psychological contracts make it more likely that employees in the 21 st century will experience higher levels of job insecurity, stress, tension, and other emotional reactions. The increased emotional experiences of workers will have a profound impact on the types of leaders that will be required to manage relationships. Below, I expand on my contention that the context of the workplace - and thus the competencies needed for effective leadership - is changing rapidly in the 21 st century. Ultimately, I argue that 
emotions are now a fundamental aspect of the contemporary workplace and leadership scholars need a better understanding of the traits that effect the way leaders evoke, frame and, mobilize emotions in the workplace.

\section{Changing Nature of Leadership}

During the industrial period, organizations' were not very concerned with identifying or developing leaders (Aditya, House, \& Kerr, 2000). House (1995) notes that this is because those in charge were needed simply to observe, monitor, and control large numbers of workers doing physical labor. However, as work in the late 20th century became more emotional and intellectual (i.e., psychological), it became a much more difficult task to monitor, observe, and control workers (House, 1995).

Thus, the changing nature of modern work - with work becoming more emotional and intellectual and less physical - marks an important point in the study of leadership. Leadership is now commonly understood to be a dynamic activity, one that is required to adapt to different environments and new challenges in the workplace (Hogan \& Kaiser, 2005). Social skills as well as shared knowledge expertise are now requisite competencies in organizations (Kozlowski \& Bell, 2003), and to be effective, today's leaders need increasing amounts of these emotionally-laden capabilities (Gill, 2007). However, a postmodern view of leadership has only recently existed. For instance, one sees that many of the extant academic studies of leadership might be better characterized as studies of supervision or management (Aditya et al., 2000). But as economic factors force organizations to place a greater emphasis on a worker's emotional and intellectual abilities rather than physical ability, the differences between leaders and managers became more distinct. 
Abraham Zaleznik (1977) did much to articulate and conceptualize the differences between leaders and managers. His work illustrated that leaders are of a psychologically different type than managers. According to Zaleznik, leaders are inspiring visionaries who are concerned about substance, while managers are planners who are concerned with process. Managers tend to administer and maintain; leaders innovate and develop. In making these distinctions, Zaleznik was able to crystallize an understanding of how the changing nature of work was affecting the way industries and organizations operate. Not only was work changing from being primarily physical to being primarily emotional and intellectual, but, as Zaleznik contended, there were also changes in the nature of work as one progresses up in the organizational hierarchy. His paper was a cogent argument as to why greater emphasis needed to be placed on the study of leadership - as well as the changing nature of the competencies that predict leadership effectiveness.

At about the same time, Burns (1978) published an even more influential book called Leadership. He argued that the relationship between leader and follower inherently entails a transactional exchange. When followers act according to the wishes of their leaders, the followers receive certain outcomes that they value (e.g., money, notoriety). However, Burns made an incremental contribution to leadership theory in distinguishing between two types of exchanges that exist. One type of exchange is characterized in the traditional, economic sense (e.g., salary, bonus). That is, when a worker performs well, the leader should increase this worker's pay accordingly. However, it is the second kind of exchange that has subsequently spurred much leadership research. Burns noted that an exchange could also be psychological in nature. That is, a follower may receive payment in the form of positive emotions (i.e., an award for outstanding service). Making a 
distinction between economic exchange and psychological exchange is very similar to the distinctions that Zaleznik noted between managers (who are concerned with process) and leaders (who are concerned with substance).

Zaleznik and Burns theses marked a turning point in the study of leadership not because they offered groundbreaking empirical findings (both works were theoretical in nature), but because both authors correctly assumed that the changing nature of work would have broad implications for the study of leadership. However, leadership is also changing in the sense that work itself is changing (Howard, 1995). For instance, as manufacturing jobs begin to disappear and jobs in the service sector increase in numbers, the people in organizations become more important than capital or equipment (Barney, 1991). If employees are the most central assets to postmodern organizations, we might also conclude that it is paramount that organizational leaders understand the emotional needs and values of their workers in order to stay competitive.

Emotion in the Workplace

After a long period of dormancy in the organizational sciences - partly because of the cognitive revolution (e.g., Bandura, 1997) - the study of emotions in the workplace has seen a recent resurgence (Brief \& Weiss, 2002). Although this resurgence may be partly the result of recent intense interest in emotions in general in the field of psychology (e.g., Zajonc, 1998), it is also partly because of knowledge that emotions experienced at work influence both work attitudes (e.g., loyalty, commitment, satisfaction) and affect-driven work behaviors such as counterproductive and prosocial performance (Ashkanasy \& Daus, 2002). 
As stated above, the changing nature of the psychological contract is an important factor behind why organizational scientists have shown increasing attention towards emotion in the workplace. For instance, Cascio (2003) has characterized the new psychological contract as one of increased change, uncertainty, job insecurity, disloyalty, and temporariness. The negative emotions that workers feel (e.g., distrust, anger, stress, etc.) have direct effects on organizational productivity (Cascio, 2003). The ability to manage employees' emotions - as well as to motivate in the face of the new psychological contract - is a competency only recently explored by leadership scholarships.

In line with these arguments, Brandel (2001) has written that a number of young workers are opting out of high-paying, high-stress jobs and entering non-profit and government work. Although pay tends to be lower in these jobs, employees report that they are changing lines of work because they are motivated more by intrinsic rewards (e.g., belief in the organization's mission, capability to actualize individual values) than extrinsic rewards (e.g., salary). In short, workers are leaving traditional organizations due to the "emotional payment" they receive from non-profit and government work; that is, the fulfillment of organizational goals that are aligned with their own personal values (Bretz, 2005). The findings above suggest that if management wants to continue to retain their top employees, they need to be considerate of the emotions of their workers.

At the same time, we have also seen a marked increase in the number of jobs in the service sector (Ryan \& Ployhart, 2003). The service sector is characterized by operating goals centered on employee accountability as well as the professional delivery of services. Papadimitriou (2007, p. 573) has described the aims of service production as 
"identifying and satisfying socially defined needs and expectations." Employees are of utmost importance to achieving service sector goals; so much so that some have suggested that the employees are the services, and thus the product, in this type of environment (e.g., Barbeito \& Bowman, 1998).

For the most part, service sector jobs require extensive interaction with customers (Wong \& Law, 2002). In many customer service jobs, there are strong social norms regarding displays of emotions (e.g., smiling). For instance, an airline flight attendant is expected to smile and "act happy" during every single customer interaction, even when he or she may be in a bad mood. At certain points during these types of customer service jobs, one does not "feel" like smiling; but they go ahead and smile anyway because its a requirement of performing the job well. As Ashkanasy and Daus (2004, p. 79) write, “The need to manage one's emotions or express emotions contrary to one's true feelings characterizes most jobs to some degree or another."

The expression of "false" emotions has been studied under the rubric of emotional labor. Research in this area has shown that customer perceptions of service and of employee attitudes are significantly related to employees' positive display of emotions (Pugh, 2001). Indeed, the display of positive emotions creates favorable impressions in the minds of customers; this phenomenon has also been labeled "emotional contagion." And because customer service jobs cannot be readily performed, improved, or replaced by physical capital, the ability to motivate and influence workers at an "emotional level" has become a critical leadership competency (Wong \& Law, 2002).

However, it is not just the service sector that has seen emotions play an increasing role in the workplace. The 21 st century has seen "an ongoing shift from work organized 
around individual jobs to team-based work structures," (Kozlowski \& Klein, 2003, p. 333). As work becomes more social in nature, the interactions and emotions of individual employees have more impact on group-level outcomes (George, 1990). When working in a team, an individual employee must consider his or her own emotions, as well as the emotions of those in his or her group if they aim to avoid group conflict (Heath \& Jourden, 1997).

The changing demographics of the workforce also make emotions important to study and understand. As women increasingly become a part of the skilled workforce, some have noted that their role requirements as mothers are not decreasing (Williams, Suls, Alliger, Learner, \& Wan, 1991). Because of multiple role juggling, research has suggested that women experience higher levels of stress at both work and home than men. Thus, the spillover effect of negative emotions at work - via experienced negative emotions at home - is becoming a critical issue in organizations (e.g., Williams \& Alliger, 1994).

Moreover, organizations also face the challenge of integrating an increasing number of ethnic minorities into the workplace (Howard, 1995). Research has demonstrated that as work groups increase in racial diversity, negative work outcomes (e.g., turnover, absenteeism) also increase (e.g., Tsui, Egan, \& O’Reilly, 1991). Herriot and Pemberton (1995) have explained that negative work outcomes may be the result of negative emotions associated with workers being forced to spend time with other workers who are not "like" them. Nevertheless, as ethnic minorities continue to increase in numbers in the workforce, management will be forced to consider the issues associated with increased diversity. The organization that is able to successfully manage these types 
of diversity issues will have a competitive advantage (Cleveland, Stockdale, \& Murphy, 2000). Taken together, organizations will need leaders who can evoke, frame and, mobilize emotions in the workplace.

In the previous paragraphs, I have discussed the reasons why emotions are playing an increased role in organizations. I suggested that workers are displaying their emotions more frequently than they did in the past. I also suggested that workers value their emotions more than they previously have and that the workplace is becoming increasingly emotionally-laden. In sum, I have attempted to make the case for why the management, understanding, and regulation of emotion should be a required competency for any leader in the 21 st century. I now steer the discussion towards some of the ways that leaders use emotions to influence followers and conclude the current section by arguing that emotional intelligence - a specific trait associated with understanding one's own and others' emotions - should prove to be critical for leadership effectiveness. Emotion and Leadership

The effects of leaders' emotions in the leadership process have not been extensively examined until very recently (e.g., Conger \& Kanungo, 1998). A lack of research in this area is surprising considering that emotions have been shown to influence quality of decision-making, creativity, memory, and inductive as well as deductive reasoning; all competencies essential to being an effective leader (George, 2000). For example, Demasio (1994) noted that emotions help us to make choices and decide among varying options. Despite the fact that we tend to think people make their best choices when they are "cool" and rationally detached from emotion, Demasio's (1994, p. 53) work suggests, "reduction in emotion may constitute an equally important source of 
irrational behavior." Indeed, experiencing both positive and negative emotions can enhance a leader's decision-making quality and foster systematic and careful information processing (e.g., Isen et al., 1987; Sinclair, 1988).

In a similar vein, there has also been research showing that a leader's emotions can effect the emotions of followers. George (1992, p.84) asserted, "Leaders who feel excited, enthusiastic, and energetic themselves are likely to similarly energize their followers, as are leaders who feel distressed and hostile likely to negatively activate their followers." Frost (2003) has discussed how emotionally insensitive leader attitudes and behaviors can have negative effects on followers (i.e., emotional pain). Lewis (2000) found that followers felt increased nervousness and fatigue when they observed a leader expressing sadness or lack of emotion. In a conceptual model, Prati et al. (2003) suggested that leader emotional intelligence is a critical aspect of linking team processes to organizational outcomes.

Furthermore, a number of prominent leadership scholars have suggested that a fundamental component of leadership is the emotional nature of the process (Ashkanasy \& Tse, 2000; Bass, 2002). Ashford and Humphrey (1995) have written about how the leadership process is intrinsically emotional and value laden and that it is impossible to separate cognition or rationale behavior from emotion. Bass and Avolio (1990) suggested that leaders provide the symbolic and emotional force behind organizational change. Ashkanasy and Tse (2000) argue that leadership is merely a function of emotion management, and that emotion-related variables are important at every stage of the process linking leadership to work group outcomes. Goleman (1998) has asserted that leaders of today's organizations are being judged not only by how much expertise and 
knowledge they possess, but also by their ability to handle themselves and others. He noted that empathy, expressions of care and concern, willingness to listen, and open communication skills are important emotional and personal qualities that make the difference between successful leaders and unsuccessful leaders.

In sum, it appears that traits involving the identification, understanding, and management of emotions (in oneself and others) are worth studying in the context of leadership. As written above, the major aim of my dissertation is to explore whether effective leaders possess certain emotional traits (or competencies) that allow them to develop social influence better than poor leaders. These emotion competencies have been addressed by emotional intelligence theory and research. Emotional intelligence essentially describes one's ability to effectively link emotions and reasoning, one's ability to use emotions to facilitate reasoning and one's ability to reason intelligently about emotions (Mayer \& Salovey, 1997). That is, “emotional intelligence taps into the extent to which people's cognitive capabilities are informed by emotions and the extent to which emotions are cognitively managed," (George, 2000, p. 1033).

The emerging body of EI research has been linked with leadership effectiveness, and some suggest that it plays an important role in predicting organizational outcomes, power and politics, and decision-making processes (Cooper \& Sawaf, 1997; Goleman, 1997; Mayer \& Salovey, 1997). As theorized, a combination of EI capabilities informs cognition and guides dynamic leadership behavior. In the next section, I further describe emotional intelligence, as well as theory and research that suggests it should be significantly related to leadership effectiveness. 


\section{Emotional Intelligence}

Salovey and Mayer (1990) were some of the first to use the term emotional intelligence (EI) when they attempted to describe the human ability to recognize and regulate emotions. Original theories of EI were offshoots of the earlier theories of multiple intelligences and social intelligences (Gardner, 1983; Thorndike, 1920). What distinguishes EI from Gardner's and Thorndike's theories of social intelligence, however, is the emotional component. These early authors were mainly concerned with an interpersonal capability. Or, as Thorndike (1920) put it, "the ability to understand and manage men and women, boys and girls — to act wisely in human relations."

In its original form, Salovey and Mayer defined EI as "a form of intelligence that involves the ability to monitor one's own and others' feelings and emotions, to discriminate among them, and to use this information to guide one's thinking and actions," (Salovey \& Mayer, 1990, p. 189). However, since then, the definition of the construct has changed to the "ability to perceive emotion, integrate emotion to facilitate thought, understand emotions and regulate emotions and to promote personal growth," (Mayer \& Salovey, 1997, p. 101). A number of other scholars have proposed their own definitions for EI (e.g., Bar-On, 1997; Goleman, 1995), however, the differences are minor and the scientific community has reached consensus to adopt Mayer and Salovey's definition (Ashkanasy \& Daus, 2005).

I should also note that there is some debate over the proper conceptualization of EI. Despite agreement among the academic community on a concise definition of EI (e.g., Mayer \& Salovey, 1997), two ostensibly competing models have emerged, jockeying for position on the nomonological network (Mayer, Salovey, \& Caruso, 2000). The first is 
called the ability model, and characterizes EI as an ability and classifies it as an intelligence. The second is known as the mixed model and conceptualizes EI as a combination of cognitive, motivational, and affective constructs and is classified as more of a dispositional characteristic. I will discuss the nuances of these competing models of EI in a later section of this dissertation.

Building on Mayer and Salovey's (1997) review of EI, Petrides and Furnham (2001) also classified the two models as ability and mixed-model conceptualizations. Interestingly, while there continues to be disagreement among scientists as to whether EI is an intelligence or personality characteristic (e.g., Murphy, 2006), there is a surprising amount of overlap between the two seemingly competing models. Conceptually, perhaps the strongest commonalities among the models are that EI is postulated to consist of the same four hierarchical dimensions across both models. For instance, Petrides and Furnham, (2001) suggest that the ability model of EI is based on four first-order factors: perception, assimilation, understanding and management of emotion. Taking a mixed model approach to EI, researchers have seen extensions of the four first-order factor conceptualization to incorporate the trait relevant elements in their assessment of EI as well (Ciarocchi et al., 2000).

Using a factor analytic approach to quantitatively summarize the EI literature, work by Davies and colleagues (1998) supported Mayer and Salovey's contention that EI was comprised of four dimensions: emotion perception, regulation, understanding, and utilization. While the implications of the Davies et al. (1998) factor analyses have been debated (Ciarocchi et al. 2000), many researchers have since adopted this four dimensional approach (e.g., Mayer et al. 2000; Petrides \& Furnham, 2001; Wong \& Law, 
2002). The present study takes the four-dimensional approach to examine EI. That is, I maintain that EI can best be understood as a higher order factor with four lower order factors: (1) perception of emotion in self and others; (2) assimilation of emotion to facilitate thought; (3) understanding of emotion, and (4) regulating and managing emotion in the self and others. The higher-order EI construct is then theorized to account for the relationships between these four lower-order branches (Wong \& Law, 2002).

Psychological research on EI has increased over the past decade and the amount of widespread public attention that it has garnered is unheralded for an emerging psychological construct. Best-selling books (e.g., Goleman, 1995) and feature-length articles in prestigious periodicals such as Time Magazine have already been dedicated to the construct. In short, EI has become a popular topic with the international media. However, there may be consequences associated with the enormous amount of lay interest that EI has generated in such a short period of time. One such consequence involves assertions about EI's usefulness that are not based on science. Many of these popular works have made unfounded claims and misstatements about the present understanding of EI. For instance, Goleman (1998) has suggested that emotional intelligence accounts for 85 to $90 \%$ of performance in the upper levels of leadership. With claims such as these making their way into the national media, it is not hard to see why noted scholars have been overly critical of the EI construct (e.g., Landy, 2005; Locke, 2005).

Despite these odious research claims, a number of examinations of EI have found that it is strongly related to criteria that are of interest to organizations. For instance, using meta-analytic procedures, Van Rooy and Viswesvaran (2004) found that EI was 
significantly related to overall job performance. Sy, Tram, and O'Hara (2006) found that the EI predicted employee performance and satisfaction, even after controlling for personality factors. Another study on negotiation tactics found that teams benefited both objectively and affectively when members had higher levels of EI (Der Foo, Elfenbein, Tan \& Aik, 2004). Furthermore, when EI was administered in a high-stakes organizational setting, applicants were found to react favorably to this assessment (Whitman, Van Rooy, Viswesvaran, Kraus, \& Burns, 2006).

However, perhaps no other area has received more research attention in the EI literature than the study of leadership. George (2000) was one of the first to link EI with leadership, proposing a conceptual model and describing a logical tie between the two. Since then, empirical evidence has accumulated. For instance, Daus and Harris (2003) found that EI predicted leadership effectiveness. Cote, Lopes, and Salovey found that leaders with high EI tended to exhibit higher-quality vision and commitment. In a study of South African leaders, Coetzee and Schaap (2004) reported that EI was significantly related to high levels of both transactional and transformational leadership. Collins (2001) work suggests that leaders with high EI are better able to rate their own performance levels; those with low EI tend to overrate and overestimate their performance. Indeed, even Frank Landy (2005) - a noted critic of EI research - has suggested that EI shows promise in predicting leadership effectiveness.

In the next section, I review emotional intelligence theory and some of the mechanisms that suggest it should be significantly related to leadership effectiveness. I then provide a more in-depth review of the empirical research that has examined this 
relationship, and expand on extant findings. I culminate the current section by hypothesizing that there will be a significant correlation between EI and leadership.

\section{Linking EI with Leadership Effectiveness}

It is not hard to imagine a typical scenario in the workplace where a leader has to manage his or her emotions. For example, consider you are the owner of a restaurant and are informed by a patron that a server you recently hired used an ethnic slur in a moment of disgust. Undoubtedly, you will experience anger at the server - especially if the restaurant you own has your name on it. How you handle your emotions when you discuss this issue with the server will probably determine whether or not you fire him. Now imagine that you see an employee accidentally break a plate in the kitchen. If the level of anger that you experience is the same as when you heard that a server used a racial epithet, then it is unlikely that you have control over your emotional reactions. And as Jones and George (1998) have noted, it is difficult to build good relationship with followers and engender their trust when a leader experiences anger frequently.

On the other hand, a leader who experiences only positive emotions may ignore and fail to manage the performance of his or her staff appropriately (Jones \& George, 1998). For instance, the experience of negative and intense emotions may redirect a leader's attention towards areas of deficiency (Frigda, 1988). Illustrated here is the point that being "emotional" is not always a bad thing. Indeed, Sinclair and Mark (1992) have suggested that negative emotions may be helpful in situations that require high cognitive complexity as well as high risk.

Research on EI suggests that people can and do manage their own emotions, as well as the emotions of those around them (Salovey \& Mayer, 1990). Indeed, scholars 
have identified a number of ways in which certain competencies (e.g., ability to regulate, manage, and interpret emotions) related to emotional intelligence are predictive of leadership success. As noted above, leadership effectiveness can be described in terms of a leader's ability to influence a group towards achieving organizational goals (Judge et al., 2002). Accordingly, I will now describe a number of these essential leadership elements that are hypothesized to be linked with EI.

\section{Theoretical Linkages}

Developing collective goals and objectives and motivating employees to achieve them is an important aspect of leadership (Yukl, 1998). This is commonly referred to as “achieving the leader's vision," and there is reason to believe that EI may play a role in helping leaders to develop a vision for their group. For instance, leaders typically confront so much stimuli, laden with so much ambiguity, that their values, experiences, and personalities greatly impact their interpretation of events and the choices that they make (see Finkelstein \& Hambrick, 1996). Research on EI suggests that leaders' experiences of positive emotions are positively correlated with creativity (Cote et al., 2005). George (2000, p. 1040) has noted that "creating a compelling vision for an organization can be an exercise in creativity, positive thinking, and flexibility and such an exercise will be facilitated by positive emotions." Alternatively, leaders who understand and are in control of their emotions may be less likely to be overly optimistic when they do experience positive moods.

Leaders must also influence followers to have them "buy-in" and accept the vision in a collective, organizational sense. The ability to understand how followers feel that is, to correctly appraise their emotions - should benefit a leader here. Understanding 
what emotions followers feel and why they feel this way should allow the leader to pitch his or vision in a way that is most receptive to organizational members (Gardner \& Avolio, 1998). For instance, a leader with high emotional intelligence may know the best way to reward followers so that they experience more positive emotions at work. In turn, the positive emotions experienced by workers should translate into increased motivation, commitment, and performance (Brief \& Weiss, 2002). In sum, it appears that emotional intelligence may help leaders carry out important activities such as the collective sensemaking of goals and objectives.

Conger and Kanungo (1998) have indicated that an important part of leadership effectiveness is being able to positively influence the contextual aspect of the workplace. For instance, creating optimism among workers and encouraging them to cooperate, help, and perform other types of prosocial behaviors can have a significant impact on a business' bottom line (Motowidlo, 2003). In order to generate optimism, it is paramount that leaders be in touch with the feelings of their followers so that they know how to go about influencing them in a positive manner. Further, leaders need to be able to manage the emotions of followers during hard times; especially when an organization may be going through a rough stretch and downsizing is required. The ability to keep morale high requires a large emotional component on the part of the leader (Brief, 1998).

In other situations, a leader's ability to sense the "true" emotions of their followers may be a benefit. For instance, Ekman (1973) noted that followers often suppress their true emotions when they are in contact or communicating with a supervisor. A leader's ability to detect, say, false enthusiasm or excitement may give them an advantage during selection, promotion, and performance management processes. 
Moreover, leaders need to be able to identify conflict among group members- even when the members themselves may deny such a conflict (because they are afraid of being punished). A leader exhibiting lower levels of emotional intelligence may not even be aware of such conflict, much less able to solve this conflict. Ashkanasy and Daus (2002, p. 81) wrote, "a leader who is able to read employees well will be better equipped to intervene in emotionally challenging situations to provide individualized support." The behaviors associated with effective leaders are also related to emotional intelligence. Leaders who are high in EI are more likely to empathize with followers and understand why they are feeling the way they are. Consideration and support may go a long way towards developing a high-quality interpersonal relationship between the leader and follower, and ultimately may influence follower enthusiasm, excitement and optimism (Graen \& Uhl-Bien, 1995).

Additionally, EI has been suggested to contribute to constructive thinking (Epstein, 1990). For instance, enabling employees to solve a problem with a minimum amount of stress is one way to maintain a cooperative and trusting organizational climate. George (2000) has suggested that constructive thinking can lead to "win-win" situations where employees generate ideas to settle disagreements. Thus, leaders high in EI may facilitate trust and cooperation through the use of constructive thinking Decision-making constitutes a large portion of the activities that constitute leadership effectiveness (Zaccaro, 2002). In order to make good decisions, leaders must be able to know and manage their emotions. Gill (2007, p. 116) asserted, "Because emotions are essential self-information, their accurate appraisal is crucial for effective self-regulation in the context of leadership." As suggested above, emotions serve to 
prioritize the large amounts of information that leaders are constantly besieged with. In other words, leaders with high EI will be able to distinguish the important information from the less important information (Ashkanasy \& Daus, 2002). They may also be able to multitask better and identify commonalities among the various issues that confront them (Yukl \& Van Fleet, 1992).

Further, leaders who know and can manage their own emotions are more likely to approach problems form different angles and consider different outcomes and scenarios (George, 2000). Leaders with high EI should be aware that experiencing positive and negative emotions may cause them to view situations and decisions differently, and they will regulate their emotional experiences accordingly (Salovey et al., 1995). For example, Salovey and colleagues (1995) suggest that when leaders with high EI experience different emotions (both positive and negative), they deliberately revisit a proposed course of action. They assert that leaders gain a richer point of view when they experience the same decision situation (or proposed course of action) in two completely different emotional states.

In sum, it appears that there is overwhelming theoretical evidence suggesting a significant relationship between EI and leader effectiveness. It should not be surprising to the reader, then, to know that a number of empirical linkages have been reported in the literature. I will now discuss just a few of these studies before proposing specific hypotheses.

\section{Empirical Linkages}

Wolff, Pescosolido, and Druskat (2002) examined the role of EI and team leadership. In a longitudinal study, they found empirical evidence that EI significantly 
predicted leadership effectiveness in self-managing teams. Specifically, they suggested that EI preceded and enabled the cognitive processes that accurately assess other team members' emotions and needs. In a study of upper-level managers, Wong and Law (2002) examined the role that leader EI had on subsequent follower behaviors. While they did not find that leader EI was related to follower job performance, they did find that leader EI was related to follower job satisfaction and prosocial (or contextual) behaviors. Wong and Law suggested that leaders with high EI were able to affect these follower behaviors through management of the amount of emotional labor that followers experienced. Barbuto and Barbuch (2006) examined the role of EI in a group of publicly elected officials. They found that EI was significantly related to both self-perceptions and follower-perceptions of leadership effectiveness, and suggested that a leader's ability to empathize with followers was the driving force behind this relationship. A study by Conrad (2007) also found a significant relationship between EI and leadership effectiveness. He concluded that leaders who had high levels of EI exhibited better decision-making, higher levels of social responsibility, and displayed better interpersonal relationships.

Despite the abundance of evidence suggesting that EI predicts leadership effectiveness, there is also research that exists intimating and illusory relationship. For instance, in theoretical papers, Antonokis (e.g., 2003, 2004) has argued forcefully that EI does not predict leadership effectiveness. Also, some empirical tests have shown trivial findings; both Macik-Frey (2007) and Kobe et al. (2001) found that EI did not predict leadership criteria. However, as Hunter and Schmidt (2004) have noted, the inconsistent relationships reported across studies may be the result of sampling error. Accordingly, the 
purpose of my dissertation is to use meta-analytic methodology to cumulate the research literature assessing the relationship between emotional intelligence and leadership effectiveness. Despite some evidence to the contrary, I believe that the abundance of theoretical and empirical research presented above suggests that EI will be significantly related to leadership effectiveness. Therefore, I propose that:

Hypothesis 1: Emotional Intelligence will be significantly related to leadership effectiveness

In addition to leadership effectiveness, a number of meta-analyses examining traits and leadership criteria have also examined leadership emergence (Lord et al., 1986; Judge et al., 2002). Judge and colleagues (2002, p. 767) define leadership emergence as "whether or to what degree an individual is viewed as a leader by others, who typically have only a limited information about that individual's performance.” In other words, emergence is a concept related to perceptions of leadership rather than a leader's influence on followers (i.e., leadership effectiveness). Traditionally, leadership emergence has been examined in leaderless undergraduate groups and data was coded when a person emerged as a leader.

Although leadership emergence is an important criterion, I will not explicitly examine its relation with EI for two reasons. First, the purpose of my dissertation is to focus on leadership and influencing behaviors in organizations. Studies that examine leadership emergence generally examine undergraduates' perceptions in laboratory studies, not the leader's performance in influencing followers towards achievement of a goal. The theoretical justifications suggest that $\mathrm{EI}$ is likely to play a significant role in influencing followers; more so than in just emerging as a leader. A second reason 
pertains to the dearth of studies that have examined leadership emergence as a correlate in recent years (Judge et al., 2002). Because the first known study to examine the EIleadership relationship was conducted in the late 1990s, very few data are available to meta-analytically test this relationship. Thus, only leadership effectiveness will be examined in my study.

However, in addition to being related to leadership effectiveness criteria, it may also be the case that EI is related to more proximal criteria, such as leader behavior or style. Therefore, along with an examination of EI's relation with effectiveness criteria, I will also examine EI's relation with more proximal (i.e., behavioral) criteria as propounded in theories of transformational leadership and leader-member exchange.

\section{Transformational Leadership}

Transformational leadership theory attempts to explain how certain leaders are able to achieve extraordinary levels of follower motivation, admiration, commitment, respect, trust, and performance (Den Hartog \& Koopman, 2001). House (1996) observes that transformational (or charismatic) leadership theory is more concerned with how leaders change people rather than how leaders respond to people. Bass (1985) describes a difference between transformational/charismatic leadership (when leaders change people) and transactional leadership (when leaders simply respond to people) by conceptualizing transactional leadership as a cost-benefit exchange process; a series of implicit bargains or exchanges in the leader-follower relationship. He conceptualizes transformational/charismatic leadership as leadership that motivates and inspires followers to go beyond this cost-benefit exchange. 
Bass (1985) identified four mechanisms through which leaders transform followers, including idealized influence, inspirational motivation, intellectual stimulation, and individual consideration. Idealized influence involves the leader articulating a compelling vision, role modeling commitment to the vision, and demonstrating competence in achieving this vision. In turn, followers are believed to identifying with the leader's vision, and have trust in the leader to accomplish it. Inspirational motivation deals with a leader's ability to increase followers' understanding of mutual objectives, and occurs when leaders appeal to the emotions of followers by using symbols and images. These appeals help lead to followers becoming emotionally committed to the organization's goals. Through intellectual stimulation leaders encourage followers to question their own values, beliefs, and assumptions. By challenging followers to question their assumptions and expectations, leaders support an invigorating environment of creative and emotional development. Individual consideration takes place when leaders treat followers differently, but fairly based on their understanding of the talents, needs, and goals of their followers.

A number of studies have suggested that transformational leadership is predictive of important criteria. For instance, in the political context, Pillai, Williams, Lowe, and Jung (2003) found that transformational leadership was significantly related to reported voting behavior for the 2000 U.S. presidential candidates. Similar findings were also reported for the 1996 U.S. presidential candidates (Pillai \& Williams, 1998). Research on the relationship between transformational leadership and business unit performance has also shown to be robust. In a study of 101 senior bank managers, Howell, Neufeld, and Avolio (2005) found that transformational leadership positively predicted bank branch 
performance. Another study of 78 top-level financial managers (e.g., life insurance, investments) found similar results relating transformational leadership to business unit performance (Howell \& Avolio, 1993). In general, results suggest that a significant relationship exists between transformational leadership and organizational effectiveness (Zhu, Chew, \& Spangler, 2005).

An unintentional result of transformational leadership research being chiefly focused on organizational outcomes is that much less is known about the antecedents of this important leadership style (Bommer, Rubin, \& Baldwell, 2004). One area that has seen some research activity concerns the dispositional bases of transformational leadership. Bono and Judge (2004) attempted to link the Big Five personality factors (i.e., neuroticism, extraversion, openness, agreeableness, and conscientiousness) to aspects of transformational leadership. However, the strength of the relationships they found were not particularly robust. For instance, they found that extraversion was the only factor with $80 \%$ credibility intervals that did not include zero for the components of transformational leadership. Furthermore, few other studies that have examined personality as the underlying basis of transformational leadership (e.g., Bono \& Judge, 2004; Rubin, Munz, \& Bommer, 2005) were not particularly revealing.

On the other hand, there appears to be much promise in research that has linked EI with transformational leadership. As Ashkanasy and Daus (2002, p. 81) write, "Transformational leaders need to understand how their followers feel. In essence, transformational leaders need to have the ability to inspire and arouse their followers emotionally." Communicating a vision and strategy, as well as motivating and inspiring followers, is as much as an emotional process as it is a behavioral process (Gill, 2007). 
The ability to show individualized consideration - a key component of transformational leadership - should also be improved, as leaders with high EI are seen to be better empathizers, and thus, better communicators and managers of conflict (Boal \& Hooijberg, 2000). Finally, leaders need to be able to manage and regulate their own emotions, as well as to understand the emotions of their followers if they are to successfully challenge the status quo and develop employees to do the same (i.e., use intellectual stimulation).

A number of empirical works have also linked the two concepts. Dasborough and Ashkanasy (2002) studied the relationship between transformational leadership and EI within organizations. Their empirical results suggested a relationship between EI and transformational exists because of two central ideas: (a) leadership is an emotional process and (b) leadership is a process of social interaction. Palmer et al. (2001) also studied the relationship between transformational leadership and emotional intelligence. Specifically, they found that the ability to monitor and to manage emotions in oneself and in others was a key predictor of the inspirational motivation and individualized consideration components of transformational leadership. In a similar study, McCollKennedy and Anderson (2002) found that an emotional process explains part of the effect that transformational leadership style has on organizational performance. In particular, leaders with both high EI and transformational leadership were found to have beneficial effects on the levels of frustration and optimism (i.e., emotions) that group members experienced. In sum, it appears that EI should be an important antecedent of this important leadership style. Therefore, it is hypothesized that: 
Hypothesis 2: Emotional Intelligence will be positively related to transformational leadership

In addition, it is also proposed that EI will be related to the four underlying facets that are thought to make up the higher-order transformational leadership construct:

Hypothesis 3: Emotional Intelligence will be positively related to inspirational motivation

Hypothesis 4: Emotional Intelligence will be positively related to idealized influence

Hypothesis 5: Emotional Intelligence will be positively related to individualized consideration

Hypothesis 6: Emotional Intelligence will be positively related to intellectual stimulation

\section{Leader-Member Exchange}

Leader-member exchange (LMX) theory describes the process in which a relationship typically develops between a leader and a follower (Graen \& Uhl-bien, 1995). Leader-member exchange views leadership as an exchange process, with work roles and relationships between the leader and follower changing over time. For instance, LMX suggests that after an initial period of getting to know one another, the leader will "offer" the follower a chance to become part of the "in-group" at work. Becoming a part of the in-group means that the subordinate will be given more work, more important work, and thus, more rewards. That is, a high-quality LMX exchange involves the leader giving the follower outcomes that the follower desires (Yukl, 2006). In return, the follower provides the leader with higher work performance and levels of commitment. 
Leader-member exchange is seen to be a dyadic, reciprocal relationship that builds over time (Danseraue, Graen, \& Haga, 1975), with leaders spending more and more time with “in-group" members.

In a meta-analytic review, Gerstner and Day (1997) found that LMX was predictive of a large number of organizational criteria. For instance, LMX was significantly correlated with job satisfaction, performance, commitment, and (negatively with) turnover. Leader-member exchange has shown to be predictive of leadership effectiveness criteria across industries and job classes (e.g., Liden \& Graen, 1980), and Aryee and Chen (2006) have found support for LMX across cultures.

Recently, studies have begun to examine EI as an important antecedent to highquality LMX. For instance, a study of middle- and upper-level managers, Gordon (2007) found that leaders with high EI had better exchange relationships with their followers and were also rated by their followers as more effective leaders. Similarly, Webb (2005) found that LMX moderated the relationship between leader EI and leader effectiveness such that leaders with both high EI and LMX were the most effective leaders.

The theoretical foundation for these studies is work that suggests relationship building and maintenance are associated with high levels of EI. Indeed, the display of empathy and emotionally supportive behaviors has been seen to promote high quality relationships (Sparrowe \& Liden, 1997). Moreover, leaders who are acutely aware of others' emotions, as well as self-aware of their own emotions, should be better able to establish and maintain high-quality relationships. Tichy and Devanna (1986) suggested that leaders who are self-aware are likely to have a good understanding of their own emotional strengths and weaknesses, and thus, will be more oriented towards self- 
improvement. And leaders who are able to regulate their emotions are more likely to be seen as approachable and helpful to followers, and will be less likely to anger followers or cause conflicts (Van Velsor \& Leslie, 1995). Therefore, I hypothesize that:

Hypothesis 7: Emotional Intelligence will be positively related to high-quality $L M X$

\section{Mediation of the EI-Leadership Effectiveness Relationship}

Researchers have proposed that leadership style may be a process mechanism linking leader personality to leader outcomes (e.g., House et al., 1991; Whitman, Resick, Weingarden, \& Hiller, 2005). For instance, House and colleagues (1991) found that dispositional characteristics significantly predicted leader behavior, which in turn significantly predicted leadership effectiveness. In a similar light, Whitman and colleagues showed that bright-side and dark-side personality traits have an effect on leadership effectiveness criteria through transformational leader behavior. Hogan and Kaiser (2005) have offered a similar process model (leader traits $\rightarrow$ leader behavior $\rightarrow$ leadership effectiveness), noting that, "Who we are determines how we lead," (p. 175). Accordingly, it is hypothesized that transformational leadership and LMX will transmit some of the effect from leader EI onto leader effectiveness criteria:

Hypothesis 8: Transformational leadership will mediate the relationship between Leader EI and leadership effectiveness

Hypothesis 9: Leader-member exchange will mediate the relationship between Leader EI and leadership effectiveness 


\section{Facets of EI}

In a comprehensive review of the literature, Petrides \& Furnham, (2001) found that there is consensus among researchers that EI is based on four first-order factors: (1) appraisal and expression of emotion in the self and others (i.e., being able to accurately interpret one's own and other's emotional states); (2) use of emotion to facilitate thought (i.e., utilizing emotions in ways that enhance cognition); (3) understanding of emotion (i.e., recognizing the causes and consequences of emotions), and (4) regulating and managing emotion in the self and others (i.e., proactive evaluation of one's own and other's emotions). For instance, Mayer and colleagues (2000) - proponents of the ability model - as well as Boyatzis (2000) - a proponent of the mixed model found support through factor analytic techniques that EI is best conceptualized with four sub-facets. I now review each of these four facets and theoretically link them to leadership effectiveness, transformational leadership, and LMX.

\section{Appraisal and Expression of Emotion}

There is research that suggests people differ in their ability to both express emotion as well as to appraise the emotions of others. For instance, Emmons and Colby (1995) have conducted research that suggests some people are unable to express their true emotions, and may actually agonize over the inability to do so. It may also be the case that a person expresses emotions too haphazardly, and then later regrets it. Taylor (1984) has studied a psychological disorder known as alexithymia - the inability to accurately express emotions and communicate feelings using language. Alexithymics may even be unable to express emotions nonverbally with body language or facial expressions. Individuals who lack these emotional competencies can experience greater levels of 
tension, stress, anxiety, and lower levels of psychological well-being and social support (Katz \& Campbell, 1994).

Appraising the emotions of others is also a critical emotional competency. Being able to accurately interpret another's emotional state is critical for consistent communication. Much of this appraisal comes from non-verbal communication (Buck, 1984). However, it is also important to be able to accurately judge when another person is displaying a false emotion; individuals may be reluctant to readily express negative emotions. In a similar vein, empathy is a critical component of this dimension and relates to the individual's ability to "comprehend another's feelings and to re-experience them oneself," (Salovey \& Mayer, 1990, p. 194). George (2000) asserts that leaders who possess these competencies are better able to provide individualized support to their followers by recognizing and addressing the nonverbal cues that indicate concern, doubt, confusion, anger, or misunderstandings in followers. Rapisarda (2002) noted that individuals who possess the ability to sense the emotions and feelings of others are more successful in facilitating the development of emotional bonds that can result in increased cohesiveness and performance. Thus, leaders who possess the ability to appraise and express emotion should be able to create environments that stimulate the development of employee trust, prosocial behaviors, learning, and performance. Therefore, it is hypothesized that:

Hypothesis 10: Leader emotional expression and appraisal will be positively related to leadership effectiveness Hypothesis 11: Leader emotional expression and appraisal will be positively related to transformational leadership 
Hypothesis 12: Leader emotional expression and appraisal will be positively related to high-quality $L M X$

\section{Use of Emotion to Facilitate Cognitive Processes}

The second dimension, using emotion to enhance cognitive processes and decision-making, relates to utilizing emotions in ways that enhance cognition or decisionmaking processes (Salovey \& Mayer, 1990). Behaviors associated with this dimension of EI include: maintaining positive mood states by exhibiting enthusiasm, optimism, curiosity, openness to new ideas, and being responsive to the feelings of self and others (Mayer \& Salovey, 1997). As described earlier, Demasio (1994) found that emotions enhance the choices one makes (i.e., the decision-making process) when one is confronted with myriad stimuli. And Salovey and colleagues (1993) have shown that emotions can facilitate creativity, integrative thinking, and inductive reasoning. All of these processes should be useful as leaders confront more stimuli and face more challenges and competition.

Cooper and Sawaf (1996) also suggested that using emotions appropriately entails being aware of other's perceptions of fairness. They noted that followers regularly observe leader behaviors and interpret them regarding their fairness, consistency, and appropriateness. Thus, one would expect a leader who uses his or her emotions effectively to create an environment where employees trust their leader and "buy in" to the organization's vision, mission, and goals. George (1991) examined positive affect at work and found that leaders who create positive mood states by using their emotions appropriately influenced followers to increase the number of prosocial organizational behaviors they performed at work. George's findings are also consistent with Organ's 
(1990) OCB theory that an employee's feelings or moods while performing job-related activities are important determinants of their willingness to engage in extra role behavior. Goleman et al. (2002) also noted that leaders who can maintain optimistic and upbeat attitudes in daily activities and generate positive feelings in others are able to "craft an environment of trust, comfort, and fairness among employees," (p. 47). Taken together, it appears that leaders who are able to use emotion to facilitate cognitive and decisionmaking processes will be more successful. Therefore, it is hypothesized that:

Hypothesis 13: A leader's ability to use emotion to facilitate cognitive processes will be positively related to leadership effectiveness

Hypothesis 14: A leader's ability to use emotion to facilitate cognitive processes will be positively related to transformational leadership

Hypothesis 15: A leader's ability to use emotion to facilitate cognitive processes will be positively related to high-quality $L M X$

\section{Understanding of Emotion}

The third facet of EI, understanding emotions, deals with a person's ability to recognize the causes and consequences of emotions (Mayer \& Salovey, 1997). Cooper and Sawaf (1996) noted that emotions are neither inherently good nor bad; rather, it is how and in what way an individual responds to them that matters and ultimately determines the effect of the emotion. They suggested that the competency to recognize the increased intensity of constrictive emotions and redirect those emotions in a more positive way is critical to the application of emotionally intelligent behaviors. George (2000, p. 1037) writes, "Some people have a rudimentary understanding of how they (and 
other people) are influenced by feelings and use this knowledge in functional ways... On the other hand, some people are oblivious to the effects of feelings."

Understanding and recognizing when emotions are influencing a situation is a critical competency for leaders who want to maintain or further develop high quality working relationships (George, 200). Goleman et al. (2002) noted that a leader's inability to understand negative emotions may prevent them from obtaining the mental clarity that successful leadership demands. Zaccaro, Gilbert, Thor, and Mumford (1991) have also suggested that being able to perceive the intentions and motives of followers may enhance a leader's ability to attain organizational goals. They maintained that leaders who have these competencies could foster better interpersonal relationships, solve problems more efficiently, and elicit reciprocal prosocial behaviors among organizational members. Therefore, it is hypothesized that:

Hypothesis 16: A leader's ability to understand emotions will be positively related to leadership effectiveness

Hypothesis 17: A leader's ability to understand emotions will be positively related to transformational leadership

Hypothesis 18: A leader's ability to understand emotions will be positively related to high-quality LMX

\section{Management and Regulation of Emotion}

The final facet of EI is the management and regulation of emotion. This component of EI refers to the proactive evaluation and management of one's own and other people's emotions (Salovey \& Mayer, 1990). Salovey and Mayer noted that when an individual recognizes that they are feeling a positive emotion, they should recognize 
the situation and, later, be able to recreate those conditions contributing to the positive feelings. They could then use this ability to influence others in their social exchanges. Goleman et al. (2002) wrote that effective relationship management "boils down to handling other people's emotions," (p. 51). Behaviors associated with this facet include respect, honesty, inspirational motivation, and suppression of negative emotions (Salovey \& Mayer, 1990). Referring to the facet as the "proactive" dimension of feelings and emotions, George (2000) suggests it entails the ability to manage the emotions of others. As it relates to leadership, George (p. 1038) writes "being able to excite and enthuse other people or make them feel cautious and wary is an important interpersonal skill and vehicle of social influence." Wong and Law (2002) found that emotional regulation allowed leaders to positively influence the quality of leader-follower interactions and increase job satisfaction and performance outcomes. They suggested that leaders with high levels of EI are better able to foster interactions with others because they focus their own and other's emotional responses in ways that create synergy toward achieving organizational goals. Because it seems that the management and regulation of emotion is related to various leadership criteria, it is hypothesized that:

Hypothesis 19: A leader's ability to manage and regulate emotion will be positively related to leadership effectiveness

Hypothesis 20: A leader's ability to manage and regulate emotion will be positively related to transformational leadership

Hypothesis 21: A leader's ability to manage and regulate emotion will be positively related to high-quality $L M X$ 
Previously, I proposed that transformational leadership is a mediating mechanism that helps to explain the EI-leadership effectiveness relationship. Thus, I suggest that the four facets of EI will also have an effect on leadership via transformational leadership. Therefore, it is hypothesized that:

Hypothesis 22: Transformational leadership will mediate the relationship between leader emotional expression and appraisal and leadership effectiveness Hypothesis 23: Transformational leadership will mediate the relationship between a leader's ability to assimilate emotion to facilitate thought and leadership effectiveness

Hypothesis 24: Transformational leadership will mediate the relationship between leader understanding of emotion and leadership effectiveness Hypothesis 25: Transformational leadership will mediate the relationship between leader management and regulation of emotion in one's self and other's and leadership effectiveness

In a similar manner as above, I believe LMX will be an underlying mechanism explaining the relationship between the facets of EI and leadership effectiveness. Accordingly, I hypothesize that:

Hypothesis 26: Leader-member exchange will mediate the relationship between leader emotional expression and appraisal and leadership effectiveness Hypothesis 27: Leader-member exchange will mediate the relationship between a leader's ability to assimilate emotion to facilitate thought and leadership effectiveness

Hypothesis 28: Leader-member exchange will mediate the relationship between 
leader understanding of emotion and leadership effectiveness

Hypothesis 29: Leader-member exchange will mediate the relationship between

leader management and regulation of emotion in one's self and other's and

leadership effectiveness

Incremental Validity of EI

Since the 1950s, leadership scholars have identified two important traits intelligence and extraversion - that are predictive of effective leadership (e.g., Stodgill, 1948). The finding that general mental ability (GMA) and aspects of the Big 5 personality factors are predictive of leadership effectiveness parallel findings in the personnel selection literature (Schmidt \& Hunter, 1998; Barrick \& Mount, 1991). And although GMA and the Big Five explain a substantial amount of the variability in workrelated and leadership-related outcomes, many have noted that a large amount of unexplained variance still remains (e.g., Murphy, 1996). As a result, efforts are continually being made to identify new constructs that explain variance not accounted for by traditional constructs (Landy, 2005).

As discussed above, emotional intelligence has been one of the most researched organizational variables this decade. For instance, a recent PsycINFO search revealed that 1,369 articles have been published since the year 2000 including the keywords emotional intelligence. However, as new predictors like EI emerge, it becomes part of the applied scientist's duty and ethical code to examine the validity of these constructs. The implementation of "new" measures at the expense of more rigorously examined "traditional" measures has a direct effect on both the economic benefit that selection and development tools provide organizations as well as the long-term viability of selection 
tests (e.g., Dunnette, 1966). However, we must also recognize that establishing the validity of new measures requires going further than examining measurement and psychometric issues. Indeed, a pillar of the scientific method is the principle of parsimony, and new measures should also be rigorously examined for redundancy (Landy, 2005). As Antanokis (2004, p. 356) has written, "If EI does not predict variance in leadership emergence or effectiveness beyond that is predicted by established psychological constructs, then either EI is redundant or inutile." Thus, a goal of my dissertation is to empirically examine whether on not EI will augment the predictive validity of GMA and the Big Five.

Some have suggested that EI has more predictive validity than GMA and the Big Five combined (e.g., Goleman, 1998). Prati et al. (2001) have gone so far as to intimate that no other dispisitional variables may even matter when compared to EI. However, others have been more critical of EI and submit that it is an illusory construct once the effects of GMA and the Big Five are controlled for. For example, Antanokis (2004) did not find a single study reporting robust relationships between EI and leadership effectiveness once GMA and personality were controlled. And two personality variables that may seem to be related to aspects of EI - agreeableness and self-monitoring - have not been shown to be particularly robust relations with leadership criteria (Day, Schleicher, Unckless, \& Hiller, 2002; Judge et al., 2002).

Moreover, Van Rooy and Viswesvaran (2004) found a strong correlation between mixed-model EI and the Big Five as well as a strong correlation between ability model EI and measures of GMA. If either model of EI is to be considered a distinct construct, correlations with other constructs should be minimal to moderate (Roberts et al., 2001). 
Outside of the leadership literature, two prominent articles have found that EI does not account for variance in work performance above and beyond GMA and the Big Five. For instance, in a sample of undergraduates, Davies et al. (1998) did not find support for EI's predictive validity and labeled it an "illusory" construct. Similarly, Ree and colleagues (2004) examined a group of factory workers and did not find support for the claim that EI augments the predictive validity of GMA and the Big Five. However, Cote and Shafer (2005) found that an ability model measure of EI (the MSCEIT) predicted performance in workers after controlling for GMA and personality. And Janovics and Christiansen (2001) used the MSCEIT to examine work performance and found that EI predicted an additional 3\% in variance after GMA and the Big Five were accounted for. Accordingly, it is hypothesized that:

Hypothesis 30: Emotional Intelligence will predict incremental variance in leadership effectiveness above and beyond GMA and the Big 5 Moderating Influences on Meta-Analyzed Relationships

As mentioned above, I expect to find a significant relationship between EI and leadership effectiveness, EI and transformational leadership, and EI and LMX. However, Johns (2006, p. 386) has argued that context can affect "the occurrence and meaning of organizational behavior as well as the functional relationship between variables." Identifying additional variables that moderate these relationships could contribute more to our understanding of the role that EI plays in the leadership process. Furthermore, moderator analyses may illuminate specific areas of EI or leadership research that demand future examinations because robust findings or lack of extant studies. 
In the present study, I examine three broad groups of moderators that may influence the magnitude of EI-leadership relationships. The first moderator I examine will compare EI-leadership relations between the two competing models of EI (i.e., ability, mixed). The second moderator examines the relative validity of the EI-leadership relationship among the various EI measures and scoring formats. The third and final moderator group investigates the magnitude with which specific leadership criteria are related to EI. For example, I examine EI's relationship with criteria based on content (e.g., task performance, OCBs), source (e.g., supervisor ratings, peer ratings), level of analysis (e.g., group-level data, individual-level data), level of leadership (e.g., CEO, middle manager), and industry type (e.g., for-profit, non-profit, government). These moderator analyses will be used to provide insight into EI's relationship with leadership effectiveness, transformational leadership, and LMX.

\section{Models of EI}

The first moderator to be examined concerns the competing models of EI. There is still some debate in the EI literature over the proper conceptualization of the construct. Two competing models have emerged, and the group of authors touting each model suggests that their model is the best (Mayer, Salovey, \& Caruso, 2000). The first is called the ability model, and characterizes EI as an ability and classifies it as an intelligence. Mayer and Salovey (1997) have been the major proponents of this model, as have Schutte and collegues (1998) and Wong and Law (2002). The second is known as the mixed model and conceptualizes EI as a combination of cognitive, motivational, and affective constructs and is classified as more of a dispositional characteristic. Goleman (1998) has

been a leading proponent of the mixed model, along with Bar-On (1997). I will separately 
examine both the ability model and mixed model EI relationship with leadership effectiveness, transformational leadership, and LMX.

\section{Ability Model of EI}

The premise of the ability model is that EI is a new and unique intelligence that carries many of the abstract reasoning components of current models of general intelligence. At its earliest incarnation, Salovey and Mayer (1990) defined emotional intelligence as "the subset of social intelligence that involves the ability to monitor one's own and others' feelings and emotions, to discriminate among them and to use this information to guide one's thinking and actions," (1990, p. 189). Their definition is drawn from the definition of social intelligence proposed by Gardner (1983), which includes the knowledge about oneself and others.

Salovey and Mayer (1990) view emotions as "organized responses, crossing the boundaries of many psychological subsystems, including the physiological, cognitive, motivational and experiential systems," (p 186). They went on to state that emotional intelligence represents an individual's "core aptitude or ability to reason with emotions," (Mayer \& Salovey, 1997, p. 15). Thus, they posit that EI is an individual's ability to utilize and understand emotions and this ability tends to emerge over time as individuals grow and experience life. They noted that effectively using emotions, as one basis for understanding and reacting to situational variables, may be an important competency required for effective social interaction.

The model of emotional intelligence that Salovey and Mayer propose is composed of four main abilities. One facet is the expression and appraisal of emotion within the self and others. Examples of the facet include the empathy we feel towards others, both verbal 
and non-verbal behaviors in oneself, and non-verbal perception we interpret from others. A second facet concerns humans' ability to be able to address their own emotional states. For instance, someone who is able to quickly assess their emotional state would have a high EI in this area. The third facet of their model is the regulation of emotion in oneself and in others. They believe the regulation of one's emotions occurs in real -time, as well as when a person thinks back on past experiences. The act of reflecting on the experience demonstrates the individual's ability to access the emotions in a previous experience and their willingness and ability to try and evaluate the experience. The final facet is assimilation of emotion to facilitate thought. Examples include the use of emotion to promote flexible planning, creative thinking, and redirecting attention and motivation. In other words, this facet addresses an individual's need to harness their intrapersonal emotions to solve problems.

A number of organizational scholars have argued that the ability model of EI, as defined above, is the "gold standard" of EI research (e.g., Jordan et al., 2003). Daus and Ashkanasy (2005) go so far as to argue that the mixed model of EI (i.e., the competing conceptualization) is a completely different construct. They suggest that a fundamental and unique component of the ability model of EI is that people must "demonstrate" the EI competencies. For instance, they write, "The operationalization of emotional intelligence as an ability model means that people must demonstrate skill in these four domains to be considered emotionally intelligent. As examples of how this is done, participants must demonstrate that they can accurately read emotions on others' facial expressions, and show that they could use good judgment and make good decisions regarding emotionallyladen scenarios," (Daus \& Ashkanasy, 2005, p. 456). 
Previously, I have argued that EI should be associated with leadership effectiveness, transformational leadership, and LMX. Because the ability model of EI taps the actual demonstration of the emotional competencies that should be related to leadership, the ability model should also be significantly related to leadership.

Accordingly, it is hypothesized that:

Hypothesis 31: The ability model of EI will be significantly related to leadership effectiveness

Hypothesis 32: The ability model of EI will be significantly related to transformational leadership

Hypothesis 33: The ability model of EI will be significantly related to high-quality $L M X$.

Mixed Model of EI

The mixed model conceptualizes EI as a combination of cognitive, motivational, and affective constructs. Goleman (1995) was one of the first proponents for a mixed model conceptualization. Building upon the works of Mayer and Salovey, Goleman added a stronger connection to the application of emotional intelligence skills. He defines EI as "a different way of being smart. It's not your IQ. It's how well you handle yourself and handle your relationships, how well you work on a team, and your ability to lead," (Goleman, 1995, p. 14). As can be seen from this definition, it appears that mixed model EI has a closer alignment with more traditional personality variables in psychology (i.e., self-monitoring, agreeableness, extraversion, etc.)

Goleman proposed four facets of EI including: self-awareness, self-management, social awareness, and relationship management. Self-Awareness is the ability to read and 
recognize ones emotions to guide decisions. Self-management concerns the ability to control ones emotions and impulses while adapting to different situations. Social awareness regards one's ability to recognize, understand, and respond to others' emotions in social or organizational settings, and relationship management is the ability to influence, inspire, and develop others and manage conflict (Goleman, 1995).

Bar-On (1997) has also helped to establish the mixed model of EI. Basing much of his research on his dissertation (1988), Bar-On's work focuses on the affective components of emotional intelligence. He is credited with developing the popular concept “emotional quotient" (EQ). Bar-On describes EI as a mix of emotional, personal, and social abilities. Essentially, Bar-On views EI as a noncognitive intelligence, and considers it an important factor in determining a person's ability to succeed in life, to cope with daily situations, and to get along in the world.

Goleman (1998) offered the mixed model of EI as a theory of performance that predicts personal effectiveness in the workplace, particularly in leadership behaviors. Since then, Goleman (2001) has asserted that people who are intellectually the brightest are often not the most successful, either in business or in their personal lives. Thus, organizational success, effectiveness, transformational leadership, and LMX may have more to do with emotional intelligence than with GMA, technical expertise, or even experience (Cooper \& Sawaf, 1996; Luthans, 2002). Accordingly, it is hypothesized that:

Hypothesis 34: Mixed model EI will be significantly related to leadership effectiveness

Hypothesis 35: Mixed model EI will be significantly related to transformational leadership 
Hypothesis 36: Mixed model EI will be significantly related to high-quality LMX

For a number of reasons, the mixed model of EI has received more criticism than the ability. One has to do with the fact that many of the proponents of mixed model EI have adopted affective- and personality-driven concepts (e.g., Matthews et al., 2002). For instance, concepts such as agreeableness, negative/positive affectivity, and extraversion seem to overlap with aspects of mixed model EI (Davies et al., 1998). A second criticism is that the mixed model of EI may have strayed too much from the original direction of focus of EI (e.g., Mayer \& Salovey, 2004). Ashkanasy and Daus (2005, p. 456) note that mixed model EI "came from other, broader concepts and theories (e.g., psychological well-being), and they seem to have commandeered the term "emotional intelligence."' Finally, many have argued that the ability model of EI has developed a more credible and substantial body of academic evidence and support (Daus \& Ashkanasy, 2005; Mayer \& Salovey, 2004). Thus, it is likely that the ability EI-leadership relationship will be stronger than the mixed model EI-leadership relationship.

However, it may also be the case that a miscellaneous construct may be broader in scope, and therefore, capture more variance in the prediction of leadership. For instance, in a meta-analysis of smoking cessation methods, Viswesvaran and Schmidt (1992) found that a "miscellaneous" category of cessation methods actually predicted the most variance on the cessation of smoking. Perhaps something similar will be found with mixed-model EI. Because the mixed-model is an amalgamation of motivational, affective, and personality constructs, it may predict variance in a manner similar to the miscellaneous category in Viswesvaran and Schmidt (1992) or a compound variable such as integrity in the personality domain (Ones, Viswesvaran, \& Schmidt, 1993). 
Accordingly, I will proffer a research question to investigate the comparative predictive validity of the competing models of EI.

\section{Measures and Scoring Format of EI}

The second moderator that I examine concerns the various measures and scoring formats proposed in the area of EI. In view of the expansive literature that surrounds the EI construct, researchers have developed numerous instruments that claim to measure its characteristics. For example, some measures employ performance-scoring criteria (i.e., expert or consensus formats), while others employ self-report methods (i.e., Likert-type scales). However, theorists have suggested that many of these measures may not be valid (Ciarrochi et al., 2000; Davies et al., 1998; Mayer et al., 2000). Although I do not make specific hypotheses regarding the validity with which these measures infer a leader's effectiveness, I will explore whether the relationship hypothesized earlier are moderated by the specific measures used. I will also explore the moderating effect of scoring format on the hypothesized relationships. I will now briefly review the more frequently used measures and scoring formats in the EI literature.

As mentioned above, meta-analytic generalizations can proceed across two different levels (Hunter \& Schmidt, 2004). The first level of generalization involves demonstrating how different measures of the same construct generalize across situations. Because research has shown that different measures of constructs also have a substantial amount of unique variance associated with it, some meta-analytic researchers have argued for combining instruments to enhance construct validity (e.g., Ones, Viswesvaran, \& Schmidt, 1993). That is, what is shared across instruments is more construct valid. The 
second level of generalization represents the arguments and hypothesis described previously in this dissertation.

However, there is also a second dimension or level of generalization in that one can cumulate results from one specific instrument that is applied across situations. For instance, another group of researchers (e.g., Hogan \& Hogan, 1995) have called for instrument specific meta-analyses. I now present five commonly used measures of EI and discuss differences in development and intended usage that may explain instrument specific variance in predicting leadership effectiveness.

\section{Emotional Quotient Inventory}

Bar-On's (1997) Emotional Quotient Inventory (EQI) has been described as a measure of "emotionally and socially competent behavior which provides an estimate of one's emotional and social intelligence," (Gowing, 2001, p. 107). The EQI consists of 15 distinct scales and 133 items. It was designed to measure a person's ability to deal with day-to-day pressures and demands. The scales measure emotional self-awareness, assertiveness, self-regard, self-actualization, independence, empathy, and other emotionrelated traits. Mayer et al. (2000) has classified the EQI as a mixed model measure of EI.

Rueven Bar-On developed the EQI in 1996 and normed the test using a sample of 3,831 North Americans. Although the measure was originally designed to examine a host of life outcomes, including giftedness and development problems, mental health problems, subjective well-being and academic performance, the measure has also been used to examine work outcomes related to job performance, team development, and leadership effectiveness. A recent study (Bar-On, 2004) showed a significant relationship (.39) between the EQI and follower ratings of 21 different leadership criteria. 
Of all the measures reviewed here, the EQI is probably the most trait-based one. For instance, a study by Dawda and Hart (2000) found that the average correlation between EI and the big five personality factors was .50. Another study showed an even stronger correlation (-.77) between the EQI and an Cattell's 16PF anxiety scale, suggesting that the measure of EI overlaps substantially with a well-established measure of trait anxiety (Newsome, Day, \& Catano, 2000).

Emotional Competence Inventory

The ECI is based on the emotional competencies identified by Goleman (1998). Gowing (2001) developed the 360-degree scale, which gathers self, subordinate, peer, and supervisory ratings on 20 social and emotional competencies. The ECI measures selfawareness, self-management, social awareness, and social skills. The scale is self-report and largely a behavioral measure. It was designed to help organizations identify "star" performers. Thus, a unique aspect of the ECI is that it assesses the emotional competencies of individuals as well as organizations. Mayer et al. (2002) considered the ECI to be one of the most popular mixed-model EI measures.

However, an issue with ECI remains the large number of empirical criterionrelated validity studies that are reported in the technical manual of the ECI but remain unpublished (e.g., Matthews et al., 2002). For example, despite a large number of citations involving the ECI, Van Rooy and Viswesvaran (2004) only found six studies that reported an effect size between the ECI and work performance. Their reported mean predictive validity of .20 was also the weakest of the various measures they examined. 


\section{The Mayer-Salovey-Caruso Emotional Intelligence Test}

The MSCEIT (Mayer, Salovey, \& Caruso, 2002) is a skill-based and objective measure of EI. It is comprised of the four subfacets of EI outlines above. The MSCEIT consists of 141 items and is designed to yield an overall emotional intelligence score as well as subscale scores. The aim of the MSCEIT is on measuring how emotions can facilitate thinking and adaptive behavior. Thus, it is probably the only "true" abilitybased EI measure on the market. Many in the field of I/O psychology have suggested that it is the only "credible and substantial" measure of EI. However, others have been critical of the measure (e.g., Gowing, 2001) and lamented that there is little evidence of its validity in workplace settings.

There are two issues related to the MSCEIT that suggest this measure of EI may predict unique variance in leadership compared to the other measures. The first concerns the scoring methodology of the MSCEIT. Because the MSCEIT is an ability test, the developers have tried different ways to assess which answers are "correct". For instance, experts in EI can choose which answers are correct or majority opinion can be used. Although these two methods appear to be highly correlated (Mayer, Salovey, \& Caruso, 2002), researchers have discussed with skepticism the accuracy of these methods and whether they conform to accepted scientific standards (Conte \& Dean, 2006).

Second, of all the frequently used measures of EI, the MSCEIT appears to have the highest correlations with GMA. For instance, Schulte and colleagues (2004) found that the MSCEIT correlated .45 with a measure of GMA. Thus, a number of the process mechanisms explaining the GMA-leadership effectiveness relationship may also be 
related to those that explain unique variance in the MSCEIT-leadership effectiveness relationship.

\section{Wong and Law Emotional Intelligence Scale}

The Wong and Law EI Scale (Wong \& Law, 2002) was developed in response to a recognized need for a measure of emotional intelligence which is practical, simple, and psychometrically sound. The WLEIS is the only publicly available measure of EI that was developed specifically for organizational research. The WLEIS contains 16 items and measures the four facets of EI that were discussed above. The WLEIS is a self-report measure, however, it was developed using the Mayer and Salovey (1997) conceptualization, so there is debate in the literature regarding whether it is a mixedmodel or ability-model measure of EI.

Because the WLEIS was developed specifically for use in organizations, it is likely that instrument-specific variance predicting leadership is related to the initial workspecific context of the test. For example, Ones and Viswesvaran (2001) have argued that selection measures should be constructed to explicitly maximize overlap with work criterion constructs (e.g., job performance, counterproductivity). Measures developed for describing individual differences in a general range of settings may still be relevant for broad usage, but it is likely that their usage for personnel selection and screening will result in diminished validity. In this vein, the WLEIS probably holds the most promise in terms of strength of correlation with workplace constructs such as leadership effectiveness. 


\section{Emotional Intelligence Scale}

The EIS (Schutte et al., 1998) is a frequently used, publicly available measure of EI. The EIS contains 33-itmes, and like the WLEIS, is a self-report measure based on the Salovey and Mayer (1990) model of emotional intelligence. Schutte et al. (1998) noted that Salovey and Mayer's model is the most comprehensive model of EI, as it conceptualizes the various dimensions of an individual's emotional development. In addition, most the dimensions of other popular measures can also be integrated into EIS (Schutte et al., 1998).

Unlike the other tests of EI examined in this dissertation, its developers treat the EIS as a uni-dimensional measure. That is, the four facets of EI are not explicitly examined in any of the studies using the EIS. Thus, facet-specific variance may not be measured. Moreover, Schutte and colleagues (1998) recommended that the EIS not be used for selection decisions. Although examining for leadership effectiveness is not the same as examining validity for selection decisions, the test development process does bring into question the possibility that the EIS is not an appropriate measure for any type of organizational setting.

Scoring Format

Besides grouping into ability and mixed-model measures, another way to group the measures is by scoring format (Daus \& Ashkanasy, 2005). Performance based measures of EI provide the test-taker with multiple choices per item and have right/wrong answers. These measures are normed like other ability tests (e.g., GRE, Wonderlic) and designed so that an individual must actually demonstrate their emotional competencies and skills. Currently, the MSCEIT is the only known performance-based measure of EI. 
At the same time, there have been various proposed formats (i.e., expert, consensus) for scoring performance-based measures of EI (Mayer \& Salovey, 2004). Expert scoring methods are those in which subject-matter experts (SMEs) identify the correct answers on the test based on their knowledge of EI. Consensus scoring methods identify correct answers based on the answers that are selected most frequently by an initial set of testtakers, regardless of whether the answers are deemed "correct" by SMEs. Although some research has suggested that there is a high correlation between expert and consensus scoring (Mayer et al., 2002), the sentiment should also be empirically tested in the context of predicting leadership effectiveness.

In contrast, self-report measures use Likert-type scales to identify a test-takers relative standing on an item tapping an emotional competency. For instance, a respondent who indicates they "strongly agree" with the item "I understand my own emotions" would receive a score indicating they have a high level of the EI facet that taps the understanding of emotions. The ECI, WLEIS, EIS, and EQI fall into this category. In my dissertation, I will explore the relative validity of performance-based and self-report measures of EI for predicting leadership effectiveness, transformational leadership, and LMX.

\section{Leadership Criteria}

The final moderator that I examine concerns the various conceptualizations of leadership criteria. So far, I have discussed three broad leadership criteria: leadership effectiveness, transformational leadership, and LMX. However, there are specific aspects of these criteria that may be more important to organizational stakeholders, or may be more strongly related to EI. For instance, organizations may be more interested in 
increasing follower job performance than they are in increasing follower job satisfaction. It may also be the case that practitioners are interested in predicting group-level variables at higher levels of analysis (e.g., Harter et al., 2003). Also, the source of the data (e.g., peer-rating, supervisor-ratings) may influence EI's relation with leadership effectiveness criteria. Finally, specific aspects of the context such as level of leadership (e.g., CEO, middle-manager) or industry (e.g., profit, non-profit status) may moderate the validity of EI. Therefore, I will examine these moderators as they relate to EI and leadership effectiveness, transformational leadership, and LMX.

\section{Content}

Perhaps the most commonly included outcome of interest in organizational research is employee performance. There is empirical support for a positive relationship between leader emotional intelligence and follower performance (e.g., Wong \& Law, 2002). Follower prosocial or organizational citizenship behaviors (OCB) are defined as "employee behaviors that, although not critical to the task or job, serve to facilitate organizational functioning," (Lee \& Allen, 2002, p. 132). Although related to performance, OCB involves behaviors above what is considered necessary or expected for the job. Like performance, OCB has been positively linked to EI and leadership (e.g., Coetzee \& Schaap, 2005; Wong \& Law, 2002).

I will also examine follower attitude outcomes. These include attitudinal facets such as job satisfaction, satisfaction with leader and satisfaction with group. Leader EI has been shown to have positive relationships with employee satisfaction measures (DeGroot et al., 2000). 


\section{Levels of Analysis}

Researchers are increasingly becoming interested in how leadership predicts variance in group-level variables (Hogan \& Kaiser, 2006). Thus, I will examine unitoriented criteria such as profit, productivity, and withdrawal (e.g., turnover). Guided by multi-level theory (e.g., Klein \& Kozlowski, 2000), I will draw a distinction between global unit data and shared unit data. The distinction between these two criteria concerns the level of measurement at which the data are collected (or manifest). Data that are manifest and collected only at the unit-level is considered global unit data (Kozlowski \& Klein, 2000). Conversely, data collected at the individual level and aggregated to the unit-level is known as shared unit data. Global unit data are unlike shared unit data in that they are evident only at the higher level of analysis. These data are observable and descriptive characteristics of single (higher) level phenomena (Klein et al., 1994). Global unit data may be obtained from archival records (e.g., profit) or from individuals (e.g., CEOs, customers) who observe the unit functioning as a whole (e.g., customer satisfaction).

In contrast, shared unit data are assessed at the individual level and then aggregated to represent a unit-level construct. Shared unit data is presumed to originate at the individual level, but through interaction and vibrant group processes, this data emerges as representative of the unit (Chan, 1998). Supervisors and coworkers or employee self-ratings are typically used to assess these data. Examples of these criteria may include group-level job satisfaction and group-level OCBs. 
Source

Most work criteria are typically assessed using supervisor ratings. However, criteria can also be measured using subordinate-, peer-, and self-ratings (Viswesvaran, Ones, \& Schmidt, 1996). In the present paper, I will examine the source of the rater as a moderating variable of leadership effectiveness, transformational leadership, and LMX. Other aspects related to source may also influence the validity of the EI-leadership effectiveness relationship. For example, I will examine whether level of leadership (i.e., supervisor, middle-manager, CEO) moderates the EI-leadership effectiveness relationship (Yukl, 2006). Goleman (1995) has contended that there would be range-restriction in CEOs regarding GMA (i.e., all CEOs are very smart), however, such range-restriction would not exist regarding EI. Thus, EI may matter more as a leader moves up to higher echelons in the organization. Goleman's hypothesis has yet to be examine-my study will be the first to put it to an empirical test.

I will also examine whether industry (i.e., profit, non-profit, government) affects the correlations of EI with leadership effectiveness, transformational leadership, and LMX. Brandel (2001) has noted that pay tends to be lower for school and non-profit employees because they are motivated more by intrinsic rewards (e.g., belief in the organization's mission, capability to actualize individual values) than extrinsic rewards (e.g., salary). Harrison (1995) has shown that high-levels of empathy may be another reason that individuals to choose to volunteer or work for lower levels of pay in the education or non-profit sector. These arguments suggest that having a leader high in EI may be more important for organizations in the non-profit and education sector because employees in these industries expect a leader to have empathy and emotional 
understanding. Thus, I will also examine whether the strength of the EI-leadership relationship is moderated by industry sector.

\section{Conclusion}

In sum, my dissertation aims to answer a host of important theoretical and empirical research questions that have never been directly examined in the literature. By cumulating and empirically examining the theoretical rationales of EI as it relates to leadership, the fundamental aim of this study would be to contribute broadened understanding of the importance of emotional intelligence in the workplace. And because there is widespread lay interest in the emotional intelligence construct, the findings in this dissertation will be of interest (as well as beneficial) to more than the typical audience (i.e., researchers and practitioners) of an academic study in the organizational sciences. 


\section{CHAPTER III}

\section{Method}

Search for Primary Data

Computer and manual searches were conducted to find articles reporting a relationship between emotional intelligence and a measure of performance. Various combinations of keywords (e.g., emotional intelligence, satisfaction, productivity, performance, etc.) were entered into the PsychINFO databases. I also searched the Proquest marketing and business databases for additional research. Articles that appeared to report an EI-leadership effectiveness relationship were obtained, and in a snowball approach these reference sections were searched for additional articles meeting my initial criteria. I also searched a computer database for dissertations using the same combinations of keywords. Additionally, the programs from the annual conferences for the Academy of Management and the Society for Industrial and Organizational Psychology were searched. Finally, I used the Social Sciences Citation Index to find research that cited articles I had already deemed acceptable for inclusion in the metaanalysis. In instances where relationships were discussed, but no explicit effect sizes were provided (e.g., LaBo, 2005), the author(s) were contacted in an attempt to obtain the relevant values. The initial literature search resulted in 322 articles that appeared relevant.

\section{Criteria for Inclusion and Variables Coded}

The next step was to determine which of these 322 articles yielded truly codable data. I defined a set of rules a priori to be followed when determining which studies to include. To be included, a manuscript had to (a) report an emotional intelligence score for a leader, (b) report a leadership criteria (i.e., effectiveness, transformational leadership, 
follower task performance, group productivity), (c) provide the necessary statistical information to compute effect sizes, and (d) consist of an adult sample. The final metaanalytic database consisted of 92 studies with sample sizes ranging from 26 to 322 leaders.

A team of undergraduates was recruited and a coding scheme was developed. We assessed inter-rater agreement on these key indices (i.e., effect size, predictor and criterion reporting, level of independence) as well as study characteristics for moderator analyses (i.e., level of leadership). For each study, the coders independently coded these key indices and variables. Initial inter-rater agreements exceeded .85; any disagreements about whether to include a study in the meta-analysis were resolved via consensus.

In order to maintain the independence assumption, a composite EI score was created if multiple facets were reported, but no overall score was provided. For instance, if the correlations between each of the four facets of EI and leadership effectiveness were reported - but no overall EI-leadership relationship was available - I took the average of those four correlations to represent the overall EI-leadership effectiveness relationship. However, if a study reported the validity of overall EI along with the validity of the facets, I did not form a composite using the facets. If a study reported a manipulation, I only included it if results were available for a pre-test or control group (Groves, McEnrue, \& Shen, 2008). Finally, if multiple time periods were reported, I computed results based on the concurrent effect size. Lagged (i.e., predictive) results were not calculated due to an insufficient number of studies.

Predictor. As discussed above, a number of different measures of EI have been frequently used in organizational research. I have identified five of the most commonly 
used measures and will investigate them separately (as well as "overall" EI constructed as a composite of all measures). These include: the Emotional Quotient Inventory (EQI: Bar-On, 1997), the Emotional Competence Inventory (ECI; Gowing, 2001), the The Mayer-Salovey-Caruso Emotional Intelligence Test (MSCEIT; Mayer, Salovey, \& Caruso, 2002), the Wong and Law Emotional Intelligence Scale (WLEIS; Wong \& Law, 2002), and the Emotional Intelligence Scale (EIS; Schutte et al., 1998). I also examined the four distinct facets of EI; these include (1) perception of emotion in self and others; (2) assimilation of emotion to facilitate thought; (3) understanding of emotion, and (4) regulating and managing emotion in the self and others.

Criterion. As noted above, I sought to examine leadership effectiveness as an overall criterion. The criterion will include data such as follower performance, satisfaction with leader, turnover, unit-level outcomes, and productivity. Transformational leadership and LMX will also be examined as leadership criteria. In addition, the four facets of transformational leadership (i.e., individualized consideration, inspirational motivation, intellectual stimulation, and individual consideration) will be separately examine as criteria.

Moderators. In the present study, I examine three distinct moderators that may influence the magnitude of EI-leadership relationships. The first moderator I examine will compare EI-leadership relations between the two competing models of EI (i.e., ability, mixed). The second moderator examines the relative validity of the EI-leadership relationship among the various EI measures and scoring formats. The third moderator investigates the magnitude with which specific leadership criteria are related to EI. For example, I examine EI's relationship with criteria based on content (e.g., task 
performance, OCBs), source (e.g., supervisor ratings, peer ratings), level of analysis (e.g., group-level data, individual-level data), level of leadership (e.g., CEO, middle manager), and industry type (e.g., for-profit, non-profit, government). Moderator analyses will be used to provide insight into EI's relationship with leadership effectiveness, transformational leadership, and LMX.

\section{Meta-Analytic Procedure}

I will employ the Hunter and Schmidt (2004) meta-analytic procedure to compute results using the interactive artifact-distribution based meta-analysis program. The artifact distribution used will be derived from the database. The Hunter and Schmidt methods allows for an assessment of the percentage of correlational differences across studies that are a result of statistical artifacts (e.g., sampling error). In addition, this method accounts for differences based on sample size and provides a way to correct observed correlations for statistical artifacts. I report the sample size weighted mean observed correlation as well as the true score correlation that has been corrected for sampling error and unreliability (via coefficient alpha scores) in both the predictor and criteria. Standard deviations are reported for the corrected correlations as well as $80 \%$ credibility interval around the corrected correlation for each meta-analysis. To examine hypotheses and moderator analyses, I will examine whether the $80 \%$ credibility intervals include zero (Hunter \& Schmidt, 2004).

\section{Mediation Analyses}

In my analyses I use both regression and path analysis (e.g., Hunter \& Hamilton, 1992) to examine the mediating role that leadership style (i.e., transformational leadership, LMX) has in the EI-leadership effectiveness relationship. Two models in total 
will be estimated for leadership effectiveness. In the first regression, the dependent variable will be regressed on leadership style. In the second regression, the dependent variable will be regressed onto leadership behavior as well as leader emotional intelligence. Taken together, the first and second regressions form a hierarchical regression analysis in which leadership style is entered on the first step and emotional intelligence is added on the second step. Significance will be evaluated depending on the value of the leadership effectiveness coefficient and the change in multiple-R.

The method for interpreting mediation (i.e., full, partial, indirect) suggested by Mathieu and Taylor (2006) will be adopted to examine these relationships. According to the estimation guidelines and decision rules proposed by Mathieu and Taylor, full mediation occurs when the $\mathrm{X} \rightarrow \mathrm{Y}$ path drops to a non-significant level when the $\mathrm{X} \rightarrow \mathrm{M}$ and $\mathrm{M} \rightarrow \mathrm{Y}$ paths are entered into the equation. However, if the $\mathrm{X} \rightarrow \mathrm{Y}$ path remains significant after the paths to and from the mediator are considered, then, Mathieu and Taylor (2006, p. 1041) write, "the hypothesis of full mediation should be rejected and the researchers should consider the alternative hypothesis of partial mediation." Partial mediation "rests on the significance of all three paths: $\mathrm{X} \rightarrow \mathrm{M}$ and both $\mathrm{X} \rightarrow \mathrm{Y}$ and $\mathrm{M} \rightarrow$ Y when considered simultaneously" (Mathieu \& Taylor, 2006, p. 1041). Absent either of these two conditions (i.e., full or partial mediation) described above, the decision rules suggest an interpretation that the data are not consistent with a hypothesis of mediation.

Meta-analytic estimates for these relationships will be derived from the present study for most of the models. However, three of the mediator-dependent variable relationships will be derived from previous studies. For the meta-analytic estimate between LMX and leadership effectiveness, I will incorporate findings from Gerstner and 
Day (1997). For the meta-analytic estimate between transformational leadership and leadership effectiveness, I will incorporate findings from Judge and Piccolo (2004). For the meta-analytic estimate between the Big five and leadership effectiveness, I will incorporate findings from Judge and colleagues (2002). The harmonic mean of the estimates will be used as input to create the correlation matrices used for each of the regression analyses (Viswesvaran \& Ones, 1995).

Incremental Variance

Hierarchical regression and path analysis will also be used to examine the incremental validity of EI on leadership criteria (i.e., leadership effectiveness, transformational leadership, and LMX) after controlling for the Big 5 and GMA. Two models in total will be estimated for each of the three leadership criteria. In the first regression, the dependent variable will be regressed on the Big 5 and GMA (i.e., the control variables). In the second regression, the dependent variable will be regressed onto the control variables as well as EI. Taken together, the first and second regressions form a hierarchical regression analysis in which the control variables are entered on the first step and EI is added on the second step. Significance will be evaluated depending on the value of the EI coefficient and the change in multiple-R. 


\section{CHAPTER IV}

\section{Results}

Results of the overall meta-analysis of the emotional intelligence-leadership effectiveness relationship are provided in Table 1. The sample size weighted mean correlation between emotional intelligence and leadership effectiveness was .22, uncorrected for artifacts. When corrected for unreliability in measures of emotional intelligence and leadership effectiveness measures, the estimated population value was .25 . For this overall estimate, the $80 \%$ credibility intervals excluded zero. The results suggest that the mean true correlation between emotional intelligence and leadership effectiveness is distinguishable from zero and significant in magnitude. Thus, Hypothesis 1 is supported.

Table 2 reports the estimated true correlations between emotional intelligence and transformational leadership $(\rho=.37)$. Also included in Table 2 are the relations between EI and the four facets of transformational leadership; idealized influence $(\rho=.29)$, inspirational motivation $(\rho=.34)$, intellectual stimulation $(\rho=.27)$, and individual consideration $(\rho=.30)$. For all five relationships the $80 \%$ credibility intervals did not include zero, indicating support for Hypotheses 2, 3, 4, 5, and 6. At the bottom of Table 2, I also report the relationship between leader emotional intelligence and transactional leadership. Although there was no hypothesized relationship between these two variables, the results indicate a significant relationship $(\rho=.10)$, albeit much weaker one than that of EI and transformational leadership. In Table 3, I report the estimated true correlation 
between EI and leader-member exchange ( $\rho=.27)$. The relationship is significant and the $80 \%$ credibility intervals did not include zero. Thus, Hypothesis 7 is supported.

\section{Leadership Style as a Mediator}

I used the methodology described by Mathieu and Taylor (2005) to test whether leadership style mediated the relationship between EI and leadership effectiveness. In earlier tables, I presented the mean true correlations between EI and leadership effectiveness as well as EI and leadership style (i.e., transformational leadership, LMX). The input for the transformational leadership-leadership effectiveness relationship and the LMX-leadership effectiveness relationship were derived from Judge and Piccolo (2004) and Gerstner and Day (1997), respectively. These meta-analytic estimates were used as input to conduct the test of mediation. Table 4 depicts the results of the path analysis/regression. As can be seen in the upper half of the table, when entered into the first step of the equation, transformational leadership significantly predicted leadership effectiveness $(\beta=.44, p \leq .01)$. Moreover, transformational leadership accounted for approximately $19 \%$ of the variance in leadership effectiveness $(p \leq .01)$. However, when entering EI into the second step of the equation, the path from EI to leadership effectiveness did not drop to a non-significant level $(\beta=.10, p \leq .01)$. EI explained an additional $1 \%$ of the variance in leadership effectiveness $(p \leq .01)$. According to the interpretation rules proffered by Mathieu and Taylor (2005), transformational leadership partially mediates the relationship between EI and leadership effectiveness, and thus, provides only limited support for Hypothesis 8 .

Moving now to the bottom half of Table 4, when entered into the first step of the equation, LMX significantly predicted leadership effectiveness $(\beta=.30, p \leq .01)$. 
Moreover, LMX accounted for approximately $9 \%$ of the variance in leadership effectiveness $(p \leq .01)$. When entered EI into the second step of the equation, the path from EI to leadership effectiveness did not drop to a non-significant level $(\beta=.18, p \leq$ $.01)$. Emotional Intelligence explained an additional $3 \%$ of the variance in leadership effectiveness $(p \leq .01)$. Again, this suggests that LMX partially mediates the relationship between EI and leadership effectiveness, and thus, provides only limited support for Hypothesis 9.

Facets of EI

Turning now to the predictive validities of the facets of EI, I first report the relationship between appraisal of emotion and leadership outcomes (i.e., effectiveness, transformational leadership, LMX). As can be seen in Table 5, the estimated true score correlations between appraisal of emotion and leadership effectiveness $(\rho=.14)$, transformational leadership $(\rho=.19)$, and $\operatorname{LMX}(\rho=.10)$, were all significant and the $80 \%$ credibility intervals did not include zero. Thus, the data indicate support for Hypotheses 10, 11, and 12. In Table 6, I report the estimated true score correlations between the use of emotion dimension and leadership outcomes. The relationship for leadership effectiveness $(\rho=.15)$, transformational leadership $(\rho=.17)$, and $\operatorname{LMX}(\rho=$ .11 ), were all significant in that the $80 \%$ credibility intervals did not include zero. Thus, the data indicate support for Hypotheses 13, 14, and 15.

In Table 7, I report the estimated true score correlations between the understanding of emotion dimension and leadership outcomes. The relationship for leadership effectiveness $(\rho=.19)$, transformational leadership $(\rho=.25)$, and LMX ( $\rho=$ .15 ), were all three significant in that the $80 \%$ credibility intervals did not include zero. 
Thus, the data indicate support for Hypotheses 16, 17, and 18. Finally, In Table 8, I report the estimated true score correlations between the management and regulation of emotion dimension and leadership outcomes. The relationship for leadership effectiveness ( $\rho=$ $.15)$, transformational leadership $(\rho=.28)$, and $\operatorname{LMX}(\rho=.18)$, were all significant in that the $80 \%$ credibility intervals did not include zero. Thus, the data indicate support for Hypotheses 19, 20, and 21.

\section{Leadership Style as a Mediator of the Facets of EI}

In analyses identical to those above (Table 4), Hypotheses $22-29$ were tested using hierarchical regression. Leadership style (transformational leadership, LMX) was hypothesized to mediate the relationship between each dimension of EI and leadership effectiveness. The results of these analyses can be seen in Table 9 and 10. First concerning the dimension of EI $\rightarrow$ transformational leadership $\rightarrow$ leadership effectiveness relationship, it appears that transformational leadership partially mediates three of the four EI dimensions (Table 10). Specifically, transformational leadership explains 19\% of the variance in leadership effectiveness whereas the dimensions of appraisal of emotion, use of emotion, and understanding of emotion account for an additional $1 \%$ of the variance. Thus, partial support has been shown for Hypotheses 22, 23, and 24. Because the management and regulation of emotion dimension did not account for any additional variance in predicting leadership effectiveness, it is suggested that transformational leadership fully mediates this relationship. Thus, Hypothesis 25 is supported.

We now turn to the role of LMX as a mediator in the EI facet-leadership effectiveness relationship. Table 10 presents the results of these analyses for all four dimensions of EI. Specifically, LMX explains 9\% of the variance in leadership 
effectiveness whereas the dimensions of appraisal of emotion, use of emotion, understanding of emotion, and management and regulation of emotion account for an additional $1-3 \%$ of the variance. Results suggest that LMX partially mediates the relationship between the dimensions of EI and leadership effectiveness. Thus, partial support has been shown for Hypotheses 26, 27, 28, and 29.

\section{Incremental Validity of EI}

In order to examine the potential for redundancy among new constructs such as EI, I also examined the incremental validity of EI above and beyond the Big Five personality factors and general mental ability (GMA). The results of the hierarchical regression analyses used to test Hypothesis 30 are presented in Table 11. At the top of the table is incremental validity of EI when the Big 5 are controlled for (that is, entered in the first step of the equation). Results indicate that EI (entered into the second step of the equation) predicts an additional $1 \%$ of the variance $(p \leq .01)$ over and above the Big Five. In the middle of the table, analyses are presented in which GMA is entered into the first step (it accounts for $7 \%$ of the variance in leadership effectiveness) and EI is entered into the second step. These data indicate that EI predicts an additional $4 \%$ in the predicted variance $(p \leq .01)$ of leadership effectiveness beyond that of GMA.

At the bottom of Table 12 is a test of the predictive validity of EI beyond both the Big Five and GMA. When entered into the first step of the equation, the Big Five and GMA predict $18 \%$ of the variance in leadership effectiveness. When EI is entered into the second step, it accounts for an additional $1 \%$ in the variance $(p \leq .01)$. Because EI predicts a statistically significant amount of variance the Big Five and GMA, Hypothesis 
30 is supported. However, the practical significance of predicting an additional $1 \%$ of variance is considered further below.

Moderator Analysis by Model of EI

Because many scholars have suggested that the construct of EI is confounded between two different and competing models, I also separately examined the validity of the ability model of EI and the mixed model of EI. In Table 12, I report the estimated true score correlations for the relationship between ability EI and leadership. The relationship for leadership effectiveness ( $\rho=.21$ ), transformational leadership $(\rho=.25)$, and LMX ( $\rho=.24)$, were all significant in that the $80 \%$ credibility intervals did not include zero. Thus, the data indicate support for Hypotheses 31, 32, and 33. In Table 13, the validities for mixed model EI and leadership effectiveness are reported. The relationship for leadership effectiveness $(\rho=.27)$, transformational leadership $(\rho=.43)$, and LMX ( $\rho=$ .27 ), were all significant because the $80 \%$ credibility intervals did not include zero. Thus, the data indicate support for Hypotheses 34, 35, and 36. Taken together, these results indicate that mixed model EI may have a slightly higher predictive validity for various leadership outcomes than ability EI.

However, to better answer this research question, I also examined the incremental validity of each model of EI after controlling for the Big Five and GMA. The results of these exploratory analyses for the incremental validity of ability EI are presented in Table 14. At the top of the table, we see that Ability EI predicts an additional $1 \%$ in the variance of leadership effectiveness $((p \leq .01)$ above and beyond the Big Five. When controlling for GMA, Ability EI predicts an additional $2 \%$ of the variance $(p \leq .01)$ in 
leadership effectiveness. However, when accounting for both the Big Five and GMA, Ability EI fails to predict any additional variance in leadership effectiveness.

Table 15 presents the results of incremental validity using mixed model measures of EI. At the top of the table, we see that Mixed Model EI predicts an additional 1\% in the variance of leadership effectiveness $(p \leq .01)$ above and beyond the Big Five. When controlling for GMA, Ability EI predicts an additional $6 \%$ of the variance $(p \leq .01)$ in leadership effectiveness. Data support the findings of Van Rooy and Viswesvaran (2004, which suggested that Mixed Model EI might be less theoretically related to GMA than Ability EI. When accounting for both the Big Five and GMA, Mixed Model EI fails accounts for an additional $1 \%$ of the variance $(p \leq .01)$ in leadership effectiveness. Again, while these numbers are statistically significant, there may be less practical significance regarding these numbers than some proponents of EI may like.

\section{Moderators of EI by Measure and Scoring Format}

I also examined the predictive validity of EI by measure. I selected the five most commonly used measures of EI and report these estimated true score correlations in Table 16. Because the MSCEIT is the only known measure of an Ability model EI, the correlations presented at the top of the table are identical to those in Table 13. To repeat, the validities for the MSCEIT and leadership outcomes were .21 for leadership effectiveness, .25 for transformational leadership, and .24 for LMX.

Next, I examined the predictive validities among four different measures of Mixed Model EI. For the ECI, the validity for leadership effectiveness was .31 and for transformational leadership it was .45. For the EIS, For the ECI, the validity for leadership effectiveness was .38 and for transformational leadership it was .57. For the 
EQ-i, the validity for leadership effectiveness was .29 and for transformational leadership it was .44. And for the WLEIS, the validity for leadership effectiveness was .29 and the validity for transformational leadership was .36. Overall, the pattern of results indicate that all measures of EI tend to predict leadership outcomes, with measures of Mixed Model EI a bit superior to measures of Ability EI.

An alternative way to conceptualize measurement of EI is by scoring format. In Table 17, I report separate validities for performance-based scoring of EI and self-report scoring of EI. For performance-based scoring, the estimated true score correlations between EI and leadership effectiveness was .21. The same relationship for self-report measures of EI was .27. As mentioned above, there have been various proposed formats (i.e., expert, consensus, empirical) for scoring performance-based measures of EI (Mayer \& Salovey, 2004). The estimated true score correlations between EI and leadership effectiveness were .19 for consensus scoring, .18 for expert scoring, and .29 for empirical scoring methods. Unfortunately, very few studies reported the type of scoring method that was used for performance-based measures, so I would caution against interpreting too much from the present results.

Moderators of EI by Content, Level-of-Analysis, and Source

Although so far I have discussed leadership effectiveness as a monolithic construct, it is possible to provide a finer grained analysis of this dependent variable. In Table 18, I break down leadership effectiveness into three distinct moderators. The first moderator examines the validity of EI according to leadership effectiveness criteria. Specifically, the estimated true score correlation for leader task performance (e.g., supervisor or subordinate ratings of a leader's performance) was .29, for follower OCB 
the validity was .21 , for follower job satisfaction the correlation was .16 , for follower satisfaction with leader the correlation was .23, and for follower turnover the estimated true score correlation was .11.

One could also examine leadership effectiveness by the level of analysis at which the criteria was collected. For instance, global level data measures an indicator of effectiveness that has no individual-level equivalent (e.g., customer satisfaction). The correlation between a leader's level of EI and his or her group's global level outcome was .19. The correlation between shared level data (e.g., aggregated job satisfaction) and the leader's EI was .28.

Finally, I examined whether the source of the rater influenced the relationship between EI and leadership effectiveness. When supervisors reported a leadership effectiveness criteria, the EI-leadership effectiveness relationship was .23. The same relationship when reported by peers was .29 and the relationship was .27 when reported by subordinates.

\section{Moderators of EI by Level of Leadership and Industry-Type}

Table 19 reports the relationship between EI and leadership effectiveness when the level of the leader is considered. For low-level leaders (e.g., supervisors) the correlations between EI and effectiveness was .30. For mid-level leaders (e.g., middle manager), the correlation between EI and effectiveness was .20. Finally, for upperechelon leaders, the same relationship was .26.

Table 20 reports results of the EI-leadership effectiveness relationship by industry type and sectors. This included examining differences between leaders' effectiveness in business and educational organizations, differences between leaders' effectiveness in for- 
profit, non-profit, and government organizations, and the differences between leaders' effectiveness in service and manufacturing organizations. Specifically, the validities were stronger in organizations that were in the for-profit (vs. non-profit or government) sector ( $\rho=.28$ vs. $\rho=.22 ; 17$ ), when organizations were in the service (vs. the manufacturing) sector $(\rho=.28$ vs. $\rho=.23$ ). Validities were lowest for leaders in the education sector ( $\rho$ $=.12)$. 


\section{CHAPTER V}

\section{Discussion}

The current study examines several empirical and theoretical issues that previous research on emotional intelligence has not addressed. The most important of these matters concerns the relationship between EI and leadership effectiveness. Although a number of management scholars have been critical of EI theory and research in general, even those that have been the most critical (e.g., Antonakis, 2004; Landy, 2005) have intimated that EI theory may be applicable in specific situations involving the prediction of leadership effectiveness. Overall, the results of this study tend to support a linkage between leader EI and effectiveness. Specifically, I found the EI-leadership relationship was moderate in nature $(\rho=.25)$, with $80 \%$ credibility intervals excluding zero. In addition, the positive manifold of the effect sizes presented above - ranging from .10 to .44 - indicate that emotional intelligence has meaningful relations with myriad leadership outcomes including effectiveness, transformational leadership, LMX, follower job satisfaction, and others. The fact that all of the 53 meta-analyses conducted had $80 \%$ credibility intervals above zero implies that a positive relationship holds across all situations studied here, even when sampling error accounts for somewhat lower percentages of variance. Furthermore, the strength and unequivocal nature of the relationships that I report are in line with recent meta-analytic examinations of frequently cited individual difference variables (Judge et al., 2002; Judge et al., 2004) such as extraversion $(\rho=.25)$, emotional stability $(\rho=.22)$, openness $(\rho=.24)$, and intelligence $(\rho=.27)$. 
Furthermore, my dissertation examined potential process mechanisms that may account for the EI-leadership effectiveness relationship. I explicitly examined the role that leadership behaviors (i.e., transformational leadership, LMX) have in explaining the relationship between emotional intelligence and leadership effectiveness. My analyses revealed that both transformational leadership and LMX partially mediate EI-leadership effectivness relationship. Thus, leadership behavior appears to be one route through which a leader's level of EI has an impact on his or her effectiveness and these findings provide further support for Hogan and Kaiser's (2005, p. 127) argument that "who we are is how we lead." It should also be noted that compared to the relatively large number of studies separately examining (a) EI and leadership effectiveness and (b) EI and leadership behavior, fewer than 20 studies simultaneously examined all three variables. I therefore had to conduct separate meta-analyses to derive the EI $\rightarrow$ leadership behavior $\rightarrow$ leadership effectiveness relationship. It is clear that more research is needed to determine the role that leadership behavior has as an explanatory process mechanism, especially as it concerns LMX.

Despite the significant validities found for predicting leadership effectiveness and evidence that leadership behavior is a process mechanism in the EI-leadership relationship, there remain some reasons to temper the conclusions presented above. Of these, the most striking is the small amount of incremental validity that EI provides in predicting leadership effectiveness above and beyond that of the Big Five and GMA. As I discussed above, a major question confronting theories of EI relates to its overall distinctiveness. That is, is EI just "a new label for existing constructs" (Neubauer \& Freudenthaler, 2005, p. 48) or is it altogether some new construct? The evidence 
presented in this paper does not bode well for those scholars who claim that EI is a new construct. Indeed, after controlling for both the Big Five and GMA, EI only predicts an additional $1 \%$ in leadership effectiveness. Although the amount of incremental variance predicted is significant, this was probably the result of the large sample size of the present meta-analysis rather than the practical significance of such an increase in predictive validity.

Matthews et al. (2004) have suggested that there appears to be little distinction between mixed model (i.e., self-report) measures of EI and the Big Five. One might take their statement one step further and suggest that there is little distinction between either model of EI (mixed or ability) and the Big Five. Both the ability model of EI and the mixed model predicted an additional $1 \%$ of variance in leadership effectiveness once the Big Five were controlled for. The results for incremental validity over and above GMA are not that much better for EI; in line with the findings of Van Rooy and Viswesvaran (2004), I found that mixed model EI was less related to GMA than ability EI. Mixed EI predicted an additional $6 \%$ in variance when GMA was held constant whereas Ability EI only predicted an additional $2 \%$ in variance. However, not to be overly critical, the lack of incremental validity above and beyond personality and intelligence is not the death knell for a construct. I further discuss the implications of these findings below, and separately consider what these findings mean for theorists and practitioners.

As an exploratory issue, I was also interested in how much each model of EI predicted leadership effectiveness above and beyond the competing model of EI. That is, how much incremental variance in predicting leadership effectiveness does the ability model of EI have once the mixed model of EI is controlled for (and vice versa)? For the 
meta-analytic estimate between the ability model of EI and the mixed model of EI, I incorporated the findings from Van Rooy and Viswesvaran (2004). In Table 22 I present the results of these analyses. As can be seen in the upper half of the table, the mixed model of EI predicts an additional $4 \%$ of variance in leadership effectiveness. However, in at the bottom of the table, we see that ability EI only predicts an additional $1 \%$ of variance after mixed model EI is controlled for. Taken together with the previously presented analyses involving the big five and GMA, as well as the comparison of validities for mixed model EI (.27) versus ability EI (.21), it appears that mixed model EI appears to be an overall better predictor of leadership than ability EI. These findings are in somewhat contrast with extant EI theory, and, below, I discuss the implications of these results.

\section{Moderators}

Because meta-analysis combines findings from several studies, another contribution from this paper is the ability to examine theoretical issues that would be difficult for a single study to examine. For instance, there were no studies included in this meta-analysis that simultaneously compared the validities of mixed and ability model EI among leaders. The findings are somewhat befuddling considering the debate in the literature over which model of EI is appropriate. Ashkanasy and Daus (2005) have gone to great efforts to argue that the ability (i.e., Mayer and Salovey) model of EI is the "gold standard" of EI and measures that were developed using this conceptualization (i.e., the MSCEIT) have proven to be the most reliable and valid. However, the data presented in Tables 13 and 14 would seem to contradict their assessment. Indeed, the validities for mixed model EI were stronger (.27) than those of ability model EI (.21). Moreover, the 
data presented in Table 17 suggest that of the five different measures of EI examined in this study, the MSCEIT has the weakest validity in predicting leadership effectiveness.

At the same time, meta-analysis may offer insights and conclusions to frequently asked questions. Of these, perhaps the most pertinent to EI scholars is the examination of the validities of the four facets of EI. A number of researchers have suggested that there is a higher-order factor structure to EI (Mayer \& Salovey, 1997; Whitman, Van Rooy, Viswesvaran, \& Kraus, In Press) and that different facets may have different relations with criteria. For instance, Mayer and Salovey (1997) suggest a hierarchical relationship among the EI facets wherein the ability to manage and regulate emotions will have the strongest predictive validity and the ability to appraise and express emotions will have the weakest predictive validity. While there do seem to be some differences in predictive validity among the facets (Tables 6-9), the data does not support Mayer and Salovey's hierarchical hypothesis. In fact, the management and regulation of emotion facet has almost the same validity (.15) as the appraisal and expression of emotion (.14) and the use of emotion (.15) dimensions. The ability to understand emotions had the strongest relationship with leadership effectiveness (.19).

I conducted exploratory analyses to examine the inter-relationships of the four facets of EI. In Table 21, I present the meta-correlation matrix among these dimesnsions. As can be seen from the table, all correlations among the facets are significant. The values range from .39 to .47 . In addition, I also report the correlation between overall EI and the four facets. The values, which are all significant, range from .69 to .84 . Please keep in mind, however, that these correlations were examined among the subset of EI studies that only examine leadership. A number of other studies exist that examine the 
relations among the four dimensions using non-leadership samples and criteria (e.g., Whitman, Van Rooy, Viswesvaran, \& Kraus, In Press). Future research should metaanalyze these relationships and compare them with those in the present study to infer differences (or not) among leadership and non-leadership samples.

Goleman (1995) has also suggested that EI should become more important as an employee moves up within the hierarchy of an organization. That is, that EI will matter more for CEOs than it will matter for lower-level supervisors. Although scholars frequently tout such a notion (e.g., Daus \& Ashkanasy, 2005; Wong \& Law, 2002), no previous study has tested their hypothesis. Again, we see in Table 20 that the data do not bear out some commonly held assumptions about the nature of EI. Although the relationship between EI and leadership effectiveness is higher among high-level leaders (.26) than it is among middle-managers (.20), the highest effect sizes come from those at the lowest levels of management (.30).

The rationale proffered by Goleman (1995) concerning his hypothesis was that there would be range-restriction in CEOs regarding GMA (i.e., all CEOs are very smart), however, such range-restriction would not exist regarding EI. Thus, successful CEOs could be identified by their levels of EI being much higher than those of their less successful counterparts. However, the hypothesis by Goleman does not appear to be well thought out. That is, why would GMA be range-restricted whereas EI would not be? If EI is related to leadership effectiveness, then it would also make sense that many of those in leadership positions have high EI (just as they tend to have high GMA). In fact, the data seem to support such a conclusion; the GMA-leadership effectiveness relationship is very 
similar to the EI-leadership effectiveness relationship. Thus, a moratorium on the rationale that EI should matter more at higher levels of leadership appears to be in order.

Moreover, the present research tends to support the notion that EI may actually matter more at lower levels of leadership. Lower level leaders such as supervisors are probably in greater day-to-day contact with employees and, thus, need to be able to manage relations on a personal basis. Understanding and managing the emotions of their followers may be a primary task for supervisors as it relates to their ability to influence. For example, supervisors often need to deliver performance feedback and other organizational information to employees. Such communication usually occurs in rich channels such as face-to-face interaction (Robbins \& Judge, 2008). Those supervisors who understand and can manage the emotions of lower-level employees are probably more likely to keep those employees motivated or improve their performance. Conversely, upper echelon leaders may be more concerned with the overall strategy of the organization, and vision oriented behaviors should be more important for these types of leaders (Zaccaro, 2001). They would probably have less knowledge of the emotions of their followers simply because they interact less frequently (face-to-face) with their followers.

\section{Theoretical Implications}

The theoretical implications resulting from the relationship between EI and leadership effectiveness appear to provide a mixed bag as far as conclusions go. On the one hand, EI demonstrated validities on par with some of the most researched individual difference variables in the field of leadership (e.g., extraversion, openness, intelligence). As a number of prominent scholars have previously intimated (e.g., Judge et al., 2001; 
Schmidt \& Hunter, 1998), validities approaching .30 are nothing to scoff at in the applied sciences. Thus, it appears that emotional intelligence, as it is currently measured, is a valid predictor of leadership effectiveness.

On the other hand, however, EI demonstrated an almost trivial amount of incremental variance (an average of .01) above and beyond that of personality and intelligence. The findings - resulting from cumulations across a substantial number of leadership studies - provide evidence against the argument that EI is something wholly new to our science. A frequent criticism of EI is that it is a new name for individual difference variables that have long been studied by I-O psychologists (Murphy, 2006). And because EI is a relatively new construct, the validity of the inferences that we make about this new construct must stand up to the rigors of scientific examination. In particular, the results of this paper indicate that the scientific principals of parsimony and redundancy are being violated when it comes to explaining the relationship between EI and leadership effectiveness. While these results do not warrant a moratorium on EI research altogether, they do indicate that inferences about leadership effectiveness are probably not the best way to support the validity (or distinctiveness) of the EI construct.

Not to be overly critical, I will end my discussion of the present findings' theoretical contributions on a positive note. The real value in EI theory may be much more rich when it comes to explaining the antecedents of transformational leadership. Although transformational leadership fully mediates the relationship between EI and leadership effectiveness, there is still much theoretical value in understanding the EI $\rightarrow$ transformational leadership $\rightarrow$ leadership effectiveness relationship. The joint significance of the three variables explicated in this process model provides fertile ground 
for fruitful research endeavors. The scientific study of leadership has long been criticized for being a disorganized and piecemeal field (Bass, 1990); so a model that provides a route through which to better understand leadership effectiveness should be welcome to the literature.

Practical Implications

For business managers and practitioners, the implications of this meta-analysis are not as grim. Indeed, there appears to be a moderate relationship between EI and leadership effectiveness. From a marketing perspective, this is important as a number of the more outlandish claims made by Goleman $(1995 ; 1998)$ have referred to EI's power in predicting leadership outcomes. For instance, Goleman (1998, p. 187) noted that “outstanding leaders' emotional intelligence make up $85 \%$ to $100 \%$ of the competencies crucial for success." One of the reasons many scholars have reacted so vehemently against EI research is due to the outrageous (an obviously untrue) claims of Goleman and other commentators. Consequently, it is important to temper these ridiculous claims and put forward a more reasonable assertion as the "face" of EI research. In fact, the results derived from this meta-analysis suggest that EI explains leadership outcomes somewhere in the $5 \%$ to $10 \%$ range. Such a number is not inconsequential, and comparable to the Big Five as well as GMA. Thus, measures of EI should provide businesses with moderate levels of utility in identifying, selecting, and promoting leaders.

Furthermore, from the perspective of business utility, the results above suggest that it may behoove managers to use mixed model measures of EI rather than the abilitybased model. There are three separate arguments for this suggestion. First, mixed model measures of EI display higher levels of validity than ability model measures. Second, 
many of the mixed model measures are publicly available (i.e., free), whereas the MSCEIT must be purchased from a testing company. Third, mixed model measures of EI are much quicker to take. For instance, the WLEIS is a 16-item self-report measure and takes only a couple of minutes to take. Proper administration of the MSCEIT takes upwards of an hour (Mayer \& Salovey, 1997). Taken together, it is clear that mixed model measures of EI may be the way for businesses to go.

Another concern pursuant to those of managers is adverse impact and diversity. It has been pointed out that women still hold a very small percentage of leadership positions in Fortune 500 companies (Northouse, 2007). The hypothesis that the lack of diversity is due to gender differences in important predictors has been discounted (Eagley, 2006). For instance, research suggests that there are no significant differences between women and men in intelligence and personality. Rather, the lack of gender diversity in corporate America may be better explained via lenses of bias and stereotype (e.g., Caleo \& Heilman, 2009). In line with Van Rooy and Viswesvaran (2004), my dissertation found that females scored significantly higher than men on tests of EI (.16). Thus, even though EI may not explain incremental validity above and beyond GMA and personality, it may show promise as that rare valid selection measure in which women score higher. At the minimum, organizations valuing the strategic business leverage of increased gender diversity should explore the benefits of EI testing.

Finally, from a practical perspective, it may be the case that job candidates enjoy taking tests of EI. That is, they have positive reactions to these types of tests. Understanding why job candidates might react negatively to selection procedures is beneficial for an organization for many reasons. For instance, an applicant's negative 
reaction to a selection tool is often cited as a primary reason for litigation against an organization (Cascio, 1991). Moreover, Murphy (1986) demonstrated that there is a significant loss in selection tool utility when top applicants opt out of the selection process. Research has also shown that negative reactions to selection procedures may result in reduced job-related motivation (Arvey, Strickland, Drauden, \& Martin, 1990) or withdrawal from the selection process (Rynes, Bretz, \& Gerhart, 1991), both of which may lower test utility and reduce the operational validity of the selection procedure. Previous research on applicant reactions to EI has suggested that, on the whole, testtakers in high-stakes testing contexts tend to have positive reactions to EI (Whitman, Van Rooy, Viswesvaran, \& Kraus, 2006). Furthermore, women (vs. men) and ethnic minorities (vs. whites) tended to have the most positive reactions to EI. Combined with the knowledge that EI displays a moderate correlation with leadership effectiveness, there may be even more reason for managers to use EI in the workplace.

\section{Limitations and Future Research}

Although the present study makes an important contribution to the emotional intelligence and leadership literatures, it is not without its limitations. Nonetheless, given the importance of an empirical examination of EI's potential leadership correlates and consequences as well as the conditions under which its effects are more pronounced, it is crucial. In the absence of such a meta-analysis, researchers are likely to base judgments on the findings of individual studies, or perhaps even outlandish claims (e.g., Goleman, 1995, 1998), which would be even more likely to lead to error. While I am unaware of any concrete guidelines regarding a minimum number of studies necessary to utilize meta-analysis, the small number of articles available in some of the meta-analyses above 
should be pointed out (Hunter \& Schmidt, 2004). The small sample sizes presented in some of the moderator meta-analyses should be augmented with additional research in this area. A goal of meta-analysis is to identify areas where future research is needed. Hence, I view this study merely as an initial "snapshot" of the extant research investigating the EI-leadership effectiveness relationship, not a definitive conclusion to this important research stream.

Because a meta-analysis is only as good as the articles it cumulates, I should also note that only a couple of the studies cited were published in top-tier journals (e.g., Cote et al., 2005; Law \& Wong, 2002). The lack of top-tier publications concerns me from the standpoint that either (1) not enough top-tier researchers are doing EI research or (2) not enough top-tier journals are accepting EI research. Consequently, one or both of these factors have lead to a glut of poor quality EI studies. As I mentioned above in the methodology, using a PsycINFO keyword search, I initially identified over 300 studies that appeared to be relevant. On closer inspection, however, a majority of these studies did not include adequate statistics with which to report an effect size (e.g. a correlation). While these poor quality studies did not effect the results of my meta-analyses, it does make me worry about the quality of the extant research and who is citing it. Hopefully this study will serve to guide those seeking to gain a better scientific understanding of the relationship between EI and leadership.

I was also surprised that very few studies examined ethnic group differences in scores (e.g., black leaders vs. white leaders). However, maybe this should not surprise me; maybe there are just so few ethnic minorities in positions of leadership that this type of sample is hard to get. Nevertheless, Van Rooy et al. (2005) have shown that ethnic 
minorities (e.g., Blacks, Hispanics) tend to score higher than Whites on tests of EI. As with problems pertaining to gender diversity, findings that protected minority groups score higher on a valid test would be of great interest to managers and practitioners. The present findings would be particularly appealing to issues regarding adverse impact, especially if EI's predictive validity is almost the same as GMA's, but it does not come to the table with the large white-black score gap. More research should examine ethnicity as a moderator of the EI-leadership effectiveness relationship as this appears to be the key issue in warranting continued research in this area.

Another area that appears fruitful for future EI research is examination of additional process mechanisms. Indeed, extant theory suggests that there are a number of other variables besides personality, intelligence, and leadership style (i.e., transformational leadership, LMX) that may mediate the EI-Leadership effectiveness relationship. From the followers perspective, interpersonal justice may be an additional motivational mechanism at work in the EI-leadership process model. Interpersonal justice (Colquitt, 2001) has been described as how an individual is treated by his or her leader in terms of honesty, truthfulness, and courtesy (Mitchell \& Daniels, 2001). It is likely that leaders with high EI treat their employees fairly because they have a better understanding of the emotions of the employees in a work unit. Research has also shown that empathy and considerate treatment boost subordinates' perceived interpersonal justice and ultimately have an effect on increased follower cooperation and performance (De Cremer \& Knippenberg, 2002). Rationally, subordinates who perceive they are fairly treated by their leaders tend to find ways to contribute more in a cooperative way with other members (Ehrhart, 2004). This relationship between fair treatment and improved 
cooperation has been evidenced by research aimed at the effect of justice on OCBs (Greenberg, 1996).

Follower self-efficacy may also explain part of the EI-leadership effectiveness relationship. Self-efficacy is the belief in one's capabilities to organize and execute actions required to manage prospective situations (tasks) and to obtain desired results (Bandura, 1977). Specifically, self-efficacy makes a difference in how people feel, think, and act. Previous research has shown that a high sense of self-efficacy facilitates cognitive processes in variety of settings, including quality of decision-making and academic and job performance. Because people with high self-efficacy choose more challenging tasks, set higher goals and stick to them, it is not surprising that high-self efficacy is strongly related to one's overall task performance in the workplace (Bandura, 1997). In line with this, Stajkovic and Luthans (1998) found a meta-analytic correlation of .38 between self-efficacy and work-related performance.

Bandura (1997) has specified two of the sources through which self-efficacy is learned and modified. In particular, he noted that (1) social persuasion (receiving a verbal and/or non-verbal encouragement) and (2) physiological state could increase selfefficacy. As discussed earlier, a leader's EI is likely to be intertwined with these sources of a follower's self-efficacy. That is, both positive emotional understanding and managing emotions in others are directly associated with social persuasion and improving positive mood.

At the same time, it is also likely that there are mediators of the EItransformational leadership relationship. Previous research has shown that the big five personality factors are related to transformational leadership (Judge \& Bono, 2002). I 
was unable to examine personality as a mediator of this relationship due to insufficient sample sizes in the available studies. Although research has yet to examine the relationship between GMA and transformational leadership, it may also be fruitful to examine GMA as a mediator because of the moderate relationship that we know exists between GMA and EI.

Future research should also examine both LMX and transformational leadership as a mediator of the EI-leadership effectiveness. Because of the lack of studies that examine both of these styles of leadership, I was unable to examine this research question. For instance, it may be of interest to leadership and EI researchers to find out that one of these leadership styles is more important than the other in explaining the EIleadership effectiveness relationship.

Finally, I believe a fertile ground that needs toiling is the development of new and better EI measures. Two key areas need to be addressed: (1) test-type and (2) test content. Regarding test-type, EI tests should be designed to measure competencies associated with the understanding, management, and expression emotion. A majority of the measures that were analyzed in this study were self-report format appear to simply have a difficult time capturing these competencies. While the MSCEIT does diverge a bit from this test-type, no EI measures currently attempt to involve or engage test-takers into a truly emotional situation. That is, measures should be developed that elicit emotional responses and changes. The development of a situational judgment test is one option, but EI theory seems to warrant a move beyond the pencil-and-paper variety. For instance, perhaps EI could be tested using video or virtual interaction. It might also be measured within the context of an assessment center. 
The second issue - test content - is more relevant to organizational scientists. The fact that the WLEIS is the only known measure of EI developed with an occupational focus should be of concern to both managers and practitioners. The rest of the EI measures that are commonly used for selection (e.g., Bar-On, 1997; Mayer \& Salovery, 1997) were developed for broader uses. That is, test developers examined the criterionrelated validity of the EI construct with the purpose of accurately describing individual differences in EI that could be used in a whole range of settings; the use of these EI measures for personnel screening and selection is just one of their many applications. Because these measures were not developed with organizations in mind, future research should be aimed at developing new measures constructed to explicitly maximize overlap with work criterion constructs (leadership, job performance, counterproductivity).

\section{Conclusion}

My study meta-analytically examined the relationship between EI and leadership effectiveness. Overall, the results supported a linkage between leader EI and effectiveness that was moderate in nature $(\rho=.25)$. In addition, the positive manifold of the effect sizes presented in this study - ranging from .10 to .44 - indicate that emotional intelligence has meaningful relations with myriad leadership outcomes including effectiveness, transformational leadership, LMX, follower job satisfaction, and others. Furthermore, this paper examined potential process mechanisms that may account for the EI-leadership effectiveness relationship and showed that both transformational leadership and LMX partially mediate the relationship. However, while the predictive validities of EI were moderate in nature, path analysis and hierarchical regression suggests that EI contributes less than or equal to $1 \%$ of explained variance in leadership effectiveness 
once personality and intelligence are accounted for. At the very least, EI seems to be old wine in a new bottle. To continue to warrant research in this area, future studies should focus on EI's potential for favoring underrepresented minority job candidates (i.e., females, blacks, Hispanics) and its role in possibly absolving adverse impact issues regarding an alternative form of intelligence testing. 


\section{REFERENCES}

Aditya, R. N., House, R. J., \& Kerr, S. (2000). Theory and practice of leadership: into the new millennium. In L. Cooper and E. Locke (Eds.), Industrial and Organizational Psychology: Linking Theory and Practice (pp. 130-165). Oxford: Blackwell.

Antonakis, J. (2004). On why "Emotional Intelligence" will not predict leadership effectiveness beyond IQ or the "Big Five": An extension and rejoinder. Organizational Analysis, 12, 171-182.

Antonakis, J., Cianciolo, A. T., \& Sternberg, R. J. (2004). The nature of leadership. Thousand Oaks. CA: Sage Publications.

Aryee, S. \& Chen, Z.X. (2006). Leader-member exchange in a Chinese context: Antecedents, the mediating role of psychological empowerment and outcomes. Journal of Business Research, 59, 793-801.

Ashford, B.E., \& Humphrey, R.H. (1995). Emotion in the workplace: a re-appraisal. Human Relations, 48, 97-125.

Ashkanasy, N. M., \& Daus, C. S. (2005). Rumors of the death of emotional intelligence in organizational behavior are vastly exaggerated. Journal of Organizational Behavior, 26, 441-452.

Ashkanasy, N. M. \& Daus, C. S.( 2002). Emotion in the workplace: The new challenge for managers. Academy of Management Executive, 16, 76.

Ashkanasy, N. M., \& Tse B. (2000). Transformational leadership as management of emotion: a conceptual review. In N. Ashkanasy, C.E.J. Härtel and W.J. Zerbe, (Eds.), Emotions in the workplace: research, theory, and practice, pp. 221235.Quorum Books, Westport, CT.

Arvey, R. D., Rotundo, M., Johnson, W., \& McGue, M. (2003). The determinants of leadership: The role of genetics and personality. Paper presented at the 18th Annual Conference of the Society for Industrial and Organizational Psychology. Orlando, FL.

Arvey, R. D., Strickland, W., Drauden, G. \& Martin, C. (1990). Motivational components of test taking. Personnel Psychology, 43, 695-716.

Avolio, B.J. (2005). Leadership development in balance: Made/Born. NJ: Erlbaum \& Associates.

Bandura, A. (1997). Self-efficacy: The exercise of control. New York: H.W. Freeman. 
Barbeito, C. L., and J. P. Bowman. (1998). Nonprofit Compensation and Benefits Practices. New York: John Wiley \& Sons.

Barbuto, J. E., \& Burbach, M. E. (2006). The emotional intelligence of transformational leaders: A field study. The Journal of Social Psychology, 146, 51-64.

Barney, J. (1991). Firm resources and sustained competitive advantage. Journal of Management, 17, 99-120.

Bar-On, R. (1997). The Bar-On Emotional Quotient Inventory (EQ-i): A Test of Emotional Intelligence. Toronto, Canada: Multi-Health Systems.

Bar-On, R. (1988). The development of a concept of psychological well-being. Unpublished doctoral dissertation, Rhodes University, South Africa.

Barrick, M.R., \& Mount, M.K. (1991). The Big Five personality dimensions and job performance: a meta-analysis. Personnel Psychology, 44, 1-26.

Barsade, S. G., Brief, A. P., \& Spataro, S. E. (2003). The affective revolution in organizational behavior: The emergence of a paradigm. In J. Greenberg (Eds.), Organizational behavior: The state of the science (pp. 3-52). Mahwah, NJ: Erlbaum.

Bass, B. M. (2002). Cognitive, social, and emotional intelligence of transformational leaders. In R.E. Riggio, S.E. Murphy, \& F.J. Pirozzolo (Eds.), Multiple intelligences and leadership (pp 105-118). Mahwah, NJ: Lawrence Erlbaum.

Bass, B. M., \& Avolio, B. J. (1990). Manual for the Multifactor Leadership Questionnaire. Palo Alto, CA: Consulting Psychologists Press.

Bass, B. M. (1990). Bass \& Stogdill's handbook of leadership: Theory, research, \& managerial applications. ( ${ }^{\text {rd }}$ Ed.). New York: Free Press.

Bass, B. M. (1985) Leadership and Performance Beyond Expectation. New York: Free Press.

Bennis, W. (1994), On Becoming a Leader. Addison-Wesley Publishing, Reading, MA.

Bennis, W. (1959). Leadership theory and administrative behaviour. Administrative Science Quarterly, 4, 259-301.

Boal K. B., \& Hooijberg R. (2001). Strategic leadership research: Moving on. Leadership Quarterly, 11, $515-549$. 
Bono, J.E., Judge, T.A. (2004). Personality and Transformational and Transactional Leadership: A Meta-Analysis. Journal of Applied Psychology, 89, 901-910.

Brief, A. P., \& Weiss, H. M. (2002). Organizational behavior: Affect in the work place. Annual Review of Psychology, 53, 279-307.

Bryman, A. (1992). Charisma and leadership in organizations. London: Sage.

Burns, J. M. (1978). Leadership. New York: Harper \& Row.

Carlyle, T. (1907). On heroes, hero-worship, and the heroic in history. Boston: Houghton Mifflin.

Cascio, W.F. (2003). Managing human resources: Productivity, quality of work life, profits (6th ed.). Boston: McGraw-Hill Irwin.

Cascio, W.F. (1991). Applied psychology in personnel management (4th ed.). Englewood Cliffs, NJ: Prentice-Hall International.

Chemers, M. M. (1997). An integrative theory of leadership. Mahwah, NJ: Lawrence Earlbaum Publishers.

Ciarrochi, J. V., Chan, A. Y. C., \& Caputi, P. (2000). A critical evaluation of the emotional intelligence construct. Personality and Individual Differences, 28, 539561.

Cleveland, J. N., Stockdale, M., \& Murphy, K. R. (2000). Women and men in organizations: Sex and gender issues at work. Mahwah, NJ: Erlbaum.

Coetzee, C. \& Schaap, P. (2004). The relationship between leadership styles and emotional intelligence. Paper presented at the 6th Annual Conference of the Society of Industrial and Organizational Psychology, Sandton, South Africa.

Cooper, R. \& Sawaf, A. (1997). Executive EQ. Orion Business Books.

Cooper, R. K., \& Sawaf, A. (1996). Executive EQ: Emotional intelligence in leadership and organizations. New York: Perigee Books.

Conger, J. A., \& Kanungo, R. N. (1998). Charismatic leadership in organizations. Thousand Oaks, CA: Sage.

Costa, P.T., \& McCrae, R.R. (1992). NEO PI-R. Professional manual. Odessa, FL: Psychological Assessment Resources, Inc. 
Dansereau, F., Graen, G. B., \& Haga, W. J. (1975). A vertical dyad linkage approach to leadership within formal organizations. Organizational Behavior and Human Performance, 13, 46-78.

Dasborough, M. T., \& Ashkanasy, N. M. (2002). Emotion and attribution of intentionality in leader-member relationships. Leadership Quarterly, 13, 615-634.

Daus, C. S. \& Ashkanasy, N. M. (2005). The case for the ability-based model of emotional intelligence in organizational behavior. Journal of Organizational Behavior, 26, 453-466.

Daus, C. S. \& Harris, A. (2003). Emotional intelligence and transformational leadership in groups. Paper/presentation of symposium: Multilevel Perspectives on Emotions in Organizations at the $18^{\text {th }}$ Annual Meeting of the Society for Industrial and Organizational Psychologists, Orlando, FL.

Day, D.V., Schleicher, D.J., Unckless, A.L., \& Hiller, N.J. (2002). Self-monitoring personality at work: A meta-analytic investigation of construct validity. Journal of Applied Psychology. 87, 390-401.

De Groot, R.S., van der Perk, J., Chiesura, A., Marguliew, S., (2000). Ecological functions and socio-economic values of critical natural capital as a measure for ecological integrity and environmental health. In: Crabbe, P., Holland, A., Ryszkowski, L., Westra, L. (Eds.), Implementing Ecological Integrity: Restoring Regional and Global Environmental and Human Health. (Vol. 1, pp.191-214) NATO-Science Series, IV. Earth and Environmental Sciences, Kluwer Academic Publishers, Dordrecht/Boston/London.

Den Hartog, D.N. \& Koopman, P.L. (2001). Leadership in organizations. In: Anderson, N.,Ones, D.S., Sinangil, H. \& Viswesvaran, C. (eds.). Handbook of industrial, work and organizational psychology. London: Sage.

Demasio A. R., (1994). Descartes' Error: Emotion, Reason, and the Human Brain. New York: Avon Books.

Drucker, P.F. (1954). The Practice of Management. Harper \& Row, New York, NY.

Dunnette, M.D. (1966). Personnel selection andplacement. Belmont, CA: Wadsworth, 1966.

Ekman, P. (1973). Darwin and facial expression; a century of research in review. New York: Academic Press. 
Emmons, R. A., \& Colby, P.M. (1995). Emotional conflict and well-being: Relation to perceived availability, daily utilization, and observer reports of social support. Journal of Personality and Social Psychology, 68, 947-959.

Epstein, S. (1990).Cognitive-experiential self-theory. Pervin, L.A. (Eds),Handbook of Personality: Theory and Research, Guilford Press, New York, NY.

Fiedler, F.E. (1967) A Theory of Leadership Effectiveness. New York: McGraw-Hill.

Finkelstein, S., \& Hambrick, D.C. (1996). Strategic Leadership: Top Executives and Their Effects on Organizations. West, St Paul, MN, .

Foo, M.D., Elfenbein, H., Tan, H, \& Aik, V. (2004). Emotional intelligence and negotiation: The tension between creating and claming value. International Journal of Conflict Management, 15, 411-429.

Frigda, N. H. (1988). The laws of emotion. American Psychologist, 43, 349-58.

Galton, F. (1869). Hereditary Genius. New York: Appleton.

Gardner, W.L., \& Avolio, B.J. (1998). The charismatic relationship: A dramaturgical perspective. Academy of Management Review, 23, 32-58.

Gardner, H. (1983). Frames of mind. New York: Basic Books.

George, J. M. (2000) Emotions and leadership: The role of emotional intelligence. Human Relations, 51, 1027-1055.

George, J.M. (1992). The role of personality in organizational life: Issues and evidence. Journal of Management, 18, 185-213.

George, J.M. (, 1991). State of trait: Effects of positive mood on prosocial behaviors at work. Journal of applied Psychology, 76, 299-307.

George, J.M. (1990). Personality, affect, and behavior in groups. Journal of Applied Psychology, 75, 107-116.

Gerstner, C.R., \& Day, D.V. (1997). Meta-analytic review of leader-member exchange theory:Correlates and construct issues. Journal of Applied Psychology,82, 827844.

Gibb, C.A. (1947). The principles and traits of leadership. Journal of Abnormal and Social Psychology, 42, 267-84.

Gill, R. (2006). Theory and practice of leadership. Thousand Oaks, CA: Sage. 
Goldberg, L.R. (1990). An alternative description of personality: The Big-Five factor structure. Journal of Personality and Social Psychology, 59, 1216-29.

Goleman, D., Boyatzis, R., \& McKee, A. (2002). Primal leadership: Realizing the power of emotional intelligence. Boston, MA: Harvard Business School Press.

Goleman, D. (1998). What makes a leader? Harvard Business Review on What makes a leader. Harvard Business School Press: Boston.

Goleman, D. (1997). Emotional intelligence: Why it can matter more than IQ. New York: Bantam Books.

Goleman, D. (1995). Emotional intelligence. New York: Bantam Books.

Gottfredson, L. S. (1997). Intelligence and social policy. Intelligence, 24,1.

Gowing, M.K. (2001). Measurement of individual emotional competence. In C. Cherniss \& D. Goleman (Eds.), The emotionally intelligent workplace (pp. 83-131). San Francisco: Jossey-Bass.

Graen, G.B. \& Uhl-Bien, M. (1995). Relationship-based approach to leadership: Development of leader-member exchange (LMX) theory of leadership Over 25 years: Applying a multi-level, multi domain perspective. Leadership Quarterly, 6, 219-247.

Harrison, J. K., \& Clough, M. W. (2006). Characteristics of "State of the Art" Leaders: Productive Narcissism versus Emotional Intelligence and Level 5 Capabilities. Social Science Journal, 43, 287-292.

Heath, C., \& Jourden, F. (1997). Illusion, disillusion, and the buffering effect of groups. Organizational Behavior and Human Decision Processes, 69, 103-116.

Herriot, P. \& Pemberton, C. (1995). New deals. The Revolution in Managerial Careers, John Wiley \& Sons: Chichester.

Hogan, R., \& Kaiser, R. B. (2005). What we know about leadership. Review of General Psychology, 9, 169-180.

Hogan, R., Curphy, G. J., \& Hogan, J. (1994). What we know about leadership. American Psychologist, 49, 493-504.

Hough, L. (1992). The "Big Five" personality variables - construct con-fusion: Description versus prediction. Human Performance, 5, 139-155. 
House, R. J., \& Aditya, R. N. (1997). The social scientific study of leadership: Quo vadis? Journal of Management, 23, 409-447.

House, R. J. (1996). Path-Goal Theory of Leadership: Lessons, Legacy and a Reformulated Theory. Leadership Quarterly, 7, 323-352.

House, R. J., Spangler, W. D., \& Woycke, J. (1991). Personality and charisma in the U. S. Presidency: A psychological theory of effectiveness. Administrative Science Quarterly, 36, 334-396.

House, R. J. (1971). A path-goal theory of leader effectiveness. Administrative Science Quarterly, 16, 321-339.

Howard, A. (1995). High-involvement leadership and its implications for leadership educators. Proceedings of the 1995 Leadership Education Conference, The University of Richmond.

Howell, J.M., \& Avolio, B.J. (1993). Transformational leadership, transactional leadership, locus of control, and support for innovation: Key predictors of business unit performance. Journal of Applied Psychology, 78, 891-902.

Hunter, J. E., \& Schmidt, F. L. (2004). Methods of meta-analysis: Correcting for error and bias in research findings. Thousand Oaks, CA: Sage Publications.

Hunter, John E. \& Hamilton, Mark A. (1992). Path . Program to perform recursive path analysis, version 4.0. -Computer program.

Janovics, J., \& Christansen, N. (2001). Emotional intelligence in the workplace. Poster presented at the Annual Conference of the Society for Industrial and Organizational Psychology, San Diego, CA.

Jenkins, W.O. (1947). A review of leadership studies with particular reference to military problems. Psychological Bulletin, 44, 54-79.

Jones, G.R, \& George, J.M. (1998). The experience and evolution of trust: implications for cooperation and teamwork. Academy of Management Review, 23, 531-546.

Jordan, P.J., Ashkanasy, N.M., \& Härtel, C.E.J. 2003. The case for emotional intelligence in organizational research. Academy of Management Review, 28, 195-197.

Judge, T.A., Colbert, A.E., \& Ilies, R. (2004). Intelligence and leadership: a quantitative review and test of theoretical propositions. Journal of Applied Psychology, 89, $542-552$. 
Judge, T. A., Bono, J. E., Ilies, R., \& Gerhardt, M. W. (2002). Personality and leadership: A qualitative and quantitative review. Journal of Applied Psychology. 87, 765780 .

Judge, T. A., \& Piccolo, R. F. (2004). Transformational and transactional leadership: a meta-analytic test of their relative validity. Journal of Applied Psychology, 89, 755-768.

Katz, D., Maccoby, N., Gurin, G., \& Floor, L. (1951). Productivity, supervision, and morale among railroad workers. Ann Arbor: Survey Research Center, University of Michigan.

Kerr, R., Garvin, J., Heaton, N., \& Boyle, E. (2006). Emotional intelligence and leadership effectiveness. Leadership \& Organization Development Journal, 27, 265-279.

Klein, K. J., \& Kozlowski, S. W. J. (2000). From micro to meso: Critical steps in conceptualizing and conducting multilevel research. Organizational Research Methods, 3, 211-236.

Klein, K. J., Dansereau, F., \& Hall, R. J. (1994). Levels issues in theory development, data collection, and analysis. Academy of Management Review, 19, 195-229.

Kobe, L.M., Reiter-Palmon, R., \& Rickers, J.D. (2001). Self-reported leadership experiences in relation to inventoried social and emotional intelligence. Current Psychology: Developmental, Learning, Personality, Social, 20, 154-163.

Kozlowski, S. W. J., \& Bell, B. S. (2003). Work groups and teams in organizations. In W. C. Borman, D. R. Ilgen, \& R. J. Klimoski (Eds.), Handbook of Psychology: Industrial and Organizational Psychology (Vol. 12, pp. 333-375). Hoboken, NJ: John Wiley \& Sons.

Kozlowski, S. W. J., \& Klein, K. J. (2000). A levels approach to theory and research in organizations. In K. J. Klein \& S. W. J. Kozlowski (Eds.), Multilevel theory, research and methods in organizations (pp. 3-90). San Francisco, CA: JosseyBass.

Landy, F.J. (2005). Some historical and scientific issues related to research on emotional intelligence. Journal of Organizational Behavior, 26, 411-24.

Law, K.S., Wong, C.S., \& Song, L.J. (2004). The construct and criterion validity of emotional intelligence and its potential utility for management studies. Journal of Applied Psychology, 89, 483-96. 
Lee, K., \& Allen, N. J. (2002). Organizational citizenship behavior and workplace deviance: The role of affect and cognitions. Journal of Applied Psychology, 87, 131-142.

Lewis, D. (2000), "Leadership and management challenges with a multicultural workforce: an Australian case study and its global implications", Refereed Conference Proceedings of 3rd European Project Management Conference, Jerusalem, Israel, June, reproduced in CD-ROM format, pp.11-16.

Liden, R. C., \& Graen G. (1980).Generalizability of the Vertical Dyad Linkage Model of Leadership. Academy of Management Journal, 23, 451-465.

Locke, E.A. (2005). Why emotional intelligence is an invalid concept. Journal of Organizational Behavior, 26, 425-31.

Loehlin, J. (1992), Latent Variables Models, Erlbaum, Hillside, NJ.

Lord, R.G., DeVader, C.L., \& Alliger, G.M. (1986). A meta-analysis of the relation between personality traits and leadership perceptions: An application of validity generalization procedures. Journal of Applied Psychology. 71, 402-410.

Lowe, K. B., \& Gardner, W. L. (2000). Ten years of the leadership quarterly: Contributions and challenges for the future. Leadership Quarterly, 11, 459-514.

Luthans, F. (2002). The need for and meaning of positive organizational behavior. Journal of Organizational Behavior, 23, 695-706.

Luthans, F. (2002). Positive organizational behavior: Developing and managing psychological strengths. Academy of Management Executive, 16, 57 - 72.

Macik-Frey, M. (2007). Communication-centered approach to leadership: The relationship of interpersonal communication competence to transformational leadership and emotional intelligence. The University of Texas at Arlington.

Mathieu, J. E., \& Taylor, S. R. (2006). Clarifying conditions and decision points for mediational type inferences in organizational behavior. Journal of Organizational Behavior, 27, 1031-1056.

Matthews, G., Zeidner. M., \& Rubens. R. D. (2002). Emotional intelligence: Science and myrh. Cambridge. MA: MIT Press.

Mayer, J. D., Salovey, P., \& Caruso, D. R. (2002). Mayer-Salovey-Caruso Emotional Intelligence Test: Manual. Toronto, Ontario, Canada: Multi-Health Systems 
Mayer, J. D., Salovey, P., \& Caruso, D. R. (2000). Models of emotional intelligence. In R. J. Sternberg (Eds.), Handbook of Human Intelligence (2nd ed), pp 396-420. New York: Cambridge.

Mayer, J. D., \& Salovey, P. (1997). What is emotional intelligence? In P. Salovey \& D. Sluyter (Eds.), Emotional Development and Emotional Intelligence: Implications for Educators (pp. 3-31). New York: Basic Books.

McColl-Kennedy, J.R,. \& Anderson, R.D. (2002). Impact of Leadership Style and Emotions on Subordinate Performance. The Leadership Quarterly, 13, 545-559.

Motowidlo, S. J. (2003). Job Performance. W. C. Borman, D. R. Ilgen, R. J. Klimoski, \& I. B. Weiner(Eds.), Handbook of Psychology: Industrial and Organizational Psychology (Vol. 12 pp. 39-53).

Murphy, J., \& Vriesenga, M. (2006). Research on school leadership preparation in the United States: an analysis. School Leadership \& Management, 26, 183.

Murphy, J. (2006). Preparing school leaders: An agenda for research and action. Lanham, MD: Rowman \& Littlefield.

Murphy, E.C. (1996). Leadership IQ. New York : John Wiley \& Sons.

Neubauer, A. C., \& Freudenthaler, H. H. (2005). Models of emotional intelligence. In R. Schultz \& R. D. Roberts (Eds.), Emotional intelligence: an international handbook (pp. 31-50). Cambridge, MA: Hogrefe.

Northhouse, G. (2008) Introduction to Leadership: Concepts and Practice. Sage Publishing.

Northouse, G. (2007). Leadership theory and practice. (4th ed.) Thousand Oak, London, New Delhe, Sage publication.

Ones, D., Viswesvaran, C., \& Schmidt, F. L. (1993). Meta-analysis of integrity test validities. Journal of Applied Psychology, 78, 679-703.

Organ, D.W. (1990). The motivational basis of organizational citizenship behaviour. Research in Organizational Behaviour, 12, 43-72.

Petrides, K. V., \& Fuhnham, A. (2001). Trait emotional intelligence: Psychometric investigation with reference to established trait taxonomies. European Journal of Personality, 15, 425-448.

Pemberton, C. (1997). Goal Setting. Linfield College Leadership Development Workshop. 
Pillai, R., Williams, E., Lowe, K., \& Jung, D. (2003). Personality, transformational leadership, trust, and the 2000 U.S. presidential vote. The Leadership Quarterly, 14, 1-32.

Pillai, R., \& Williams, E. A. (1998). Does leadership matter in the political arena? A study of voter perceptions of candidates' transformational and charismatic leadership in relation to the 1996 U.S. presidential vote. Leadership Quarterly, 9, 283-302.

Prati, L. M., Douglas, C, Ferris, G. R. Ammeter, A. P., \& Buckley, M. R. (2003a). Emotional intelligence, leadership effectiveness, and team outcomes. The Intemational Journal of Organizational Analysis, 11, 21-30.

Prati, L. M., Douglas, C, Ferris, G. R. Ammeter, A. P., \& Buckley, M. R. (2003b). The role of emotional intelligence in team leadership: Reply to the critique by Antonakis. The International Journal of Organizational Analysis, 11, 363-369.

Pugh, S. D. (2001). Service with a smile: emotional contagion in the service encounter. Academy of Management Journal, 44, 1018-1027.

Rahim, M. A., \& Psenicka, C. (2005). Relationship between emotional intelligence and effectiveness of leader role: A dyadic study in four countries. International Journal of Organizational Analysis, 13, 327-342.

Rapisarda, B. A. (2002). The impact of emotional intelligence on work team cohesiveness and performance. The International Journal of Organizational Analysis, 10, 363-379.

Roberts, R.D., Zeidner, M.,\& Matthews, G. (2001). Does Emotional Intelligence Meet Traditional Standards for Intelligence? Some New Data and Conclusions. Emotion, 1, 196-231.

Rousseau, D.M. (1995). Psychological contracts in organizations: Understanding written and unwritten agreements. Thousand Oaks, CA: Sage Publications.

Rubin, R., Munz, D., \& Bommer, W. (2005). Leading from within: The effects of emotion recognition and personality on transformational leadership behavior. Academy of Management Journal, 48, 845-858.

Ryan, A. M., \& Ployhart, R. E. (2003). Customer service behavior. In R. J. Klimoski, W. C. Borman, \& D. R. Ilgen (Eds.), Handbook of Psychology (Vol. 12 377-397. Wiley \& Sons: Hoboken, N.J.

Rynes, S. L., Bretz, R. D., \& Gerhart B. (1991). The importance of recruitment in job choice: A different way of looking. Personnel Psychology, 44, 487-521. 
Salovey, P., Mayer, J.D., \& Caruso, D. (2002). The positive psychology of emotional intelligence. In C.R. Snyder \& S.J. Lopez (Eds.). The handbook of positive psychology (pp. 159-171). New York: Oxford University Press.

Salovey, P., \& Mayer, J.D. (1990). Emotional intelligence. Imagination, Cognition, and Personality. 9, 185-211.

Schmidt, F. L., \& Hunter, J. E. (1998). The validity and utility of selection methods in personnel psychology: Practical and theoretical implications of 85 years of research findings. Psychological Bulletin, 124, 262- 274.

Schutte, N.S., Malouff, J.M., Hall, L.E., Haggerty, D.J., Cooper, J.T., Golden, C.J., et al. (1998). Development and validation of a measure of emotional intelligence. Personality and Individual Differences, 25, 167-177.

Sinclair, R. C., \& Mark, M. M. (1992). The influence of mood state on judgment and action: Effects on persuasion, categorization, social justice, person perception, and judgmental accuracy. In L. L. Martin \& A. Tesser (Eds.), The construction of social judgments, (pp. 165-193). Hillsdale, NJ. Erlbaum.

Spangler, W. D., House, R. J., \& Palrecha, R. (2004). Personality and leadership. In B. Schneider and B. Smith (Eds.), Personality and organizations. Mahwah, NJ: Erlbaum.

Sparrowe, R.T. \& Liden, R.C. (1997). Process and structure in leader-member exchange. Academy of Management Review, 22, 522-552.

Stogdill, R. M. (1948) Personal factors associated with leadership. A survey of the literature. Journal of Psychology. 25, 35-71.

Stogdill, R., \& Coons, A. (Eds.). (1957).Leader behavior: Its description and measurement (Monograph 88). Columbus, OH: Bureau of Business Research, Ohio State University.

Sy, T., Tram, S. \& O'Hara, L. A. (2006). Relation of employee and manager emotional intelligence to job satisfaction and performance. Journal of Vocational Behavior, $68,461-473$.

Taylor, G. J. (1984). Alexithymia: Concept, measurement, and implications for treatment. American Journal of Psychiatry, 141, 725-732.

Terman, L. M. (1904). A preliminary study in the psychology and pedagogy of leadership. Pedagogical Seminary, 11, 413-451.

Thorndike, R.K. (1920). Intelligence and Its Uses. Harper's Magazine, 140, 227-235. 
Tichy, N.M., and Devanna, M.A. (1986). The Transformational Leader, New York: Wiley.

Tsui, A.S., Egan, T.D., O'Reilly, C.A. (1992). Being different: relational demography and organizational attachment. Administrative Science Quarterly, 37, 549-579.

Van Velsor, E., Leslie, J. (1995). Why executives derail: perspectives across time and culture? Academy of Management Executive, 9, 62-72.

Van Rooy, D. L., \& Viswesvaran, C. (2004). Emotional intelligence: A meta-analytic investigation of predictive validity and nomological net. Journal of Vocational Behavior, 65, 71-95.

Viswesvaran, C. , Ones, D. S. , \& Schmidt, F. L. (1996). Comparative analysis of the reliability of job performance ratings. Journal of Applied Psychology, 81, 557560 .

Viswesvaran, C. , \& Ones, D. S. (1995). Theory Testing: Combining Psychometric MetaAnalysis and Structural Equations Modeling. Personnel Psychology, 48, 865-885.

Viswesvaran C, Schmidt F. L. (1992): A meta-analytic comparison of the effectiveness of smoking cessation methods. Journal Applied Psychology, 77, 554-561.

Webb, S. (2005). Examining emotional intelligence and leadership. University of South Florida.

Williams, K. J. \& Alliger, G. M. (1994). Role stressors, mood spillover, and perceptions of work-family conflict in employed parents. Academy of Management Journal, $37,837-868$.

Williams, K.J., Suls, J., Alliger, G.M., Learner, S.M., \& Wan, C.K. (1991). Multiple role juggling and daily mood states in working mothers: An experience sampling study. Journal of Applied Psychology, 76, 664-674.

Wolff, S. B., Pescosolido, A. T., \& Druskat, V. U. 2002. Emotional intelligence as the basis of leadership emergence in self-managing teams. Leadership Quarterly, 13, 505-522.

Wong, C., \& Law, K. S. (2002). The effects of leader and follower emotional intelligence on performance and attitude: An exploratory study. The Leadership Quarterly. 13, 243-274.

Yukl, G. (2006). Leadership in Organizations (6th ed.). Upper Saddle River, N.J.: Prentice Hall. 
Yukl, G. A. (2002). Leadership in organizations (5 ed.) Upper Saddle River, NJ: Prentice Hall.

Yukl, G.A. (1998). Leaderhip in Organizations. Prentice-Hall, New Jersey.

Yukl, G., Tracey, J.B. (1992). Consequences of influence tactics used with subordinates, peers, and the boss. Journal of Applied Psychology, 77, 525-35.

Zaccaro, S. J. (2007). Trait-based perspectives of leadership. American Psychologist, 62, 6-16.

Zaccaro, S. J. (2002). Organizational leadership and social intelligence. In R.E. Riggio, S.E. Murphy, \& F.J. Pirozzolo (Eds.), Multiple intelligences and leadership (pp. 29-54). Mahwah, NJ: Lawrence Erlbaum Associates, Inc.

Zaccaro, S. J., Foti, R. J., \& Kenny, D. A. (1991). Selfmonitoring and trait-based variance in leadership: An investigation of leader flexibility across multiple group situations. Journal of Applied Psychology. 76, 308-315.

Zaccaro S.J., Gilbert J., Thor K.K., \& Mumford M.D. (1991). Leadership and social intelligence: Linking social perceptiveness and behavioral flexibility to leader effectiveness. The Leadership Quarterly, 2, 317 - 331.

Zajonc, R. B. (1998). Emotions. In D. T. Gilbert, S. T. Fiske \& G. Lindzey (Eds.), The handbook of social psychology vol. 1 (4th ed.) (pp. 591-632). Boston, MA: McGraw-Hill.

Zaleznik, Abraham (1977). Managers and leaders: Are they different? Harvard Business Review, 70, 126-135. 
Table 1

Meta-Analysis of Emotional Intelligence and Leadership Effectiveness

\begin{tabular}{|c|c|c|c|c|c|c|c|c|}
\hline \multirow[b]{2}{*}{ Criteria } & \multicolumn{5}{|c|}{ Average } & \multirow[b]{2}{*}{$\begin{array}{c}\% \text { variance due to } \\
\text { all artifacts }\end{array}$} & \multicolumn{2}{|c|}{$80 \% \mathrm{CV}$} \\
\hline & $k$ & $N$ & $r$ & $\rho$ & $S D_{\rho}$ & & Lower & Upper \\
\hline Leadership Effectiveness & 52 & 6052 & .22 & .25 & .09 & 51 & .13 & .38 \\
\hline
\end{tabular}

Note. $k=$ number of correlations; $N=$ total sample size for all studies combined; $r=$ average uncorrected correlation; $\rho=$ average true score correlation, computed by correcting observed mean for unreliability $(\alpha)$ in both measures; $S D_{\rho}=$ standard deviation of corrected (true score) correlation; $80 \% \mathrm{CV}=80 \%$ credibility interval computed as $\rho \pm 1.28\left(S D_{\rho}\right)$ 
Table 2

Meta-Analysis of Emotional Intelligence and Transformational Leadership

\begin{tabular}{|c|c|c|c|c|c|c|c|c|}
\hline \multirow[b]{2}{*}{ Criteria } & \multicolumn{5}{|c|}{ Average } & \multirow[b]{2}{*}{$\begin{array}{c}\% \text { variance due to } \\
\text { all artifacts }\end{array}$} & \multicolumn{2}{|c|}{$80 \% \mathrm{CV}$} \\
\hline & $k$ & $N$ & $r$ & $\rho$ & $S D_{\rho}$ & & Lower & Upper \\
\hline Transformational Leadership & 38 & 4519 & .32 & .37 & .16 & 26 & .16 & .58 \\
\hline Idealized Influence & 21 & 2398 & .25 & .29 & .15 & 31 & .10 & .48 \\
\hline Inspirational Motivation & 20 & 2334 & .29 & .34 & .17 & 25 & .13 & .58 \\
\hline Intellectual Stimulation & 20 & 2375 & .22 & .27 & .14 & 32 & .09 & .46 \\
\hline Individual Consideration & 20 & 2322 & .26 & .30 & .16 & 26 & .09 & .51 \\
\hline Transactional Leadership & 18 & 2141 & .08 & .10 & .00 & 100 & .10 & .10 \\
\hline
\end{tabular}

Note. $k=$ number of correlations; $N=$ total sample size for all studies combined; $r=$ average uncorrected correlation; $\rho=$ average true score correlation, computed by correcting observed mean for unreliability $(\alpha)$ in both measures; $S D_{\rho}=$ standard deviation of corrected (true score) correlation; $80 \% \mathrm{CV}=80 \%$ credibility interval computed as $\rho \pm 1.28\left(S D_{\rho}\right)$ 
Table 3

Meta-Analysis of Emotional Intelligence and Leader-Member Exchange

\begin{tabular}{|c|c|c|c|c|c|c|c|c|}
\hline \multirow[b]{2}{*}{ Criteria } & \multicolumn{5}{|c|}{ Average } & \multirow[b]{2}{*}{$\begin{array}{c}\% \text { variance due to } \\
\text { all artifacts }\end{array}$} & \multicolumn{2}{|c|}{$80 \% \mathrm{CV}$} \\
\hline & $k$ & $N$ & $r$ & $\rho$ & $S D_{\rho}$ & & Lower & Upper \\
\hline Leader-Member Exchange & 10 & 880 & .23 & .27 & .18 & 27 & .04 & .50 \\
\hline
\end{tabular}

Note. $k=$ number of correlations; $N=$ total sample size for all studies combined; $r=$ average uncorrected correlation; $\rho=$ average true score correlation, computed by correcting observed mean for unreliability $(\alpha)$ in both measures; $S D_{\rho}=$ standard deviation of corrected (true score) correlation; $80 \% \mathrm{CV}=80 \%$ credibility interval computed as $\rho \pm 1.28\left(S D_{\rho}\right)$ 
Table 4

Summary of Path Analysis for Leadership Behavior Mediating the Relationship between Emotional Intelligence and Leadership Effectiveness

\begin{tabular}{|c|c|c|c|}
\hline Variable & $\beta$ & $R^{2}$ & $\Delta R^{2}$ \\
\hline \multicolumn{4}{|l|}{ Transformational Leadership } \\
\hline Step 1: & & $.19 * *$ & \\
\hline Transformational Leadership & $.44 * *$ & & \\
\hline Step 2: & & $.20 * *$ & \\
\hline Transformational Leadership & $.43 * *$ & & \\
\hline Emotional Intelligence & $.10^{* *}$ & & $.01 * *$ \\
\hline \multicolumn{4}{|l|}{$\underline{\mathrm{LMX}}$} \\
\hline Step 1: & & $.09 * *$ & \\
\hline LMX & $.30 * *$ & & \\
\hline Step 2: & & $.12 * *$ & \\
\hline LMX & $.29 * *$ & & \\
\hline Emotional Intelligence & $.18^{* *}$ & & $.03 * *$ \\
\hline
\end{tabular}

Note. Harmonic Mean $=1327$

$* p \leq .05$. ** $p \leq .01$ 
Table 5

Meta-Analysis of Appraisal of Emotion Dimension and Leadership Outcomes

\begin{tabular}{lccccccccc}
\hline & \multicolumn{4}{c}{ Average } & & \multicolumn{2}{c}{$80 \% \mathrm{CV}$} \\
\cline { 2 - 9 } \multicolumn{1}{c}{ Criteria } & $k$ & $N$ & $r$ & $\rho$ & $S D_{\rho}$ & \% variance due to & all artifacts & Lower & Upper \\
\hline Leadership Effectiveness & 20 & 2058 & .12 & .14 & .00 & 100 & .14 & .14 \\
Transformational Leadership & 12 & 1018 & .17 & .19 & .08 & 62 & .09 & .29 \\
LMX & 5 & 422 & .08 & .10 & .00 & 100 & .10 & .10 \\
\hline
\end{tabular}

Note. $k=$ number of correlations; $N=$ total sample size for all studies combined; $r=$ average uncorrected correlation; $\rho=$ average true score correlation, computed by correcting observed mean for unreliability $(\alpha)$ in both measures; $S D_{\rho}=$ standard deviation of corrected (true score) correlation; $80 \% \mathrm{CV}=80 \%$ credibility interval computed as $\rho \pm 1.28\left(S D_{\rho}\right)$ 
Table 6

Meta-Analysis of Use of Emotion Dimension and Leadership Outcomes

\begin{tabular}{|c|c|c|c|c|c|c|c|c|}
\hline \multirow[b]{2}{*}{ Criteria } & \multicolumn{5}{|c|}{ Average } & \multirow[b]{2}{*}{$\begin{array}{c}\% \text { variance due to } \\
\text { all artifacts }\end{array}$} & \multicolumn{2}{|c|}{$80 \% \mathrm{CV}$} \\
\hline & $k$ & $N$ & $r$ & $\rho$ & $S D_{\rho}$ & & Lower & Upper \\
\hline Leadership Effectiveness & 20 & 2058 & .12 & .15 & .04 & 84 & .08 & .19 \\
\hline Transformational Leadership & 12 & 1018 & .15 & .17 & .09 & 55 & .05 & .28 \\
\hline LMX & 5 & 422 & .09 & .11 & .00 & 100 & .10 & .10 \\
\hline
\end{tabular}

Note. $k=$ number of correlations; $N=$ total sample size for all studies combined; $r=$ average uncorrected correlation; $\rho=$ average true score correlation, computed by correcting observed mean for unreliability $(\alpha)$ in both measures; $S D_{\rho}=$ standard deviation of corrected (true score) correlation; $80 \% \mathrm{CV}=80 \%$ credibility interval computed as $\rho \pm 1.28\left(S D_{\rho}\right)$ 
Table 7

Meta-Analysis of Understanding of Emotion Dimension and Leadership Outcomes

\begin{tabular}{|c|c|c|c|c|c|c|c|c|}
\hline \multirow[b]{2}{*}{ Criteria } & \multicolumn{5}{|c|}{ Average } & \multirow{2}{*}{$\begin{array}{c}\% \text { variance due to } \\
\text { all artifacts }\end{array}$} & \multicolumn{2}{|c|}{$80 \% \mathrm{CV}$} \\
\hline & $k$ & $N$ & $r$ & $\rho$ & $S D_{\rho}$ & & Lower & Upper \\
\hline Leadership Effectiveness & 20 & 2058 & .16 & .19 & .09 & 55 & .07 & .30 \\
\hline Transformational Leadership & 12 & 1018 & .22 & .25 & .18 & 21 & .01 & .50 \\
\hline LMX & 5 & 422 & .12 & .15 & .00 & 100 & .10 & .10 \\
\hline
\end{tabular}

Note. $k=$ number of correlations; $N=$ total sample size for all studies combined; $r=$ average uncorrected correlation; $\rho=$ average true score correlation, computed by correcting observed mean for unreliability $(\alpha)$ in both measures; $S D_{\rho}=$ standard deviation of corrected (true score) correlation; $80 \% \mathrm{CV}=80 \%$ credibility interval computed as $\rho \pm 1.28\left(S D_{\rho}\right)$ 
Table 8

Meta-Analysis of Regulation and Management of Emotion Dimension and Leadership Outcomes

\begin{tabular}{|c|c|c|c|c|c|c|c|c|}
\hline \multirow[b]{2}{*}{ Criteria } & \multicolumn{5}{|c|}{ Average } & \multirow{2}{*}{$\begin{array}{c}\% \text { variance due to } \\
\text { all artifacts }\end{array}$} & \multicolumn{2}{|c|}{$80 \% \mathrm{CV}$} \\
\hline & $k$ & $N$ & $r$ & $\rho$ & $S D_{\rho}$ & & Lower & Upper \\
\hline Leadership Effectiveness & 20 & 2058 & .13 & .15 & .06 & 75 & .08 & .22 \\
\hline Transformational Leadership & 12 & 1018 & .25 & .28 & .18 & 22 & .05 & .52 \\
\hline LMX & 5 & 422 & .14 & .18 & .00 & 100 & .10 & .10 \\
\hline
\end{tabular}

Note. $k=$ number of correlations; $N=$ total sample size for all studies combined; $r=$ average uncorrected correlation; $\rho=$ average true score correlation, computed by correcting observed mean for unreliability $(\alpha)$ in both measures; $S D_{\rho}=$ standard deviation of corrected (true score) correlation; $80 \% \mathrm{CV}=80 \%$ credibility interval computed as $\rho \pm 1.28\left(S D_{\rho}\right)$ 
Table 9

Summary of Path Analysis Results for Transformational Leadership Mediating the Relationship Between Facets of Emotional Intelligence and Leadership Effectiveness

\begin{tabular}{|c|c|c|c|}
\hline Variable & $\beta$ & $R^{2}$ & $\Delta R^{2}$ \\
\hline \multicolumn{4}{|l|}{ Appraisal } \\
\hline Step 1: & & $.19 * *$ & \\
\hline Transformational Leadership & $.44 * *$ & & \\
\hline Step 2: & & $.20 * *$ & \\
\hline Transformational Leadership & $.40 * *$ & & \\
\hline Appraisal of Emotions & $.08 * *$ & & $.01 * *$ \\
\hline \multicolumn{4}{|l|}{ Use } \\
\hline Step 1: & & $.19 * *$ & \\
\hline Transformational Leadership & $.44 * *$ & & \\
\hline Step 2: & & $.20 * *$ & \\
\hline Transformational Leadership & $.41 * *$ & & \\
\hline Use of Emotions & $.07 * *$ & & $.01 * *$ \\
\hline
\end{tabular}

\section{$\underline{\text { Understanding }}$}

Step 1:

Transformational Leadership Step 2:

Transformational Leadership Understanding of Emotions

\section{$\underline{\text { Management }}$}

Step 1:

Transformational Leadership Step 2:

Transformational Leadership Management of Emotions

$\begin{array}{lll}.44 * * & .19 * * \\ & .20 * * & \\ .40 * * & & \\ .09 * * & & .01 * *\end{array}$

Note. Harmonic Mean $=1327$

$* p \leq .05$. ** $p \leq .01$ 
Table 10

Summary of Path Analysis Results for LMX Mediating the Relationship

Between Facets of Emotional Intelligence and Leadership Effectiveness

Variable

$\beta \quad R^{2}$

Appraisal

Step 1:

LMX

Step 2:

LMX

Appraisal of Emotions

$\underline{\text { Use }}$

Step 1:

LMX

Step 2:

LMX

Use of Emotions

$\underline{\text { Understanding }}$

Step 1:

LMX

Step 2:

LMX

Understanding of Emotions

$\underline{\text { Management }}$

Step 1:

LMX

Step 2:

LMX

Management of Emotions

Note. Harmonic Mean $=934$

$* p \leq .05$. ** $p \leq .01$ 
Table 11

Hierarchical Regression Analysis for Leadership Effectiveness onto

EI, Personality, and GMA

$\begin{array}{llll}\text { Variable } & \beta & R^{2} & \Delta R^{2}\end{array}$

\section{Big Five Only}

Step 1:

Openness

Conscientiousness

Extraversion

Agreeableness

Emotional Stability

Step 2:

Emotional Intelligence

\section{GMA Only}

Step 1:

GMA

Step 2:

Emotional Intelligence

\section{$\underline{\text { Big Five and GMA }}$}

Step 1:

Openness

Conscientiousness

Extraversion

Agreeableness

Emotional Stability

GMA
$.15^{* *}$

$.19^{* *}$

$.11 * *$

$.17 * *$

$.10 * *$

$.10 * *$

$.16^{* *}$

$.12 * *$

Step 2:

$.27 * *$

$.07 * *$

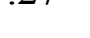

$.20 * *$

$.11 * *$

$.20 *$

$.04 * *$

Emotional Intelligence

Note. Harmonic Mean $=1651$

$* p \leq .05$. ** $p \leq .01$ 
Table 12

Meta-Analysis of Ability EI and Leadership Outcomes

\begin{tabular}{lccccccccc}
\hline & \multicolumn{4}{c}{ Average } & & \multicolumn{2}{c}{$80 \% \mathrm{CV}$} \\
\cline { 2 - 8 } \multicolumn{1}{c}{ Criteria } & $k$ & $N$ & $r$ & $\rho$ & $S D_{\rho}$ & \% variance due to & all artifacts & Lower & Upper \\
\hline Leadership Effectiveness & 20 & 2058 & .18 & .21 & .00 & 100 & .21 & .21 \\
Transformational Leadership & 12 & 1257 & .22 & .25 & .00 & 100 & .25 & .25 \\
LMX & 5 & 422 & .22 & .24 & .00 & 100 & .10 & .10 \\
\hline
\end{tabular}

Note. $k=$ number of correlations; $N=$ total sample size for all studies combined; $r=$ average uncorrected correlation; $\rho=$ average true score correlation, computed by correcting observed mean for unreliability $(\alpha)$ in both measures; $S D_{\rho}=$ standard deviation of corrected (true score) correlation; $80 \% \mathrm{CV}=80 \%$ credibility interval computed as $\rho \pm 1.28\left(S D_{\rho}\right)$ 
Table 13

Meta-Analysis of Mixed EI and Leadership Outcomes

\begin{tabular}{lccccccccc}
\hline & \multicolumn{4}{c}{ Average } & & \multicolumn{2}{c}{$80 \% \mathrm{CV}$} \\
\cline { 2 - 8 } \multicolumn{1}{c}{ Criteria } & $k$ & $N$ & $r$ & $\rho$ & $S D_{\rho}$ & \% variance due to & all artifacts & Lower & Upper \\
\hline Leadership Effectiveness & 26 & 2810 & .23 & .27 & .12 & 38 & .12 & .42 \\
Transformational Leadership & 28 & 3124 & .37 & .43 & .18 & 22 & .21 & .65 \\
LMX & 6 & 692 & .23 & .27 & .20 & 20 & .01 & .51 \\
\hline
\end{tabular}

Note. $k=$ number of correlations; $N=$ total sample size for all studies combined; $r=$ average uncorrected correlation; $\rho=$ average true score correlation, computed by correcting observed mean for unreliability $(\alpha)$ in both measures; $S D_{\rho}=$ standard deviation of corrected (true score) correlation; $80 \% \mathrm{CV}=80 \%$ credibility interval computed as $\rho \pm 1.28\left(S D_{\rho}\right)$ 
Table 14

Hierarchical Regression Analysis for Leadership Effectiveness onto Ability EI, Personality, and GMA.

$\begin{array}{llll}\text { Variable } & \beta & R^{2} & \Delta R^{2}\end{array}$

$\underline{\text { Big Five Only }}$

Step 1:

Openness

Conscientiousness

Extraversion

Agreeableness

Emotional Stability

Step 2:

Ability EI

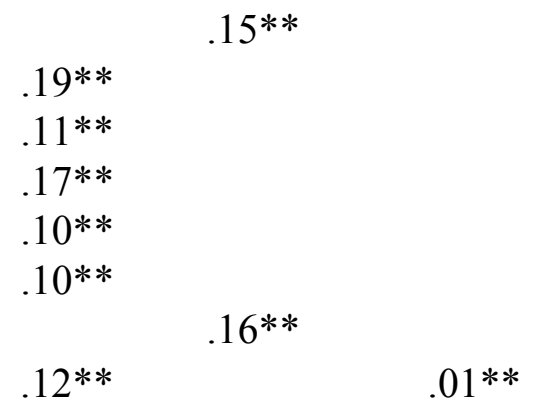

\section{GMA Only}

Step 1:

GMA

Step 2:

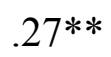

Ability EI

\section{$\underline{\text { Big Five and GMA }}$}

Step 1:

$.18 * *$

Openness

$.13 * *$

Conscientiousness

$.11 * *$

Extraversion

$.17 * *$

Agreeableness

$.12 * *$

Emotional Stability

$.09 *$

GMA

$.20 * *$

Step 2:

$.18^{* *}$

Ability EI

.07

.00

Note. Harmonic Mean $=1145$.

$* p \leq .05$. ** $p \leq .01$ 
Table 15

Hierarchical Regression Analysis for Leadership Effectiveness onto Mixed EI, Personality, and GMA.

$\begin{array}{llll}\text { Variable } & \beta & R^{2} & \Delta R^{2}\end{array}$

Big Five Only

Step 1:

$.15^{* *}$

Openness

$.19 * *$

Conscientiousness

$.12 * *$

Extraversion

$.17 * *$

Agreeableness

$.10^{* *}$

Emotional Stability

$.10 * *$

Step 2:

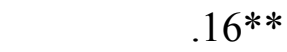

Mixed EI

$.11 * *$

$.01 * *$

\section{GMA Only}

Step 1:

GMA

Step 2:

$.27 * *$

Mixed EI

$.24 * *$

$.06^{* *}$

\section{$\underline{\text { Big Five and GMA }}$}

Step 1:

$.18^{* *}$

Openness

$.13 * *$

Conscientiousness

$.11 * *$

Extraversion

$.17 * *$

Agreeableness

$.12 * *$

Emotional Stability

GMA

$.09 *$

$.20 * *$

Step 2:

$.19 * *$

Mixed EI

$.10 * *$

$.01 * *$

Note. Harmonic Mean $=1280$.

$* p \leq .05$. ** $p \leq .01$ 
Table 16

Meta-Analysis of Measures of EI and Leadership Outcomes

\begin{tabular}{|c|c|c|c|c|c|c|c|c|}
\hline \multirow[b]{2}{*}{ Criteria } & \multicolumn{5}{|c|}{ Average } & \multirow{2}{*}{$\begin{array}{c}\% \text { variance due to } \\
\text { all artifacts }\end{array}$} & \multicolumn{2}{|c|}{$80 \% \mathrm{CV}$} \\
\hline & $k$ & $N$ & $r$ & $\rho$ & $S D_{\rho}$ & & Lower & Upper \\
\hline \multicolumn{9}{|l|}{ MSCEIT } \\
\hline Leadership Effectiveness & 20 & 2058 & .18 & .21 & .00 & 100 & .21 & .21 \\
\hline Transformational Leadership & 12 & 1257 & .22 & .25 & .00 & 100 & .25 & .25 \\
\hline LMX & 5 & 422 & .22 & .24 & .00 & 100 & .10 & .10 \\
\hline \multicolumn{9}{|l|}{ ECI } \\
\hline Leadership Effectiveness & 6 & 616 & .26 & .31 & .06 & 72 & .23 & .39 \\
\hline Transformational Leadership & 4 & 313 & .38 & .45 & .16 & 25 & .21 & .65 \\
\hline \multicolumn{9}{|l|}{ EIS } \\
\hline Leadership Effectiveness & 7 & 686 & .32 & .38 & .08 & 55 & .26 & .48 \\
\hline Transformational Leadership & 6 & 467 & .50 & .57 & .20 & 22 & .30 & .83 \\
\hline \multicolumn{9}{|l|}{ EQ-i } \\
\hline Leadership Effectiveness & 6 & 880 & .25 & .29 & .11 & 40 & .14 & .43 \\
\hline Transformational Leadership & 11 & 963 & .37 & .44 & .20 & 22 & .18 & .69 \\
\hline \multicolumn{9}{|l|}{ WLEIS } \\
\hline Leadership Effectiveness & 7 & 661 & .17 & .19 & .03 & 89 & .15 & .24 \\
\hline Transformational Leadership & 6 & 995 & .30 & .36 & .08 & 49 & .25 & .46 \\
\hline
\end{tabular}

Note. $k=$ number of correlations; $N=$ total sample size for all studies combined; $r=$ average

uncorrected correlation; $\rho=$ average true score correlation, computed by correcting observed mean for 
unreliability $(\alpha)$ in both measures; $S D_{\rho}=$ standard deviation of corrected (true score) correlation; $80 \% \mathrm{CV}=80 \%$ credibility interval computed as $\rho \pm 1.28\left(S D_{\rho}\right)$ 
Table 17

Meta-Analysis of Emotional Intelligence and Leadership Effectiveness by Scoring Format

\begin{tabular}{|c|c|c|c|c|c|c|c|c|}
\hline \multirow[b]{2}{*}{ Format } & \multicolumn{5}{|c|}{ Average } & \multirow{2}{*}{$\begin{array}{c}\% \text { variance due to } \\
\text { all artifacts }\end{array}$} & \multicolumn{2}{|c|}{$80 \% \mathrm{CV}$} \\
\hline & $k$ & $N$ & $r$ & $\rho$ & $S D_{\rho}$ & & Lower & Upper \\
\hline Performance-Based & 20 & 2058 & .18 & .21 & .00 & 100 & .21 & .21 \\
\hline Consensus & 5 & 567 & .17 & .19 & .03 & 89 & .15 & .24 \\
\hline Expert & 4 & 345 & .16 & .18 & .05 & 69 & .14 & .26 \\
\hline Empirical & 2 & 172 & .25 & .29 & .00 & 100 & .29 & .29 \\
\hline Self-Report & 26 & 2810 & .23 & .27 & .12 & 38 & .12 & .42 \\
\hline
\end{tabular}

Note. $k=$ number of correlations; $N=$ total sample size for all studies combined; $r=$ average uncorrected correlation; $\rho=$ average true score correlation, computed by correcting observed mean for unreliability $(\alpha)$ in both measures; $S D_{\rho}=$ standard deviation of corrected (true score) correlation; $80 \% \mathrm{CV}=80 \%$ credibility interval computed as $\rho \pm 1.28\left(S D_{\rho}\right)$ 
Table 18

Meta-Analysis of Emotional Intelligence and Leadership Effectiveness by Content, Level-of-Analysis, and Source

\begin{tabular}{|c|c|c|c|c|c|c|c|c|}
\hline \multirow[b]{2}{*}{ Criteria } & \multicolumn{5}{|c|}{ Average } & \multirow{2}{*}{$\begin{array}{c}\% \text { variance due to } \\
\text { all artifacts }\end{array}$} & \multicolumn{2}{|c|}{$80 \% \mathrm{CV}$} \\
\hline & $k$ & $N$ & $r$ & $\rho$ & $S D_{\rho}$ & & Lower & Upper \\
\hline Overall Effectiveness & 52 & 6052 & .22 & .25 & .09 & 51 & .13 & .38 \\
\hline Task Performance & 35 & 3567 & .26 & .29 & .03 & 89 & .25 & .34 \\
\hline $\mathrm{OCB}$ & 10 & 1056 & .16 & .21 & .08 & 69 & .14 & .26 \\
\hline Job Satisfaction & 9 & 1317 & .14 & .16 & .08 & 57 & .06 & .26 \\
\hline Leader Satisfaction & 8 & 918 & .20 & .23 & .10 & 50 & .10 & .36 \\
\hline Turnover & 6 & 898 & .10 & .11 & .00 & 100 & .11 & .11 \\
\hline \multicolumn{9}{|l|}{ Level-of-Analysis } \\
\hline Global & 15 & 2094 & .17 & .19 & .03 & 89 & .15 & .24 \\
\hline Shared & 30 & 2961 & .24 & .28 & .08 & 60 & .19 & .38 \\
\hline \multicolumn{9}{|l|}{ Source of Rater } \\
\hline Supervisor & 8 & 815 & .20 & .23 & .10 & 50 & .10 & .36 \\
\hline Peer & 2 & 172 & .25 & .29 & .00 & 100 & .29 & .29 \\
\hline Subordinate & 26 & 2810 & .23 & .27 & .12 & 38 & .12 & .42 \\
\hline
\end{tabular}

Note. $k=$ number of correlations; $N=$ total sample size for all studies combined; $r=$ average uncorrected correlation; $\rho=$ average true score correlation, computed by correcting observed mean for unreliability $(\alpha)$ in both measures; $S D_{\rho}=$ standard deviation of corrected (true score) correlation; $80 \% \mathrm{CV}=80 \%$ credibility interval computed as $\rho \pm 1.28\left(S D_{\rho}\right)$ 
Table 19

Meta-Analysis of Emotional Intelligence and Leadership Effectiveness by Level of Leader

\begin{tabular}{lccccccccc}
\hline & \multicolumn{4}{c}{ Average } & & \multicolumn{2}{c}{$80 \% \mathrm{CV}$} \\
\cline { 2 - 8 } \multicolumn{1}{c}{ Level of Leadership } & $k$ & $N$ & $r$ & $\rho$ & $S D_{\rho}$ & \% variance due to & all artifacts & Lower & Upper \\
\hline High & 6 & 230 & .23 & .26 & .00 & 100 & .26 & .26 \\
Middle & 13 & 1764 & .17 & .20 & .00 & 100 & .20 & .20 \\
Low & 12 & 1457 & .26 & .30 & .07 & 65 & .21 & .38 \\
\hline
\end{tabular}

Note. $k=$ number of correlations; $N=$ total sample size for all studies combined; $r=$ average uncorrected correlation; $\rho=$ average true score correlation, computed by correcting observed mean for unreliability $(\alpha)$ in both measures; $S D_{\rho}=$ standard deviation of corrected (true score) correlation; $80 \% \mathrm{CV}=80 \%$ credibility interval computed as $\rho \pm 1.28\left(S D_{\rho}\right)$ 
Table 20

Meta-Analysis of Emotional Intelligence and Leadership Effectiveness by Industry Type

\begin{tabular}{|c|c|c|c|c|c|c|c|c|}
\hline \multirow[b]{2}{*}{ Criteria } & \multicolumn{5}{|c|}{ Average } & \multirow{2}{*}{$\begin{array}{c}\% \text { variance due to } \\
\text { all artifacts }\end{array}$} & \multicolumn{2}{|c|}{$80 \% \mathrm{CV}$} \\
\hline & $k$ & $N$ & $r$ & $\rho$ & $S D_{\rho}$ & & Lower & Upper \\
\hline For-Profit & 30 & 2961 & .24 & .28 & .08 & 60 & .19 & .38 \\
\hline Service & 18 & 2133 & .25 & .28 & .07 & 63 & .19 & .27 \\
\hline Manufacturing & 7 & 994 & .20 & .23 & .12 & 36 & .08 & .38 \\
\hline Non-Profit & 6 & 564 & .18 & .22 & .12 & 40 & .05 & .32 \\
\hline Church & 4 & 234 & .21 & .24 & .00 & 100 & .24 & .24 \\
\hline Government & 6 & 667 & 15 & 17 & .03 & 90 & .14 & .21 \\
\hline Education & 7 & 717 & .10 & .12 & .00 & 100 & .12 & .12 \\
\hline
\end{tabular}

Note. $k=$ number of correlations; $N=$ total sample size for all studies combined; $r=$ average uncorrected correlation; $\rho=$ average true score correlation, computed by correcting observed mean for unreliability $(\alpha)$ in both measures; $S D_{\rho}=$ standard deviation of corrected (true score) correlation; $80 \% \mathrm{CV}=80 \%$ credibility interval computed as $\rho \pm 1.28\left(S D_{\rho}\right)$ 
Table 21

Meta-Correlation Matrix of Dimensions of Emotional Intelligence

\begin{tabular}{llllll}
\hline \multicolumn{1}{c}{ Dimension } & 1 & 2 & 3 & 4 & 5 \\
\hline 1. Appraisal of Emotions & -- & & & & \\
2. Use of Emotions & .46 & -- & & & \\
3. Understanding of Emotion & .39 & .40 & -- & & \\
4. Regulation of Emotion & .45 & .47 & .39 & -- & \\
5. EI (Overall) & .84 & .79 & .72 & .69 & -- \\
\hline
\end{tabular}

Note. Values in matrix are average true score correlations $(\rho)$. All relationships are significant at $p \leq .01$. 
Table 22

Summary of Path Analysis for Each Competing Model of EI Mediating the Relationship between the Alternative Model and Leadership Effectiveness

\section{Variable}

$\beta \quad R^{2}$

$\Delta R^{2}$

Step 1:

Ability EI

Step 2:

Ability EI

Mixed Model EI

$.19 * *$

$.05 * *$

$.21 * *$

$.09 * *$

$.17 * *$

$19 *$

$.04 * *$

Step 1:

Mixed Model EI

Step 2:

Mixed Model EI

Ability EI

$\begin{array}{lll} & .08^{* *} & \\ .27^{* *} & & \\ .25^{* *} & .09 * * & \\ .11^{* *} & & \\ & & .01 * *\end{array}$

Note. Harmonic Mean $=546$

$* p \leq .05$. ** $p \leq .01$ 
VITA

\section{DANIEL STEWART WHITMAN}

Born, Griffin, Georgia

$2000-2004$

B.S., Psychology

University of Georgia

Athens, Georgia

$2004-2006$

M.A., Industrial/Organizational Psychology

Florida International University

Miami, Florida

$2006-2009$

Ph.D., Industrial/Organizational Psychology

Florida International University

Miami, Florida

\section{PUBLICATIONS AND PRESENTATIONS}

Resick, C.J., Whitman, D.S., Weingarden, S.M., \& Hiller, N.J. (in Press). The bright-side and dark-side of executive ego: Examining CEO personality, transformational leadership, and strategic influence. Journal of Applied Psychology.

Whitman, D.S., Van Rooy, D.L., \& Viswesvaran, C. (in Press). Satisfaction, citizenship behaviors, and performance in work units: A meta-analysis of collective construct relations. Personnel Psychology.

Whitman, D.S., Van Rooy, D.L., Viswesvaran, C., \& Kraus, E. (in Press). Measurement equivalence of the Wong and Law emotional intelligence scale. Educational and Psychological Measurement.

Whitman, D.S., Van Rooy, D. L., Viswesvaran, C., \& Alonso, A. (2008). The susceptibility of a mixed model measure of emotional intelligence to faking: A Solomon four-group design. Psychology Science, 50, 44-63.

Weingarden, S. M., Resick, C. J., \& Whitman, D.S. (2006). Why is that executive a hall of famer? Have you seen his leadership stats? Outside the Lines, 12(2), 1-4.

Thomas, J., Whitman, D.S., \& Viswesvaran, C. (revise and resubmit). An Integrative Meta-Analysis of Constructs that Reflect a Global Proactive Orientation. Under second round of reviews at Journal of Organizational and Occupational Psychology. 
Whitman, D. S., Van Rooy, D. L., \& Viswesvaran, C. (2009, August). Satisfaction, citizenship behaviors, and performance in work units. Paper to be presented at the $69^{\text {th }}$ annual conference of the Academy of Management, Chicago, IL.

Thomas, J., Whitman, D. S., \& Viswesvaran, C. (2009, April). Exploring conceptual and empirical links between emotional intelligence and proactivity. Poster to be presented at the $24^{\text {th }}$ annual conference of the Society for Industrial \& Organizational Psychology, New Orleans, LA.

Thomas, J., Whitman, D. S., \& Viswesvaran, C. (2009, April). An investigation of group differences in proactive personality. Poster to be presented at the $24^{\text {th }}$ annual conference of the Society for Industrial \& Organizational Psychology, New Orleans, LA.

Whitman, D. S. \& Caleo, S. (2009, April). Performance ratings, personality, and the Dark-Side of the ASA cycle. Poster to be presented at the $24^{\text {th }}$ annual conference of the Society for Industrial \& Organizational Psychology, New Orleans, LA.

Whitman, D. S., Van Rooy, D. L., \& Viswesvaran, C. (2009, April). Satisfaction and counterproductive behavior in work units. Paper presented at the $24^{\text {th }}$ annual conference of the Society for Industrial \& Organizational Psychology, New Orleans, LA.

Whitman, D. S., Van Rooy, D. L., \& Viswesvaran, C. (2008, August). Does employee job satisfaction matter more for non-profit organizations? A meta-analysis. Paper presented at the $68^{\text {th }}$ annual conference of the Academy of Management, Anaheim, CA.

Whitman, D. S., Van Rooy, D. L., Viswesvaran, C, \& Kraus, E. (2008, August). Testing the factor structure and measurement equivalence of the WLEIS across gender and ethnicity. Paper presented at the $68^{\text {th }}$ annual conference of the Academy of Management, Anaheim, CA.

Oh, I., Toker, Y., Ferreter, J., Whitman, D. S., McKinniss, T., Casillas, A., Robbins, S. (2008, April). Development of the WorkKeys Talent assessment scales and indices. Poster presented at the $23^{\text {rd }}$ annual conference of the Society for Industrial \& Organizational Psychology, San Francisco, CA.

Whitman, D. S., Van Rooy, D. L., Viswesvaran, C., \& Kraus, E. (2008, April). Examining self-injurious perceptions of personnel selection procedures. Paper presented at the $23^{\text {rd }}$ annual conference of the Society for Industrial \& Organizational Psychology, San Francisco, CA. 